\title{
Bedside manners : teaching and learning in the hospital setting
}

Citation for published version (APA):

Jolly, B. C. (1994). Bedside manners : teaching and learning in the hospital setting. [Doctoral Thesis, Maastricht University]. Datawyse / Universitaire Pers Maastricht. https://doi.org/10.26481/dis.19941130bj

Document status and date:

Published: 01/01/1994

DOI:

10.26481/dis.19941130bj

Document Version:

Publisher's PDF, also known as Version of record

\section{Please check the document version of this publication:}

- A submitted manuscript is the version of the article upon submission and before peer-review. There can be important differences between the submitted version and the official published version of record.

People interested in the research are advised to contact the author for the final version of the publication, or visit the DOI to the publisher's website.

- The final author version and the galley proof are versions of the publication after peer review.

- The final published version features the final layout of the paper including the volume, issue and page numbers.

Link to publication

\footnotetext{
General rights rights.

- You may freely distribute the URL identifying the publication in the public portal. please follow below link for the End User Agreement:

www.umlib.nl/taverne-license

Take down policy

If you believe that this document breaches copyright please contact us at:

repository@maastrichtuniversity.nl

providing details and we will investigate your claim.
}

Copyright and moral rights for the publications made accessible in the public portal are retained by the authors and/or other copyright owners and it is a condition of accessing publications that users recognise and abide by the legal requirements associated with these

- Users may download and print one copy of any publication from the public portal for the purpose of private study or research.

- You may not further distribute the material or use it for any profit-making activity or commercial gain

If the publication is distributed under the terms of Article $25 \mathrm{fa}$ of the Dutch Copyright Act, indicated by the "Taverne" license above, 


\section{BEDSIDE MANNERS}

\section{Teaching and learning in the hospital setting}


CIP-DATA KONINKLIJKE BIBLIOTHEEK, DEN HAAG

Jolly, Brian Clark

Bedside Manners : teaching and learning in the hospital setting / Brian Cark Jolly. - Maastricht : Universitaire Pers Maastricht

Thesis Maastricht. - With ref. - With summary in dutch. ISBN 90-5278-161-3

Subject headings: medical education

Production: Datawyse I Universitaire Pers Maastricht 


\section{BEDSIDE MANNERS}

\section{Teaching and learning in the hospital setting}

\section{PROEFSCHRIFT}

ter verkrijging van de graad van doctor aan de Rijksuniversiteit Limburg te Maastricht, op gezag van de Rector Magnificus, Prof. dr H. Philipsen, volgens het besluit van het College van Dekanen, in het openbaar te verdedigen

op woensdag 30 november 1994 om 14.00 uur

door

\section{Brian Clark Jolly}

geboren te Portsmouth, United Kingdom, in 1949 


\section{Promotor:}

Prof. dr. H.G. Schmidt

\section{Co-promotor:}

Dr P.A.J. Bouhuijs

Beoordelingscommissie:

Prof. dr. A.C. Nieuwenhuijzen Kruseman (Voorzitter)

Prof. dr. G.G.M. Essed

Prof. dr. L.H. Rees

(Medical College of St. Bartholomew's Hospital, London, UK)

Prof. dr. H.J.M. Rossum

(Rijksuniversiteit Groningen)

Dr. C.P.M. van der Vleuten. 
Thou shalt not do as the dean pleases

Thou shalt not write thy doctor's thesis On Education

W. H. Auden 



\section{Contents}

PREFACE/ACKNOWLEDGEMENTS

CURRICULUM VITAE

\section{CHAPTER 1.}

Introduction. The development and role of clinical teaching in the general education of the physician.

\section{CHAPTER 2.}

Learning Practical Skills: the role of practical experience in undergraduate and general clinical training.

First appeared as; Education for Practice: the role of practical experience in undergraduate and general clinical training. Jolly, BC and Mcdonald, MM. (1989) Medical Education, 23, 189-195.

\section{CHAPTER 3.}

More Effective Evaluation of Clinical Teaching \& Learning: the role of the clinical teacher.

First appeared as; More Effective Evaluation of Clinical Teaching. Jolly, $B C$ and Macdonald, MM. (1986) Assessment and Evaluation in Higher Education, 12, 175-190.

\section{CHAPTER 4.}

More Effective Evaluation of Clinical Teaching \& Learning: Independent Learning - an exploration of student grand rounds.

First appeared as Jolly, BC, and Ho-Ping-Kong, H. (1991) Independent Learning: an exploration of student grand rounds at the University of Toronto. Medical Education, 24, 334-342.

\section{CHAPTER 5.}

How to Get Students to Focus on Clinical Skills:

The learning effect of re-using stations in an OSCE

First appeared as; The Learning Effect of Repeating Content Over Time in a Clinical Skills Based Examination. Jolly BC, Newble DI and Chinner, $T$. (1993) Teaching \& Learning in Medicine, 5, 66-71. 


\section{CHAPTER 6.}

Training vs Experience in the Acquisition of Bedside Manners the relationship between clinical experience and proficiency in undergraduates

Part of this chapter appeared as The effect of formal instruction on ophthalmoscopy on medical student performance. Cordeiro FM, Jolly BC and Dacre J. (1993) Medical Teacher, 15, 321-25.

\section{CHAPTER 7.}

Discussion and Conclusions. 


\section{Preface/Acknowledgements}

In the distant past Professors Phil Levy and Arthur Rothman, and Dr Neil Johnson were instrumental in providing me with the skills and knowledge that enabled me to find an academic foothold in medical education, progress to the position I now hold and develop the interests I have. I would like to take this opportunity of thanking them most sincerely.

The process of curriculum evaluation and renewal at St Bartholomew's Hospital Medical College has not been easy and the fact that much of that labour appears in this thesis is testimony to the hard work and dedication of a number of people. I would like to thank in particular Professors Peter Cull, Mal Salkind, Ed Sellars and David Newble who, through risky or challenging circumstances, all gave me opportunities I might not otherwise have had. My colleagues in JAUMDE and the Enterprise Unit were much appreciated for their support and encouragement. In particular Morag Macdonald, who also made significant contribution to the work reported here, Peter McCrorie and Gareth Holsgrove carried out tasks which I should have done when, in fact, I was absconding for the purposes of these pages.

Many of the ideas contained herein have come from discussions and work with a variety of other colleagues, and Herbert Ho-Ping-Kong, Tracy Chinner, Francesca Cordeiro and Jane Dacre will all recognise their own substantial contributions.

The thesis would not have been possible without the continual support and advice of my promoters Henk Schmidt and Peter Bouhuijs, and the hotel facilities extended to me most graciously by Marjan Bouhuijs, with the occasional assistance of the Frituur opposite the Basilica in Meerssen. I would also like to thank my colleagues Jon Fuller and Ineke Wolfhagen for their help, Anne Statham for the cover design, Alison Jones for some computer graphics, Michelle Rikken for the translation and Margaret Mirza for an outstanding contribution in retyping two of the published chapters.

Finally, there is a significant group of people who, probably without recognising it, have played crucial roles in enabling me to complete this work while also attempting to fulfil my professional responsibilities and live my life. Each has contributed uniquely and I would find it difficult 
either to explain how or to thank them enough; Vicki Carey, Jane Dacre, Lois Hill, my mother Irene Jolly, Mary Lawson, David Newble, Lesley Rees, and Richard Wakeford.

\section{Copyright}

The author gratefully acknowledges the assistance of publishers in allowing reprinting of articles from journals. Copyright of all published material reprinted here remains with the publishers. Chapters 2 and 4 are reprinted with kind permission of Blackwell Scientific Publications, Chapter 3 and part of Chapter 6 with the assistance of Carfax Publishing and Chapter 5 of Lawrence Erlbaum Associates. A version of Chapter 1 will appear in a forthcoming book published by Oxford University Press.

\section{Curriculum Vitae}

Brian Jolly was born in Portsmouth, on 4th February 1949, and attended the Southern Grammar School for boys until 1967. Subsequently he taught for 6 months in Basingstoke before proceeding to The University of Birmingham to read for a degree in Psychology. He then spent two years at Manchester Metropolitan University studying film and television production. Between 1972 and 1979 he worked as a Research Officer in the Centre for Health and Medical Education, British Medical Association. He then worked at St Bartholomew's Hospital Medical College and gained a Masters Degree in Curriculum Development in Higher Education from Sussex University in 1984. He has done research at the University of Adelaide and the University of Toronto, as well as at 'Bart's' where he is currently Senior Lecturer in Medical Education and head of the Joint Academic Unit of Medical and Dental Education. 


\section{Bedside Manners:}

\section{Teaching \& Learning in The Hospital Setting}

My method, hitherto unknown here, and possibly anywhere else, is to lead my students by the hand to the practice of medicine, taking them every day to see patients in the public hospital, that they may hear the patients' symptoms and see their physical findings. Then I question the students as to what they have noted in the patients and about their thoughts and perceptions regarding the causes of the illnesses and the principles of treatment. (Sylvius;1679, p 907) 
Chapter 1

The Development and Role of

Clinical Teaching in the General

Education of the Physician 


\section{Introduction}

Clinical exposure is an important part of medical training. The intention of this book will be to illuminate some of the characteristics and products of learning, by medical students, in the hospital setting. The studies included here were carried out in the context of courses in the UK, Canada and Australia, and were completed during a period in which the primary location of clinical teaching was the ward, the lecture theatre or the outpatient clinic, all usually in a large teaching hospital. The term 'hospital setting' has been chosen to include a wide variety of learning environments including the structure and function of clinical attachments, ward based teaching (including bedside teaching), the learning of technical skills, academic work in a clinical context and the use of outpatients. This excludes therefore, primary care and social, community and laboratory based medical disciplines, although many of the contexts used by these disciplines (e.g. bedside teaching at home and walk-in clinics) may be similar to those discussed here. The studies included form part of a general strategy to enhance the quality of modes of clinical education by comparing students' experience to what modern educational theory and practice can offer.

This chapter will outline the field and review relevant literature. It will also discuss the rationale for the remaining chapters which relate to the location of teaching, learning technical skills, the ward round and the 'Grand Round' as the focus of learning, and the relationship of clinical learning to the assessment of clinical competence. It will attempt to answer several questions; why is clinical education important; where did it come from? These issues are discussed under the canopy of historical development of clinical education. Then the major goals of clinical education as perceived by modern educators are addressed, the common practices of clinical teaching are described and finally a focused review of research on clinical teaching and learning is presented. 


\section{The Historical Development of Clinical Education}

\section{Why Clinical Education?}

The answers to such a question might seem obvious. But the history of clinical education has been littered with unchallenged assumptions. Some activities that are now taken for granted were, only a few centuries ago, unheard of or proscribed. It is difficult to envisage medical education without a clinical (patient-based) component. Yet for four hundred years prior to the 17th century much, if not all, of the preparation for practice as a physician was carried out by reading not by clinical contact (O'Malley, 1970). This almost total reliance on the printed word was eventually challenged only by the development of empiricism in Europe. The pressing need to verify theoretical assertions in terms of patient outcome created both clinical work and clinical education. The balance between practical and theoretical work had, in fact, swung backwards and forwards since mediaeval times. The equilibrium was dependent either on the interests and personalities of those in positions of power or on other significant events. For example, in the late 16 th century the rapid availability and expansion of knowledge in books consolidated medicine as an academic, not a clinical, discipline. The emphasis has changed at different times in different places. The development of Italian, Austrian and Dutch clinical 'schools' from 1600-1850, and the reorganisation of American medical education initiated in 1908, can be seen as manifestations of the superiority of practical or of theoretical orientations respectively, both of which are engaged in a perennial tension. These forces pivot around two central questions: what should the primary focus for medical education be - the needs of the patient or the demands for scientific rigour; and where should learning activity take place, the clinic, or the library? The following sections look at these issues in a little more detail, starting with a historical perspective. They challenge the notion that medical education has been developing progressively. Rather, its educational purpose and content has often been defined either by scientists or by physicians. Often the same developments have taken place in different countries at different times. Within this framework significant historical events and the work of educationally influential personalities, like Flexner (1910) and Osler (1906) should be seen as convenient, but unique, conceptual landmarks rather than as points on a medical educational (pedagogical) continuum that absorbs, and benefits from, all influences. 


\section{Where did Clinical Education come from?}

The hospital is the only proper College in which to rear a true disciple of Aesculapius. (John Abernethy: cited in Osler, 1906).

In this section the emergence of the bedside teaching method and the characteristics typical of clinical training as we know it today will be described. There were two important features of clinical medicine that influenced the evolution of clinical education. The first was the notion of the physician's personal responsibility for the patient. This was the stimulus for the systems of apprenticeship and patronage in clinical education that dominated Europe for several hundred years. The second was the fact that for much of the seventeenth and eighteenth centuries, external observation was the only method of identifying signs and symptoms and of formulating diagnoses. Observation was a skill that had to be learnt, and there were few means of objective verification of the results. Hence the prowess of physicians to see, hear and feel the essence of the disease process reached near mythical proportions. However it is important to grasp that this expertise was not necessarily seen as academic wisdom.

The primary model both for the clinical component and, to a certain extent, for its linkage with a university education, was developed in Padua by Giovanni Battista da Monte (d 1551).

"... it is Da Monte who usually receives the credit for developing such clinical instruction to the point where it was remarked upon by nonItalian students as an unusual and commendable novelty of the Paduan curriculum" (O'Malley 1970 p 95-6).

The nature of this model was that students

"accompanied their teachers to the bedside in order to observe the patient's countenance; then talk with him about his symptoms: thereafter note his pulse and observe everything necessary to gain a knowledge of the particular illness." (O'Malley op cit p 96)

and its purpose, succinctly, was to

"put the students in a position to combine theory and practice so that they might thereby become experienced physicians" (Kink, 1854)

The hospital, as a location for clinical experience, was often divorced, both physically and intellectually, from the university, the traditional seat of culture and learning. This separation featured, from time to time, in almost all early attempts to educate doctors, whether in Paris, Padua or Vienna (Coury, 1970 p 146). 
Likewise, at the Universities of Oxford and Cambridge in the early sixteenth century there was no requirement or facility for a clinical component to medical education - the decreed course being entirely lectureand book-based (O'Malley, 1970). However, despite this lack of local clinical opportunity, only Oxbridge scholars were eligible for election to the College of Physicians. Hence, to gain any clinical experience in the 18th C. such candidates had to travel to London, which had hospitals but no university, to see and investigate patients. Nearly one hundred years later, this separation of academic and practical aspects of medicine was enshrined by the General Medical Council (GMC) in the UK as the statutory model for the whole country. This divorce between theory and practice was then extended throughout the western world by colonial development and academic proliferation. (Poynter, 1970).

In western countries, current models of medical education are descended from these European beginnings, with additions and adumbrations derived from North America and it is worth discussing briefly how this development occurred.

Nineteenth century European medical education had been itself a hybrid of two influential genres. First, the seventeenth-century apprenticeship system, where one practitioner would undertake the personal supervision of a few (exclusively male) trainees over the course of several years, typically in a hospital setting. Second, the collegiate system of undergraduate training, developed at the Universities of Vienna, Padua and Leiden, and subsequently successfully exported to their European neighbours during the eighteenth century. In this model traditional scholarship preceded and was then interspersed with clinical attachments. Hence medical schools at Edinburgh, and St Bartholomew's, (which had educational facilities modelled precisely on those at Padua), developed four-year courses in which attention was paid first to basic scientific endeavour and then to clinical expertise. Also at that time the clinical examination of a hospital patient was introduced into the assessment system for the award of the M.B. This appeared first in Cambridge in 1842 (Poynter, 1970) and rapidly spread to all medical schools. By 1861 such courses became the standard that the General Medical Council, founded in the UK in 1858, adopted as suitable for national accreditation. The period of training was extended to 5 years in 1892, and six in 1920. Commonly, the last year of this training was done as a graduate house-officer. It is informative to consider briefly how the internship emerged as an educational experience both because it is a universal part of clinical training, and because of its influence on earlier parts of training (GMC, 1993). The house-year was 
partly a product of the Vienna medical school system of famuli (servants to professor), in which senior students had as part of their educational contract to 'take turns in nursing those who were put under their charge day and night' (Lesky, 1970; p 221). It is also related to the Napoleonic institution of internes and externes; divisions of junior doctors whose job it was to assist their seniors with an array of menial but essential tasks. In 1788 entry to these internships in Paris (that, like their current counterparts in the UK, all became vacant on the same day) was decreed to be by competition through written and oral examinations (Lesky, op cit).

Hence the groundwork for the typical traditional curriculum seen today was laid as far back as the early seventeenth century: a 2 or 3 year basic science course, followed by clinical attachments and then a major examination to enable admittance to an even more intensive clinical responsibility after which the student became fully qualified. Yet a description of the modern clinical curriculum would not be complete without mention of the developments of the last 90 years.

\section{Trends in the 20th Century}

In North America a review by Abraham Flexner (1910) at the end of the last century effectively decided the course of medical education for the next. Briefly, his review resulted in a comprehensive increase in the emphasis on scientific, single discipline-oriented, predominantly laboratory-based studies in the medical curriculum - an idea that had its foundations, after 1850, in the most developed of the German schools. Subsequently. Johns Hopkins became the flagship of the post-Flexnerian fleet of North American medical schools. The important features of Hopkins were:

"Recruitment of faculty based upon a nationwide search for outstanding men.... To require for admission graduation from... an approved four year scientific school.... A logical sequence of training in basic science for two years, with emphasis on laboratory work (and)... medical school and hospital were interlocked and interacting from the start. " Welch 1916, cited in Field, 1970)

The 'interlocking' of medical school and hospital was, however, not enough to secure the academic integration of clinical and basic disciplines. Even though it had originated in Europe this renewed alliance with science was re-interpreted by European schools as a new validation of one highly desirable characteristic of the profession - scientific rigour. Johns Hopkins became the school to which most UK colleges aspired. Its scientific research reputation soared. Together with dramatic expansion in student 
search reputation soared. Together with dramatic expansion in student numbers, these factors effectively put an end to the one-to-one apprenticeship model that had begun to decline in the middle of the nineteenth century and resulted, on both sides of the Atlantic, in a very similar pattern of education. The outcome was a number of relatively homogeneous courses possessing the following deep rooted characteristics (Tosteson, 1990):

- a clear separation between basic and clinical sciences

- the teacher (both clinical and basic scientist) framed in the role of expert

- piecemeal clinical exposure in different clinical units

In essence this is still the basic model for clinical education, although important changes of emphasis have taken place. Currently in most schools clinical education is preceded by a 2, 3 or 4 year pre-clinical phase in which basic and human sciences, and possibly pathology, are taught. There follows a three- (UK and Australia) or a two-year (the Netherlands, Canada and USA) undergraduate period of clinical attachments to, or rotations around, clinical departments. This is usually followed by an intensive one-year attachment (as house officer or intern) in a hospital. In most countries the house officer attachment comprises six months of medicine and six months of surgery. Family medicine internships were introduced but were few in number (e.g. see Eary, Kobernick and Vanderwagen, 1978), although they in this area are now quite common. The house officer (intern) year is universally intended as a continuation of training, although the amount of formal education that is involved has been seriously questioned in the UK by both independent researchers and government bodies (Grant and Marsden, 1989; SCOPME, 1992).

However the most recent major challenge to the Flexnerian model, one that is developing considerably (ACME-TRI, 1993), has come from the Association of American Medical Colleges report on Physicians for the 21st Century, (AAMC, 1984). This report unequivocally restored the patient (and their families) as the primary focus of medical education. In it, the role, value of and appropriate structure for clinical education was carefully described and general principles identified. In brief these include:

1. Medical faculties (as opposed to individual specialists) should specify the clinical knowledge, skills, values and attitudes that students should develop...

2. Faculties should describe the clinical settings appropriate for clinical clerkships 
3. Teachers should have adequate preparation and the necessary time to guide and supervise students in clinical clerkships

4. Clinical performance should be assessed.

5. Basic science and clinical education should be integrated to enhance the learning of key scientific principles and to promote their application to clinical problem solving. (AAMC, 1984 pp 14-19)

It is the last of these issues that will become the most challenging for the future development of clinical education. Even though far from achievement, it is the first time that such a notion has been put so forcefully, certainly by a national institution, since the age of enlightenment. Such principles have also increased interest in problem-based learning (PBL) as one of the primary methods of integrating basic science with clinical expertise in an appropriate manner. However the studies presented in this thesis were carried out primarily in traditional settings, in Canada, the UK and Australia. Hence it is useful at this point to outline the major differences and similarities between these national educational programmes.

\section{International Similarities and Differences}

Without doubt, the changes introduced by Flexner in America had been overdue, but they effectively stagnated the further development of courses for 60 years. Paradoxically, when schools in Europe began to look west for new ideas, they saw their own curricula and philosophy mirrored in the waters of Boston, New York and Baltimore. American revolution in medical education hence consolidated European orthodoxy. The effect of this was to ratify the separation between the clinical and the academic environments. Any student who wished to lay hands on a patient had first to complete a 'scientific' education. As a result colleges of medicine, almost exclusively, now take students who have previously specialised in science. In the UK, and in most other European courses, intake is direct from secondary school. The predominant difference between North American, and UK and Australasian models of medical education, has been the former's reliance on a graduate intake and the use of a four year medical programme.

The other principal difference between North American and UK/Australasian courses is the extent to which clinical skills are summatively assessed (see p. 17). In North America national examinations, until very recently, did not feature a clinical component. In the UK all schools include 
up to 3 separate evaluations (medicine, surgery and obstetrics and gynaecology) of clinical skill in their final examinations, which directly license them to practise as junior doctors.

Nevertheless the clinical environment for North American, and particularly Canadian, students is very similar to that of their UK counterparts. Canadian students usually have a four year course prior to internship, only the first two years of which are predominantly basic science. In Toronto the last two years were, at the time of the study presented in Chapter 4, spent in teaching hospitals. The first of these 'clerkship' years was spent entirely in one large general hospital rotating round various clinical attachments, whereas the second year was spent following specialties in a variety of locations. In the UK and Australia, and particularly at St Bartholomew's, and the London Hospitals' Medical Colleges, and Adelaide, where the remaining studies were done, students are usually attached to more than one hospital in every clinical year. In most other respects the clinical rotations are very similar.

It is useful at this point to look in more detail at what the goals of clinical education are considered to be and then to describe what activities students typically undertake in clinical settings to fulfil those aims.

\section{The Goals of Clinical Education}

It might be thought from the preceding discussion, that charting the relationship between educational outcomes and clinical activity would be a simple matter. However, this is far from the truth. There is as little consensus on which outcomes should be measured as on what the most appropriate learning methods should be.

In educational terms it is useful first to define goals or objectives, then to choose methods appropriate for achieving those goals and finally to assess the outcomes, comparing these with the original specifications, (Stenhouse, 1976; Davies, 1976; Newble \& Cannon, 1991). In most educational settings attempts to inculcate a variety of complex skills and behaviours would entail considerable attention to the specification of the proposed end product - in this case the doctor. The clinical component of medicine, at its essence, involves: 
“... identifying, recording and analysing symptoms presented in individual cases as a basis for diagnosis and treatment. Relentlessly inductive, clinical medicine requires accuracy in observation and testing to determine deviations from established norms" McGrew, 1985.

The fulfilment of this task is the goal of education in the hospital. However, surprisingly, less than $25 \%$ of the published studies of education in this setting address the goals of clinical education. Until very recently, most of the educational literature dealt with the educational process chiefly, as will be shown, in terms of characteristics and activities of the teacher, (e.g. see Irby, 1978; Mattern et al. 1983) rather than with the objectives, length, structure or function of the period of clinical attachment. In these studies of clinical teachers the worth, and hence the purpose, of the clinical experience is frequently assumed to be self- evident. In an early study, Reichsman et al (1964) formulated the principal objectives of clinical teaching as

“a) to help students learn methods of observation and other clinical skills;

b).... acquire a body of information c).... develop capacity for clinical reasoning d) to effect modifications in students attitudes and behaviour" p150

Recently in a questionnaire and observational study of outpatient (OP) teaching at St Bartholomew's, Towle (1991) asked 51 senior clinicians to identify the objectives and the value of such sessions. The group identified 20 different objectives, and majority consensus (by 31 staff) was reached on only one area - the physical examination and the detection of physical signs. The other objectives identified included history taking (21), patient management (18), developing appropriate attitudes to patients (12), communication with patients (10) and presentation skills (4). The value of clinical work was seen in even more equivocal terms, the most common, but still with only 9 physicians agreeing, being "seeing how doctors and clinics work in the real world" ( $\mathrm{p6}$ ). There was much more precise agreement, from 37 respondents about the problems associated with such teaching, namely staffing, workload and time availability.

Furthermore criticisms of clinical education have rarely been levelled at its aims, but frequently at the process or outcomes, (see Lowry, 1992a, $1992 \mathrm{~b}$ ). Part of the problem has been in defining precise outcomes in a professional environment in which graduation is merely a halfway house to independent practice. 'Is there an end product?' asks Lowry in one of her articles, (Lowry, 1992b). 
Two coexisting, but antithetical, views of the end product are current in the UK, and these can be seen as further examples of the perennial polarity between the academic and the practical. In 1980 the GMC first attempted to define the principle objective of basic medical education as;

"the knowledge, skills and attitudes which will provide a firm basis for future vocational training" (GMC 1980, p3).

However in a recent set of guidelines, (GMC 1993) a 'complementary' goal has been added; to produce a graduate who can function as a preregistration house officer (intern). The former is aimed very much at creating a self-directed learner capable of further development, but the latter attempts to ensure competence in a wide range of clinical skills focused on the job of the house officer.

\section{What Does Educational Activity in Clinical Settings Consist of?}

McLeod and Harden (1985) summarise the components thought to contribute to a clinical education. These comprise:

Bedside small group tutorials, in which students discuss a patient, sometimes at the bedside, with a more senior practising physician.

Ward rounds, in which students tour with consultants (attendings/senior physicians) and their staff in order to discuss appropriate management of cases on the ward.

Independent patient contact in which students 'clerk' (interview, examine and summarise in writing) a patient. This can be done in a variety of settings including the ward, outpatients, the patient's home, in general practices etc.

Classroom discussion, based either on patients or on an academic topic.

Other activities, not specifically mentioned by McLeod, would include attendance at operations, special procedures (e.g. radiography), post-mortems, and clinical case conferences, at both medical and paramedical level (psychiatric reviews, physiotherapy, etc). All of these events, of course, can be (and are) supplemented on many occasions by an array of educational techniques such as lectures, reading, laboratory classes, and so on.

The activities undertaken by students in the studies in Chapters 2-3 reflect this diversity. In their attachments of between 4 and 10 weeks to general medical and surgical units, ward work, attending lectures and 
teaching rounds, clerking patients and writing patients' notes feature prominently. Other specialty attachments might be to the accident and emergency, renal, or endocrinology departments and so on. Nevertheless such specialties might occasionally provide more general medical or surgical experience.

In addition the assessment of clinical competence is now an essential component of the educational process. As we have seen this was not always the case (see p. 19). Additionally modern developments have also made this a field in its own right (Newble, Jolly \& Wakeford, 1994). The most significant progress from the point of view of this thesis is the recognition that the mode and weight of assessment greatly modify the educational activities of students (Newble et al 1994), and the introduction of the Objective Structured Clinical Examination ( OSCE; Harden \& Gleeson, 1976 ) in the late 1970's. This procedure, that challenged and in some cases replaced examination of one patient as the primary means of clinical assessment, allowed reliable and valid assessment and increased the scope of clinical examinations to encompass a wider range of clinical tasks. Without this extension, the work reported in Chapters 5 and 6 would not have been possible. In these chapters the OSCE is used as a tool to measure the output of the otherwise hidden clinical education process.

\section{Research on Educational Outcomes and Processes in the Huspital Setting}

There are probably several reasons for the lack of rigour in the definition of the purpose of clinical education. First, the historical development of medical education, as we have seen, was linked to a system of patronage and apprenticeship. Second, in the university this was reflected as 'person culture' ( Handy, 1976; Arluke, 1980), where academic units derived their raison d'etre from the intellectual and personal characteristics of one or two key personnel. This culture permeated both the practice of medicine and the organisation of medical schools and can be seen in the operation of the ward round, the hierarchy of medical departments, the centrality of the professorial staff and so on, and became the model known today as apprenticeship. Some of the inherent control rules of this model roundsmanship - have been identified by Arluke, and essentially they act to move the focus of educational activity away from the patient and more towards the academic and game-like aspects of professional interaction (Arluke 1980). There is also the historical legacy of the existence of clinical 
teaching pre-dating ratification by Universities. In addition until the mid 1970 s there was virtually no educational research on or external scrutiny of medical courses at the consumers' level.

It is therefore not surprising that the educational model, especially in the UK, for the content of clinical education in traditional settings, is constructed more like a recipe for minestrone soup than as a carefully planned educational experience. Courses were organised by departments through various specialty studies. Although there are usually introductory courses, and a short period of general medicine and surgery, these are followed by many topics, specialties and environments, all dissected into digestible units fed to the students in a fairly random order. The exact recipe in each school depends very much on the individual chef. For example, in 1973 the GMC commissioned a national study of the curricula in UK medical schools. All schools returned a comprehensive questionnaire on the construction and delivery of their courses. There was substantial variation between schools in the length of clinical attachments and the amount of patient-based clinical experience offered. As the GMC (1977) pointed out, "There is enormous variation, even when only the major specialties are under consideration, and due to circumstances often rather than policy" (p 57). For instance, the length of attachments for 'general surgery' in the first clinical year in two schools picked at random was 7 weeks and 20 weeks. Furthermore, within any medical school students are frequently attached to different clinical units within the same subject area. Hence 2 students nominally attached to 'medicine' might nevertheless have completely different educational experiences. Such haphazard experience is widely reported, (Kowlowitz, Curtis \& Sloane, 1990; Jolly \& Rees, 1984; Hunskaar \& Seim, 1985).

Consequently it is often difficult to know what is the precise educational diet for students even within one medical school. In Toronto this led to the instigation of a database, first in the pre- clinical school (Project Oracle), to track the students' encounters with content and process throughout their undergraduate education. Students kept logs of what had been covered and by what type of teaching. This was later expanded to the clinical course,(Chin, Cohen \& Jolly, 1988). Data on topic, hands on/patient based experience, literature available or referred to, and other indicators of clinical teaching were collected by 2 students from each of a first year clinical rotation and fed into a computer data base. The principal studies of the role of clinical education have come from sociological perspectives, (Becker et al 1961; Armstrong, 1977; Atkinson, 1977). In these the assumption is made that the purpose of clinical education is to 
turn ageing adolescents into young doctors, and that this is accomplished as much by a socialisation process as by educational development. Such studies are concerned with documenting the formation of and constraints on the socialization process. As Atkinson says:

"Although it takes place within the social and physical context of hospital life, the reality of bedside teaching is a carefully managed version of medical work" (Atkinson, 1977 p 97)

Whether Atkinson is right or not about learning being a carefully managed version of medical work, his, and other sociologists', perspective on the purpose of clinical education is that it is a rite of passage designed to teach students how to cope with 'being' a doctor. This view has also been adopted by some educationists (Fleming, 1986 ).

The clinical work of a hospital unit is supposed to serve as an organisational framework for discrete educational experiences. However, while the predominant tradition of clinical education throughout the world stems from bedside teaching, the amount of teaching actually taking place at the bedside, or in the presence of the patient, is highly variable. Four studies designed to monitor educational activity in hospital settings (Chesser and Brett, 1989; Payson and Barchas, 1965; Reichsman, et al, 1964; Mattern et al, 1983 ), found evidence that the time devoted to clinical activity was erratic or even non-existent, ranging from $0 \%$ to $25 \%$ of students' time on the ward. For example, unpublished data from the Chesser and Brett study, done in one of the hospitals featured in chapter 2, indicate that on a typical week of clinical attachments some students were getting about 12 hours of bedside teaching, while others were receiving none. Mattern found that of 6 attending physician teams studied, only 3 visited the bedside for educational purposes. Teaching rounds continue to be a focus for education, but their organisation still leaves little time for bedside teaching and development of clinical skills. Miller (et al 1992) recently found that within teaching rounds $63 \%$ of the time was spent in the conference room, $26 \%$ in hallways and only $11 \%$ at the bedside. There is a growing literature on the programme evaluation of clinical teaching and its methodology. Reviews have attempted to identify a number of features that seem to contribute to student satisfaction and good teaching. Some of these have purportedly been validated in terms of resultant student abilities. For example Anderson (et al, 1991) showed that results on an objective structured clinical examination (OSCE) in neurology reflected differences in students' ratings of their teachers on attachments to 4 hospitals for their immediately preceding neurology rotations, and Higgin and Harasym (1993) that students returning from some obstetric and 
gynaecological attachments did not do so well on a focused OSCE. More recently research has demonstrated location to be a potent variable in learning diagnostic skill, even overriding the effects of centralised curriculum design (Bordage, et al 1989; Wolfhagen, 1993).

Most early research on clinical settings concentrated almost entirely on the characteristics of the teacher (Irby, 1978, Weinholtz et al, 1986), but later work has highlighted the need to look at the whole clinical environment, (Chesser \& Brett, 1989,; Towle, 1992) and at student input (Stritter et al, 1975,). Chesser and Brett, using ratings of clinical attachments at The London Hospital, identified six major factors in student satisfaction with clinical teaching; feedback to students; clinical exposure; staff-student relationships; organisation and delivery of teaching; involvement with the business of the firm and the degree of acuteness of medicine. The most important of these factors was feedback to students which accounted for $23 \%$ of the variance in student satisfaction in their study. They also showed that, although feedback and acuteness is important all round, organisation of teaching was relatively more influential on medical firms, while degree of clinical experience was more significant on surgical attachments. The necessity of feedback has been supported by numerous studies. Recent further research (Wolf \& Turner, 1989), also highlighted the perceived value of showing personal interest in students, reviewing histories and supervising physical examinations. This study also showed, as have others (Mattern, et al 1983 ; Bennard \& Stritter, 1989), that staff consistently overestimate how frequently they undertake certain teaching activities, especially those that they value highly.

There has been a great deal of interest lately in the need for self-directed or problem-based learning, (Tosteson, 1990; Barrows and Tamblyn 1980,). It is often believed that the clinical environment carries the capability for such learning. However 'teaching' ward rounds often have little opportunity for students to contribute; Foley et al (1979) found that student contribution to teaching and business rounds was even less than that in lectures, Student input was significant only in patient management conferences and morning reports. Moreover the content of such teaching as exists was frequently unconnected with patient care, clinical skills, doctorpatient communication or management. Such observational studies of ward rounds 'in action' found that discussion often focused on minutiae, or on esoteric or scientific aspects of the case not amenable to bedside investigation. In one study characteristics commonly attributed to wardround teaching - patient examination and $\mathrm{Dr}$ - $\mathrm{Pt}$ communication, occupied a small percentage of the round, (Payson and Barchas, 1965). Perhaps this 
is not surprising given that most studies have been conducted in high profile, university affiliated teaching hospitals (the Payson study took place at Yale). Research has consistently suggested that work-related, patient-based experience is more frequent and prolonged in district, community or other non-teaching/non-affiliated hospitals, although most researchers do not directly suggest why this should be the case (Payson and Barchas, 1965; Wakeford, 1983; Lockwood et al, 1986; McManus et al, 1992; Brett and Chesser, 1992). A number of factors could contribute; there may be fewer students per patient, more staff time per student, or generally more patients. However, the rules operating in major teaching hospitals may also inhibit such activity, (Arluke, 1980).

Stritter (et al 1975) originally suggested that what the students are able to contribute to attachments may be as, if not more, important than the endeavours of the teacher. With increased interest in problem-based or self-directed learning there has been concomitant attention given to this in clinical settings. Studies have shown increased diagnostic ability and slightly decreased or equivalent maintenance of factual knowledge in students from problem-based learning (PBL) curricula, (Phelan et al, 1993; Schwartz et al, 1992), but students consistently find PBL more enjoyable and motivating than traditional educational methods (Blosser \& Jones 1991). Most of this research highlights an important feature of clinical education, namely that assumptions about the amount of instructional activity taking place in clinical environments are not well founded. Although the concept of 'clinical experience' has been the driving force behind the later stages of medical training, it is difficult to find its equivalent in organised educational activity. Nevertheless it is true that students emerge from medical school, as house officers (interns) on the ward, with the knowledge, skills and attitudes that enable them, however rudimentarily, to practise medicine. So there are obviously educational outcomes and presumably these derive from learning experiences. The gap between research and reality may be because research has tended to concentrate on what the medical teacher does, rather than what happens to students and other aspects of the environment. In this thesis one of the principal issues is what is actually happening to students and what is the connection between the measurable outcomes of clinical education and its content or process. If more can be understood about the constraints, inadequacies and successes of the students' experience, organised or otherwise, then a more appropriate rationale can be developed for clinical education. 


\section{The Structure of This Thesis}

In the preceding section several roles have been identified for educational research in the clinical setting, along with some initial findings about students' and teachers' views of clinical teaching. It has been shown that it is often difficult to know precisely what has been taught and sometimes why it has been taught in the first place. Some studies have attempted to analyse positive and negative features of clinical education, but until recently have ignored the students' contributions to their own education. Also researchers have generally overlooked the clinical environment, concentrating much more on teaching or learning activities. Even so very few attempts have been made to link educational activity in the clinical setting with outcome. The remainder of this thesis is an attempt to tackle these issues. Emphasis is on factors in the educational environment influencing clinical education. Rather than concentrating on opinions, an attempt is made, especially in Chapter 6 to relate environmental factors to learning outcomes.

The next section introduces the chapters in more detail, and provides additional methodological rationale.

\section{Chapters 2-4; What Makes a Good Clinical Education?}

The shortage of knowledge about clinical education was the context in which research presented in Chapters 2 to 4 was done. In chapter 2 a report is given on some skills, techniques and experiences known to be important in the house officer year. We asked the basic questions, where, when and how are these skills learnt and what do the results of such a study tell us about the content and process of clinical education? In Chapter 3 , we continue to ask what are the characteristics of good and bad clinical teaching as perceived by the recipients. In Chapter 4 , use was made of participant observation to elucidate the most important aspects of a programme designed to make students more independent and more active learners in a traditional clinical school. Common to these three studies is the theme of preparing young doctors for the world of work. The following paragraphs expand on the nature of the argument.

At St Bartholomew's Hospital and The London Hospital Medical Colleges we had two curricula which resembled the minestrone model (see p. 24-25). An end-of-course evaluation in one school (Jolly \& Rees, 1984) had shown that clinical teaching was perfunctory, and varied in quality and quantity. The students were sometimes humiliated on the wards, teaching was often cancelled, the curriculum stressed the retention of factual knowledge and 
the course had no discernible philosophy or goals. Previous examinations of the effects of undergraduate clinical education had mostly investigated students' perceptions. They had not taken advantage of the fact that their views might change once they qualified and started to work. Furthermore at that time very little was known about precisely what skills and attributes house officers were expected to demonstrate on the job, and where they had learnt these. The opportunity arose to investigate the experience, after a year in the house-job, of a cohort of students from two medical schools. The study in Chapter 2 was aimed at fairly simple verifiable outcomes - the skills and techniques in common use in the house year. But the original data collection was wide ranging, including much more than that discussed in the paper, and utilising questionnaires, with some open ended questions, and interviews. One remit was to identify self reported outcomes of clinical education - to find out where and when students mastered the components necessary for communication with, and examination and investigation of, the patient, particularly in relation to their undergraduate or house year phases of training. Also a focal interest, generated from previous work, (Jolly \& Rees, 1984 ) was to understand how the undergraduate course prepared students for their year of work, and what gap, if any, existed between expectations of them during their clinical education and in their first job. By asking for reports of tasks and skills accomplished in addition to descriptions of educational experiences (which in a traditional school tend to be framed anyway in terms of the amount of time devoted by staff to organising and running teaching events), it was hoped to be able to pinpoint specific educational needs relating to professional duties. This study was also aimed at investigating students' perceptions of 'good' clinical teaching, partly by comparison with 'poor' teaching, and partly by exploring what were students' expectations and experiences in both undergraduate and house years.

Chapter 3 summarises some of the other results from the study presented in Chapter 2. In addition it presents data from a study of graduating students. The studies investigated, amongst other things, the characteristics of those attachments which students and house officers felt to be most enjoyable and/or well taught. Both studies encompassed the whole curriculum, so that all attachments, including those based in the community and primary care, could potentially be reflected in the data. The focus was the whole clinical attachment, including all features of clinical work, not merely the activity of the senior clinician. Chapter 3 presents some data on the difference between enjoyability of a learning experience and the usefulness of that experience for the subjects. It also reports the results of an attempt to introduce problem-based tutorials into the clinical 
environment in such a way that the problenn-solving activity normally associated with a new clinical encounter between doctor and patient was not compromised. The focus here is on the learning activity of the student, not the clinical dynamism of the physician.

As we have seen early research on clinical education typically concentrated on the aspirations, goals, and actions of senior clinical teachers, or on the perceptions of staff and students of these. (see also Weinholtz, et al, 1986). However at least one factor-analytic study (Stritter et al 1975) had found that one of the characteristics critical to 'good' clinical teaching was the ability of the clinician to 'provide a personal environment in which the student is an active participant' (p878). This included the provision of opportunities to practice both technical and problem solving skills. However, in a complex clinical environment, such provision is not always straightforward. For example in relation to problem-solving both Atkinson (1977) and Armstrong (1977) have pointed out how the problem solving process for the student, becomes distorted by the milieu of the ward round, and often leads to behaviour quite different to that associated with solving de novo clinical problems. In Toronto, in 1988, a course change had taken place that directly reflected work-related ideals and activities, and afforded the opportunity of studying a situation in which students' contribution to clinical education was both valued and encouraged. This was the student 'Grand rounds' programme. Professional 'Grand rounds'(GRs) are interdisciplinary patient-based fora for medical staff commonly held once a week in major teaching hospitals. In GRs staff present and discuss particularly interesting, important or problematic cases. They are sometimes open to students, depending on the institution. These 'rounds' are not typically ward-based, mostly being held in large discussion rooms or lecture theatres, but nevertheless form one of the landmarks of the working week in a busy teaching hospital in most UK, North American and Australasian countries. Typically (GRs have been observed by the author in the UK, Australia and Canada) between 20 and 40 senior physicians attend the medical grand round. GRs had been instituted just for students in the University of Toronto affiliated teaching hospitals. These studentgrand-rounds evolved precisely from a rationale attempting to relate students' activities more to the work of the hospital and in providing them with more meaningful clinical exposure, (University of Toronto, 1982-86). Work related experience at an undergraduate level had not often been studied in clinical education.

The study reported in Chapter 4 attempted to unravel the aims and outcomes of these grand rounds through qualitative and participant obser- 
vation strategies. In particular the study also attempted, by comparison with some British work on ward-based patient presentations (Fleming, 1986) to analyze the boundary between the socialisation and the educational functions of professional work-related activity.

\section{Chapters 5 to 7: Clinical Education and Outcome}

In Chapter 5 an attempt is made to describe the singular effect of assessing clinical skills; is there any direct connection between the assessment process and what students learn? In Chapter 6 a series of studies is described to elucidate the link between the quality of clinical teaching in hospital settings and performance on assessments. Finally in Chapter 7 guidelines derived from the studies are summarised.

If the vagaries of clinical education are such that it is impossible to control, the possibility arises that what students do may be more controllable by choosing assessment more precisely, than by trying to force essentially random variations of clinical phenomena into patterns for the educational benefit of students. Therefore a study was carried out to see, in part, what effect alterations in the make-up of clinical assessments had on student outcome, irrespective of alterations in curricular patterns. This study is repurted in Chapter 5.

Chapter 6 attempts to relate clinical experience to outcome in terms of the skills and proficiencies acquired by students. It basically seeks to answer the question, is there any evidence to suggest that differences in quantity and structure of clinical exposure result in differences in the clinical skills of students? Previous attempts to do this (both in the USA) have focused primarily either on the characteristics or activities of the teacher (Anderson et al 1991), or at a restricted specialty experience (Higgin \& Harasym, 1993). The problem with clinical education in the UK is that students are attached in quite small numbers (2-8) to a clinical unit, yet experience can vary substantially both between and within these units.

Chapter 7 attempts to coalesce the findings from the studies into a strategy for institutions to follow in the definition and assessment of clinical education.

\section{Methodological Considerations}

The studies reported here were done in real-life settings. This poses some problems for the researcher on the choice of research techniques. 
The methodologies used throughout Chapters 2-6 are eclectic, ranging from straightforward simple questionnaires, to observation and interview. The complexity of the clinical setting makes it inevitable that experimental controlled trials will rarely be possible. Even when they are, the results are sometimes disappointing in scope (Block et al 1990). Two of the main approaches used here, illuminative evaluation in Chapter 4, and representative sampling, in chapters 5 and 6 , deserve more elaboration than they receive in the articles. Both methods were developed in response to the inefficiency of classical experimental designs in dealing with the complexity of the real educational world. In general the participant observation methodology developed by sociologists and extended to educational settings (Parlett and Hamilton, 1976) is probably the most fruitful. Both paradigms, however, attempt to overcome the problems of traditional experimental design generated by the agricultural model and Fisherian statistical analyses. Briefly these are; 1 . Experiments artificially reduce or control many of the important variables in an educational environment. In so doing they do not adequately reflect the social and political complexity of the real world. 2. Experimental results often have to be pre-specified in a narrow framework. Such approaches are too inflexible to take account of the antecedents and, in particular, the processes, and intended outcomes of most educational programmes, and of changes occurring within these during the period of study. Experiments are sometimes insensitive to subtle but important influences existing in the real educational milieu. 3 . Experiments often include controls to achieve internal validity - to ensure or establish that the effects that happen are actually attributable to the independent variables. The higher this control, the tighter the grip on internal validity, the more this jeopardises external validity: the ability of the experiment to generalise to the range of circumstances from which it was concocted. Snow (1974) recognised that the degree of direct control required to generate acceptable experiments in educational settings was impossible or undesirable.

The two methodologies deal with these problems in different ways. Illuminative evaluation (Parlett \& Hamilton, 1976; see Stenhouse 1981 for a critique) seeks to filter out the important issues by using an open-ended, broad data gathering strategy, and then using the professional competence of the researcher to sift out and follow up on the most significant features. A useful analogy is the court-case in which all possible relevant evidence is amassed, irrespective of whether this is based on statistics, the perceptions of the participants, or expert advice. The researcher refines and makes judgments based on this evidence. Unlike the court-case however, the researcher has the additional option of gathering evidence in the field 
first hand, by direct observation and participation in the events which are being studied. This approach was used in Chapter 4 to explore staff, students and administrators experiences of the educationally innovative grand rounds.

The representative or ecological approach was derived from the work of pioneering psychulugist Egon Brunswik (1956), although he rarely managed to implement it in his lifetime. Brunswik appreciated that to be efficient, and to lead to meaningful outcomes, experimental designs for the study of perception should reflect (be representative of) situations and dimensions existing in the real (ecological) world. Over abstraction of stimuli was self- defeating. Snow (1974) extended this notion to educational research. In his view, even the quasi-experimental designs of Campbell and Stanley (1962) were restrictive. What was needed were studies which allowed uncontrolled or uncontrollable features in situations to vary in experiments, but under conditions which would allow some scrutiny. By frequent sampling from a range of real circumstances, in the real world, day to day invalidations of experimental conditions would be gradually eliminated, thus revealing the 'true' relationship between variables. This concept is very close to the notion of the 'universe' of generalisablity coined by Cronbach (et al 1972). The universe of generalisability of any measurement is defined by the number of facets existing in any experiment. In a 'representative' sampling framework researchers seek to sample a wide range of naturally occurring conditions of each facet, while monitoring the relationship between the variables of interest. Although measurement oriented, this technique substitutes for control the search for maintenance of effect over a wide range of conditions. In chapter 6 the variables are the natural activity levels of the clinical units to which students are attached.

In chapter 5 , the measure chosen is quite straightforward - the mean scores of students on certain repeated or non-repeated OSCE stations. However the methodological rationale is based on the principles of representative sampling. The relationship between the independent variable; the extent to which, on a relatively random basis, certain OSCE stations were repeated from year to year, and the dependent variable; the resulting scores of independent groups of students' scores on those stations, while other factors, the 12 year period, the different class years, were allowed to vary naturally. 


\section{References}

ACME-TRI. (1993) Educating Medical Students: Achieving change in medical education - the road to implementation. Academic Medicine, 68, (Supplement S1), 1-49.

Anderson DC, Harris IB, Allen S, et al. (1991) Comparing students' feedback about clinical instruction with their performances. Academic Medicine, 66, 29-34.

Arluke A. (1980) Roundsmanship: inherent control on a medical teaching ward. Social Science and Medicine, 14A, 297-302.

Armstrong D. (1977) The structure of medical education. Medical Education, 11, 244-248.

AAMC (Association of American Medical Colleges). (1984) Physicians for the 21st Century. Report of the panel on the General Professional Education of the Physician. (GPEP Report) AAMC: Washington.

Atkinson PA. (1977) The reproduction of medical knowledge, in Dingwall R, Heath C, Reid M and Stacey M. (Eds) Health care and health care knowledge. London: Croom Helm.

Atkinson PA. (1981) The clinical experience: the construction and reconstruction of medical reality. Westmead: Gower.

Barrows HS and Tamblyn R. (1980) Problem-based Learning: an Approach to Medical Education. New York: Springer Publishing Company.

Becker HS, Geer B, Hughes EC, and Strauss AL. (1961) Boys in White: student culture in medical school. Chicago: University of Chicago Press.

Bennard BC, and Stritter FT. (1989) Teaching Medical Students in Ambulatory Clinics: Prescribed vs actual practice. Proceedings, Research in Medical Education, 1989, 141-146. Washington: Association of American Medical Colleges.

Block SD, Style CB and Moore GT. (1990) Can we teach humanism? A randomised controlled trial evaluating the acquisition of humanistic knowledge, attitudes and skills in the New pathway at Harvard Medical School. Boston: Mimeo, Harvard Medical School.

Blosser A and Jones B. (1991) Problem-based learning in a surgery clerkship. Medical Teacher, 13, 289-93, 295-8.

Bordage G, Morin F and Leclere H. (1989) Comparison of the diagnostic performance of students of the old and new medical curriculum at the Laval University. Union Medicale Du Canada. 118, 187-8, 191-2, 194-5.

Brett M and Chesser A. (1992) Auditing Clinical Teaching. Address to the Association of for the Study of Medical Education, London Meeting, April 1992.

Brunswik E. (1956) Perception and the representative design of psychological experiments. Berkeley: University of California Press.

Chesser A and Brett M. (1989) Clinical Teaching in Context: A factor analysis of student ratings. Research in Medical Education. Proc. 28th Annual Conference. Washington: Association of American Medical Colleges, 49-54.

Chin V, Jolly BC and Cohen A. (1988) Use of a Database for Curriculum Monitoring - a Clinical application. Paper presented to the Conference on the Application of Computers to Medical Education. University of Toronto, Canada, April 1988.

Coury C. (1970) The teaching of medicine in France from the beginning of the 17th C. in O'Malley, CD (Ed). The history of medical education. Los Angeles: University of California Press.

Cronbach L, Gleser GC, Nanda H and Rajaratnam N. (1972). The dependability of behavioural measurements; theory of generalisability for scores and profiles. Chicago: John Wiley.

Davies IJK. (1976) Learning by Objectives. London: Kogan Page. 
Eary LE, Kobernick M and Vanderwagen WC. (1978) Pilot experience of a family practice- based combined clerkship. J. of Family Practice, 7, 1978, 54 1-6.

Field J. (1970) Medical education in the United States: late nineteenth and twentieth centuries. in O'Malley, CD (Ed). The history of medical education. Los Angeles: University of California Press.

Fleming W. (1986) Good professional reasons for poor educational practice: the interaction of medical and educational work in presenting cases during junior clinical clerkship. Paper presented to Society for Research in Higher Education, Imperial College London. Proceedings SRHE, Guildford: SRHE Publications.

Flexner A. (1910) Medical education in the United States and Canada. New York: Carnegie Foundation.

Foley R, Smilansky $\mathbf{J}$ and Yonke A. (1979) Teacher-student interaction in a medical clerkship. Journal of Medical Education, 54, 622-6.

General Medical Council. (1977) Basic Medical Education in the British Isles: the report of the GMC survey of basic medical education in the UK and the Republic of Ireland. (Vol1) London: Nuffield Provincial Hospitals Trust.

General Medical Council. (1980) Recommendations on basic medical education. London: GMC Education Committee, 1980.

General Medical Council. (1993) Guidelines on Undergraduate medical education. London: GMC Education Committee.

Grant J and Marsden P. (1989) Senior house officers and their training. II Perceptions of service and training. British Medical Journal, 299, 1265-8.

Handy C. (1976) Understanding organisations. Harmondsworth: Penguin.

Harden R McG and Gleeson F. (1979) Assessment of clinical competence using an objective structured clinical examination (OSCE). Medical Education, 13, 41-51.

Higgin JR and Harasym PH. (1992) Using the OSCE to identify strengths and weaknesses in learning at three teaching hospitals. in Hart I, Harden RMcG and Mullholland H. (Eds) Approaches to the Assessment of Clinical Competence. Proceedings of 5th Ottawa Conference on Medical Education, Dundee, 1991.

Hill DA and Lord RS. (1991) Complementary value of traditional bedside teaching and structured clinical teaching in introductory surgical studies. Medical Education. 25, 471-4.

Hunskaar S and Seim SH. (1983) Assessment of students' experiences in technical procedures in a medical clerkship. Medical Education, 17, 300-4.

Irby DI. (1978) Clinical Teacher Effectiveness Journal of Medical Education, 53, 808-815.

Jolly BC. (1985) Unpublished data from Room for Improvement.

Jolly BC and Rees LH. (1984) Room for Improvement: an evaluation of the undergraduate curriculum at St Bartholomew's Hospital Medical College. London: Mimeo, SBHMC.

Kink R. (1854) Geschichte der kaiserlichen Universitat zu Wien. Vienna: University of Vienna.

Kowlowitz V, Curtis P and Sloane PD. (1990) The procedural skills of medical students: expectations and experiences. Academic Medicine, 65, 656-8.

Lesky E. (1970) The development of bedside teaching at the Vienna medical school from scholastic times to special clinics. in O'Malley, CD (Ed). The history of medical education. Los Angeles: University of California Press.

Lockwood DN, Goldman LH and McManus IC. (1986) Clinical experience of clerks and dressers: a three year study of Birmingham medical students. Journal of the Royal Society of Medicine, 71, 38-42. 
Lowry S. (1992a) Whats wrong with medical education in Britain? British Medical Journal, 305, 1277-80.

Lowry S. (1992b) Curriculum design. British Medical Journal, 305, 1409-11.

MacManus IC, Sproston KA, Winder BC and Richards P. (1992) The experience of medical education: changing perceptions of final year students. Paper presented at Fifth Ottawa International Conference on Assessment of Clinical Competence, Dundee, September, 1991.

Mattern WD, Weinholtz D and Friedman C. (1983) The attending physician as teacher. New England Journal of Medicine, 308, 1129-1132.

McGrew R. (1985) Encyclopaedia of Medical History. London: Macmillan.

McLeod PJ and Harden RM. (1985) Clinical teaching strategies for clinicians. Medical Teacher, 1985, 7, 173-89.

Miller M, Johnson B, Greene HL, Baier M and Nowlin S. (1992) An observational study of attending rounds. Journal of General Internal Medicine. 7, 646-8.

Newble DI, Jolly BC and Wakeford RE. (Eds) (1994) The certification and recertification of doctors: issues in the assessment of clinical competence. Cambridge: Cambridge University Press.

Newble DI and Cannon R. (1991) A Handbook for Clinical Teachers. (2nd Ed) London: MTP Press (1991).

Newble DI, Dauphinee D, Dawson-Saunders B, et al. (1994) Guidelines for the development of effective and efficient procedures for the assessment of clinical competence, in Newble DI, Jolly BC and Wakeford RE. (Eds) (1994) The certification and recertification of doctors: issues in the assessment of clinical competence. Cambridge: Cambridge University Press.

O'Malley CD. (1970) Medical education during the renaissance. in O'Malley, CD (Ed). The history of medical education. Los Angeles: University of California Press, 1970.

Osler W. (1906) Aequanimitas. New York: McGraw-Hill.

Parlett M and Hamilton D. (1972) Evaluation as illumination: a new approach to the study of innovatory programs. Occasional paper No 9, Centre for Research in the Educational Sciences, University of Edinburgh.

Payson HE and Barchas JD. (1965) A time study of medical teaching rounds. New England Journal of Medicine, 273, 1468-71.

Phelan ST, Jackson JR, Berner ES. (1993) Comparison of problem-based and traditional education on student performance in the obstetrics and gynaecology clerkship. Obstetrics \& Gynaecology, 82, 159-61.

Poynter FNL. (1970) Medical education in England since 1600. in O'Malley, CD (Ed). The history of medical education. Los Angeles: University of California Press, 1970.

Reichsman F, Browning FE and Hinshaw JR. (1964) Observations of undergraduate clinical teaching in action. Journal of Medical Education, 1964, 39, 147-163.

Schwartz RW, Donnelly MB, Nash PP and Young B. (1992) Developing students' cognitive skills in a problem-based surgery clerkship. Academic Medicine, 67, 694-6.

SCOPME. (1992) Teaching Hospital Doctors and Dentists to Teach: its role in creating a better learning environment. London: Standing Committee on Postgraduate Medical Education (SCOPME).

Snow RE. (1974) Representative and quasi-representative designs for research. Review of Educationa] Research, 44 (3),265-291.

Stenhouse L. (1975) An introduction to curriculum research and development. London: Heinmann.

Stritter FT, Hain JD and Grimes MD. (1975) Clinical Teaching Re-examined. Journal of Medical Education, 50, 876-882. 
Sylvius F. (1679) Epistola Apologetica. In, Opera medica. Amsterdam: Elsevir and Wolfgang, p907.

Tosteson DC. (1990) New pathways in general medical education. New England Journal of Medicine, 322, 234-8.

Towle A. (1992) Outpatient teaching at St Bartholomew's Hospital Medical College. Mimeo, SBHMC.

University of Toronto. (1982-1986) Curriculum renewal documents. Mimeo, Faculty of Medicine, Deans Office.

Wakeford RE. (1983) Undergraduate students' experience in 'peripheral' and 'teaching' hospitals compared. Annals Royal College of Surgeons of England, 65, 374-7.

Weinholtz D et al. (1986) Effective attending physician teaching. Research in Medical Education. Proc. 24th Annual Conference, Association of American Medical Colleges, (pp151-56), Washington: AAMC.

Wolf FM and Turner EV. (1989) Congruence between student and instructor perceptions of clinical teaching in paediatrics. Medical Education. 23(2):161-7.

Wolfhagen I. (1993) Kwaliteit van klinisch onderwijs (Quality of Clinical Education). Maastricht: University of Limburg. 


\section{Chapter 2}

Learning Practical Skills:

the role of practical experience in

undergraduate and general clinical

training 


\section{LEARNING PRACTICAL SKILLS: \\ THE ROLE OF PRACTICAL EXPERIENCE IN \\ UNDERGRADUATE AND GENERAL CLINICAL TRAINING}

\section{Introduction}

Attention has been drawn to poor co-ordination of training phases and the failure of undergraduate and pre-registration experiences to equip doctors with a range of skills and sensitivities, (Kilpatrick,1983; Crisp,1985).

Restrictions have been imposed on "the nature and range of the clinical experience obtained by young doctors"(Horder 1983), by the "greatly diminished opportunities for students to participate in the care of patients". This, it is said, results in doctors lacking insight, sensitivity and appropriate knowledge of the role and scope of medicine.

Research to date on the house year has been summarised elsewhere (Wakeford, 1984). Surveys of house officers' experience of acute clinical conditions and common practical procedures have shown that some remain outside the scope of doctors' competence even after one year of practice, (Evans and Wakeford, 1983; Elizabeth and Hughes, 1986), and $72 \%$ of senior doctors feel that there is "insufficient training in communication with patients or their relatives", (Wakeford and Allery, 1986). An American study (Duffy, et al., 1980), found several of interns' communication skills deficient, including "obtaining the patient's understanding of his illness" and "explaining". A Norwegian study showed that undergraduates' experience in practical procedures was gained outside teaching sessions without adequate supervision and assessment although experience was less variable after the introduction of a check list (Hunskaar and Seim, 1983; 1984). Studies of cardiopulmonary resuscitation techniques have found serious deficiencies in newly qualified personnel, (Lowenstein, 1981; Skinner et al., 1985).

However, most recent research has investigated experiences of undergraduates or house officers in separate samples. Also, in most studies the importance of practical procedures at undergraduate level has been more or less taken for granted. This study, aimed at improving the articulation between undergraduate and postgraduate phases, examined the retrospective views on their training of one cohort of graduates from two London medical schools. (St Bartholomew's = School A, London School B). 
This paper reports data collected on the development of skills in practical procedures, experience with acute conditions and on the performance of communication skills, and on whether and why all these are felt to be important.

\section{Methods}

In summer 1985 a questionnaire covering content, experiences, career interests, supervision, rotations, satisfaction with teaching, and attitudes towards medicine in general and the job in particular for both undergraduate and house officer phases, was mailed in the last six weeks of the house post, to all 259 doctors who had graduated in 1984 from 2 London medical schools. The questionnaire also contained some open questions concerning undergraduate attachments were useful/not useful, and what changes respondents would make to their undergraduate curricula in the light of their house experience?

In addition twenty four graduates, stratified by sex and first job (medical or surgical) were randomly selected for (untaped) interview. These interviews, although schedule-based, included open questions such as "how have you found your house year?" with appropriate follow-up and clarification of the responses. They were designed to illuminate issues, and provide additional data on some of the categorical responses obtained in questionnaires.

In three questionnaire items subjects were asked to categorise their experience in each of 20 practical procedures , 18 acute conditions, and 9 common communication situations (Tables 1,2 and 3).

Categories were:

Procedures

\section{Conditions}

$0=$ neither seen nor undertaken

$0=$ never seen

$1=$ seen but not undertaken

$2=$ undertaken 1 or 2 times

$3=$ undertaken $3+$ times

$1=$ seen only once or twice

2 = seen more often/helped to manage

$3=$ seen frequently and initiated management

The list of conditions and procedures was chosen partly by reference to previous literature (e.g. Evans \& Wakeford 1983) and partly in consultation with senior teachers who, for example, wished to know how often 
experience was gained in managing conditions which required immediate action even though these might be rare (e.g. glaucoma, hypertensive encephalopathy).

These ratings were obtained for the house officer post and, on the same form, for undergraduate clinical training. For procedures, subjects were also asked to indicate whether, as house officers, they thought they were/were not proficient. In addition they were separately asked to indicate three each of the procedures and conditions in which they thought they "should have been more experienced at the beginning of the house post".

The list of communication tasks, which were similarly rated, is shown in Table 3.

In Tables 1 and 2 categories $0 / 1$ and $2 / 3$ have been combined for ease of comparison. As chi-square tests of differences in experience between undergraduate and pre-registration house officer phases are inappropriate statistically (samples are not independent) a non parametric sign test (Siegel, 1956) was applied to the direction in which each subject's experience moved from undergraduates to house officer phases, and a $t$-test was applied to the mean difference in category score (0-3) also from undergraduates to house officer phases.

\section{Results}

The 102 questionnaire respondents (61 School A, 41 School B ) were representative of the male/female populations and of grade distributions (available in School A only). Issues extracted from content analysis of the interview notes were categorised by the researchers, (Schatzman and Strauss, 1973). Since eleven of the interviewees had not submitted a questionnaire, the final sample size was 113 (43.6\% - 102 questionnaire respondents, plus 11 of 24 interviewees).

Significant differences in experience between phases were found for most practical procedures and all but one acute condition. In all cases both statistical tests used were in agreement.

In tables 1 and 2 procedures and conditions are listed in rank order according to the number of graduates requesting more experience in them at undergraduate level. Evidence from correlating the rank of each procedure or condition with its average rated experience in undergraduate or postgraduate phases or with its rating change from one to the other, 
Table 1. Differences in experience of practical procedures from undergraduate to house officer phases $(102>n>96)$

\begin{tabular}{|c|c|c|c|c|c|c|c|}
\hline \multirow[b]{2}{*}{ Procedure } & \multicolumn{2}{|c|}{$\begin{array}{l}\text { Under- } \\
\text { graduate }\end{array}$} & \multicolumn{2}{|c|}{$\begin{array}{l}\text { House } \\
\text { Officer }\end{array}$} & \multirow{2}{*}{$\begin{array}{l}\text { Difference } \\
\text { Under- } \\
\text { graduate vs } \\
\text { House Officer } \\
\quad \text { P }\end{array}$} & \multirow{2}{*}{$\begin{array}{l}\text { Wanting } \\
\text { more: } \\
\text { experience' } \\
\text { r } \%)\end{array}$} & \multirow{2}{*}{$\begin{array}{l}\text { 'Still } \\
\text { not } \\
\text { Pro- } \\
\text { ficient } \\
(\%)\end{array}$} \\
\hline & $\begin{array}{l}0 / 1 \\
(\%)\end{array}$ & $\begin{array}{l}2 / 3 \\
(\%)\end{array}$ & $\begin{array}{c}0 / 1 \\
(\%)\end{array}$ & $\begin{array}{l}2 / 3 \\
(\%)\end{array}$ & & & \\
\hline Cardiac resuscitation & 51 & 49 & 1 & 99 & $<0.01$ & 48 & 12 \\
\hline Lumbar puncture & 63 & 37 & 11 & 89 & $<0.01$ & 41 & 30 \\
\hline Noasogastric tube & 76 & 24 & 22 & 78 & $<0.01$ & 30 & 38 \\
\hline Endotrachael intubation & 25 & 75 & 38 & 62 & $<0.05$ & 23 & 63 \\
\hline Urine microscopy & 58 & 42 & 73 & 25 & $<0.01$ & 17 & 68 \\
\hline Abdominal paracentesis & 85 & 15 & 23 & 79 & $<0.01$ & 15 & 34 \\
\hline IV drip & 4 & 96 & 0 & 100 & $<0.01$ & 14 & 1 \\
\hline Pleural fluid aspiration & 73 & 27 & 6 & 94 & $<0.01$ & 13 & 16 \\
\hline Bladder catheterization $(F)$ & 35 & 55 & 25 & 75 & $<0.01$ & 12 & 20 \\
\hline Vaginal examination & 4 & 96 & 23 & 77 & $<0.01$ & 11 & 22 \\
\hline Intramuscular injection & 62 & 38 & 20 & 80 & $<0.01$ & 11 & 19 \\
\hline Interpret ECG & 9 & 92 & 0 & 100 & $<0.01$ & $<10$ & 13 \\
\hline Subcutaneous injection & 59 & 41 & 13 & 87 & $<0.01$ & $<10$ & 12 \\
\hline Bone marrow aspiration & 97 & 3 & 90 & 10 & $<0.01$ & $<10$ & 90 \\
\hline Urine biochemistryh & 50 & 50 & 43 & 56 & NS & $<10$ & 36 \\
\hline Liver biopsy & 100 & 0 & 70 & 30 & $<0.01$ & $<10$ & 82 \\
\hline Staining blood film & 57 & 43 & 96 & 4 & $<0.01$ & $<10$ & 85 \\
\hline Episiotomy repair & 3 & 98 & 88 & 2 & $<0.01$ & $<10$ & 19 \\
\hline ESR estimation & 85 & 15 & 93 & 5 & $<0.01$ & $<10$ & 84 \\
\hline Bladder catheterization (M) & 6 & 94 & 0 & 100 & $<0.01$ & $<10$ & 0 \\
\hline
\end{tabular}

suggested that those items ranked highest (e.g. Cardiopulmonary resuscitation, acute asthma) are those in which, on average, experience increases most from undergraduate to house-job. ( $r=0.40$ Procedures n.s.; 0.64 Conditions $\mathrm{p}<0.05$ ).

Significant differences between the sexes and between schools, reported in more detail elsewhere (Jolly and Macdonald, 1986), were found at undergraduate level in the distribution of experience of some skills. Briefly, respondents from School A reported more experience of episiotomy, and intramuscular injections; those from school B more of vaginal examination, lumbar puncture, and abdominal paracentesis; and women more of female catheterisation but less of cardiopulmonary resuscitation, acute congestive heart failure and asthmatic attack.(Chi-squared all p<.05). 
Table 2. Changes in experience of acute conditions from undergraduate to pre-registration house officer $(102>n>96)$

\begin{tabular}{|c|c|c|c|c|c|c|}
\hline \multirow[b]{2}{*}{ Condition } & \multicolumn{2}{|c|}{$\begin{array}{l}\text { Under- } \\
\text { graduate }\end{array}$} & \multicolumn{2}{|c|}{$\begin{array}{l}\text { House } \\
\text { Officer }\end{array}$} & \multirow{2}{*}{$\begin{array}{l}\text { Difference } \\
\text { Under- } \\
\text { graduate } \\
\text { vs } \\
\text { House Office } \\
\mathrm{P}\end{array}$} & \multirow{2}{*}{$\begin{array}{l}\text { 'Wanting } \\
\text { more } \\
\text { experience' } \\
\text { (\%) }\end{array}$} \\
\hline & $\begin{array}{l}0 / 1 \\
(\%)\end{array}$ & $\begin{array}{l}2 / 3 \\
(\%)\end{array}$ & $\begin{array}{l}0 / 1 \\
(\%)\end{array}$ & $\begin{array}{l}2 / 3 \\
(\%)\end{array}$ & & \\
\hline Acute Asthmatic & 55 & 45 & 0 & 100 & $<0.01$ & 34 \\
\hline Diabetic ketosis & 80 & 20 & 17 & 83 & $<0.01$ & 34 \\
\hline Myocardial infarction & 34 & 66 & 0 & 100 & $<0.01$ & 22 \\
\hline Respiratory failure & 77 & 23 & 4 & 96 & $<0.01$ & 19 \\
\hline Acute renal failure & 76 & 24 & 11 & 89 & $<0.01$ & 18 \\
\hline Epileptic fit & 68 & 34 & 6 & 94 & $<0.01$ & 18 \\
\hline Comatose patient & 70 & 30 & 9 & 91 & $<0.01$ & 17 \\
\hline LVF & 49 & 51 & 1 & 99 & $<0.01$ & 16 \\
\hline Pneumothorax & 98 & 2 & 80 & 20 & $<0.01$ & 12 \\
\hline Acute Glaucoma & 98 & 2 & 96 & 4 & NS & 12 \\
\hline Acute GI bleeding & 54 & 46 & 0 & 100 & $<0.01$ & $<10$ \\
\hline Acute CHF & 56 & 44 & 1 & 99 & $<0.01$ & $<10$ \\
\hline Inhaled vomit & 92 & 8 & 41 & 59 & $<0.01$ & $<10$ \\
\hline Acute Hepatic failure & 88 & 12 & 32 & 68 & $<0.01$ & $<10$ \\
\hline Hypertensive encephalopathy & 95 & 5 & 64 & 36 & $<0.01$ & $<10$ \\
\hline DVT & 44 & 56 & 3 & 97 & $<0.01$ & $<10$ \\
\hline Acute Ischaemic limb & 74 & 26 & 16 & 84 & $<0.01$ & $<10$ \\
\hline Mgt hypoglycaemia & 67 & 33 & 5 & 95 & $<0.01$ & $<10$ \\
\hline
\end{tabular}

The number of procedures and conditions which subjects had "never seen" was totalled separately for undergraduates and house officer phases for each graduate. This was done to ascertain whether there were some subjects who, as students/house officers, had been particularly lacking in experience. Figures 1-2 show the frequency distribution of these scores, separately for procedures and conditions. For both, there was a substantial number of respondents who, as students, had no experience of 7 or more items. Although subjects reported never seeing some procedures even as house-officers, these tended to be tasks such as urine biochemistry, episiotomy, staining blood, and ESR estimation, which were either no longer required or devolved to other departments. There was a significant proportion of respondents (38\%) who as students had "not seen" more than one third of the acute conditions on the list.

Undergraduate preparation for difficult communication skills was thought to be poor by most respondents, (Table 3 ). Over $85 \%$ of subjects had 
Table 3. Experience of task-related communication skills and distribution of views on undergraduate preparation

\begin{tabular}{|c|c|c|c|c|c|c|}
\hline & \multicolumn{2}{|c|}{ As House Officer } & \multicolumn{4}{|c|}{$\begin{array}{l}\text { How prepared at } \\
\text { undergraduate level (\%) }\end{array}$} \\
\hline & $\begin{array}{l}\% \text { Not done } \\
\text { done ordone } \\
\text { only once }\end{array}$ & $\begin{array}{l}\% \text { Done } \\
\text { unassisted } \\
>3 \text { times }\end{array}$ & $\begin{array}{l}\text { Not at } \\
\text { all }\end{array}$ & Poorly & $\begin{array}{l}\text { Quite } \\
\text { well }\end{array}$ & $\begin{array}{l}\text { Very } \\
\text { well }\end{array}$ \\
\hline $\begin{array}{l}\text { Inform a patient of } \\
\text { terminal illness }\end{array}$ & 12 & 88 & 24 & 48 & 23 & 4 \\
\hline $\begin{array}{l}\text { Inform a relative of } \\
\text { patient's terminal illness }\end{array}$ & 3 & 97 & 28 & 45 & 22 & 4 \\
\hline $\begin{array}{l}\text { Inform a relative that a } \\
\text { patient has died }\end{array}$ & 14 & 86 & 46 & 31 & 21 & 1 \\
\hline $\begin{array}{l}\text { Counsel a distraught patient } \\
\text { Clerk an attempted (or }\end{array}$ & 16 & 84 & 29 & 50 & 18 & 0 \\
\hline suspected) suicide & 11 & 89 & 16 & 34 & 44 & 6 \\
\hline $\begin{array}{l}\text { Respond to patient's enquiries } \\
\text { about terminal illness }\end{array}$ & 5 & 95 & 17 & 46 & 30 & 5 \\
\hline $\begin{array}{l}\text { Initiate management of } \\
\text { cardiac arrest }\end{array}$ & 39 & 61 & 19 & 43 & 36 & 0 \\
\hline Obtain 'informed consent' & 2 & 97 & 29 & 30 & 34 & 5 \\
\hline $\begin{array}{l}\text { Inform patient of operative } \\
\text { or therapeutic procedures }\end{array}$ & 1 & 99 & 17 & 30 & 44 & 6 \\
\hline
\end{tabular}

undertaken one or more of these tasks unassisted at least three times during their house year, and four interviewees contrasted their anxiety over the difficulty of communicating terminal illness or death to relatives with their sense of satisfaction stemming from helping patients to die with dignity and grace. However the consensus of opinion from questionnaire results and interviews was that neither the undergraduate curricula nor the pre-registration year adequately prepared house officers for these stressful tasks. The importance of practical experience to subjects was revealed in interview(I) and by analysis of other questionnaire items $(Q)$.

The opportunity to learn practical procedures and/or manage acute conditions was cited 84 times (Q) as a defining characteristic of a useful undergraduate attachment. It was also the most frequently cited (Q 58\%) "area for improvement" in the undergraduate curriculum, amongst "poor teaching" $(19 \%)$ and "communication skills" (19\%). Subjects often cited supervision as crucial when learning practical skills (I). The rationale for their importance was that many firms expected proficiency in these duties 


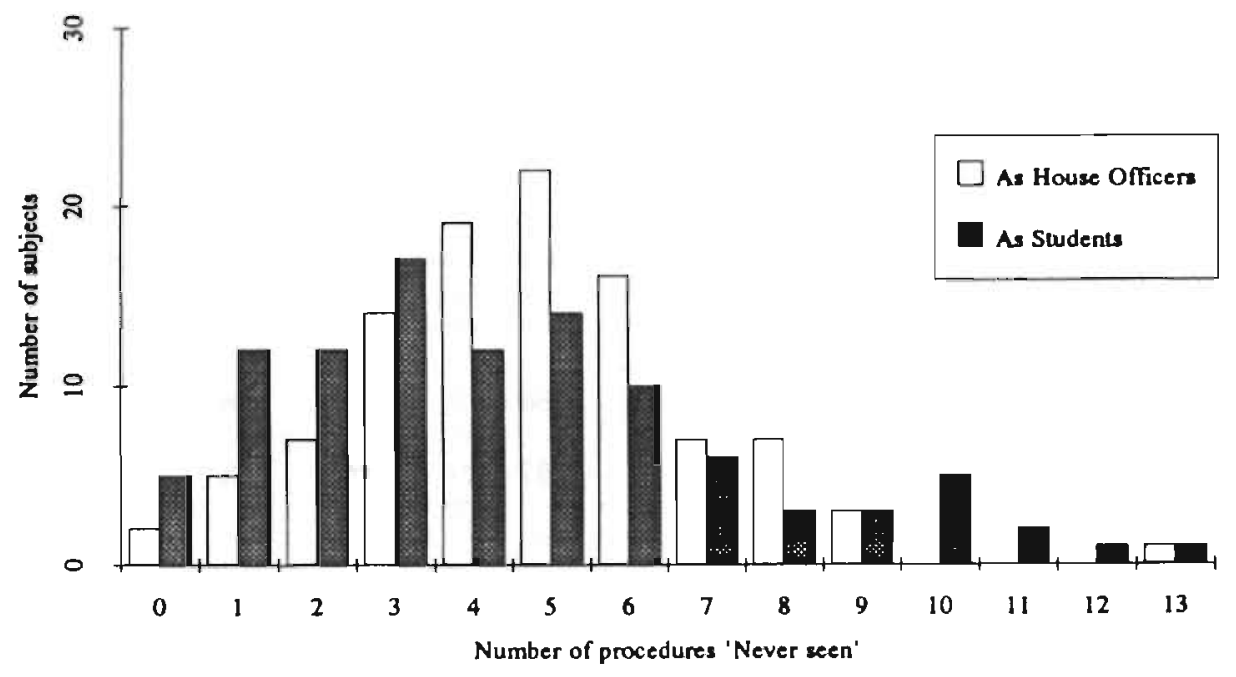

Figure 1. Frequency distribution of number of practical procedures 'never seen'

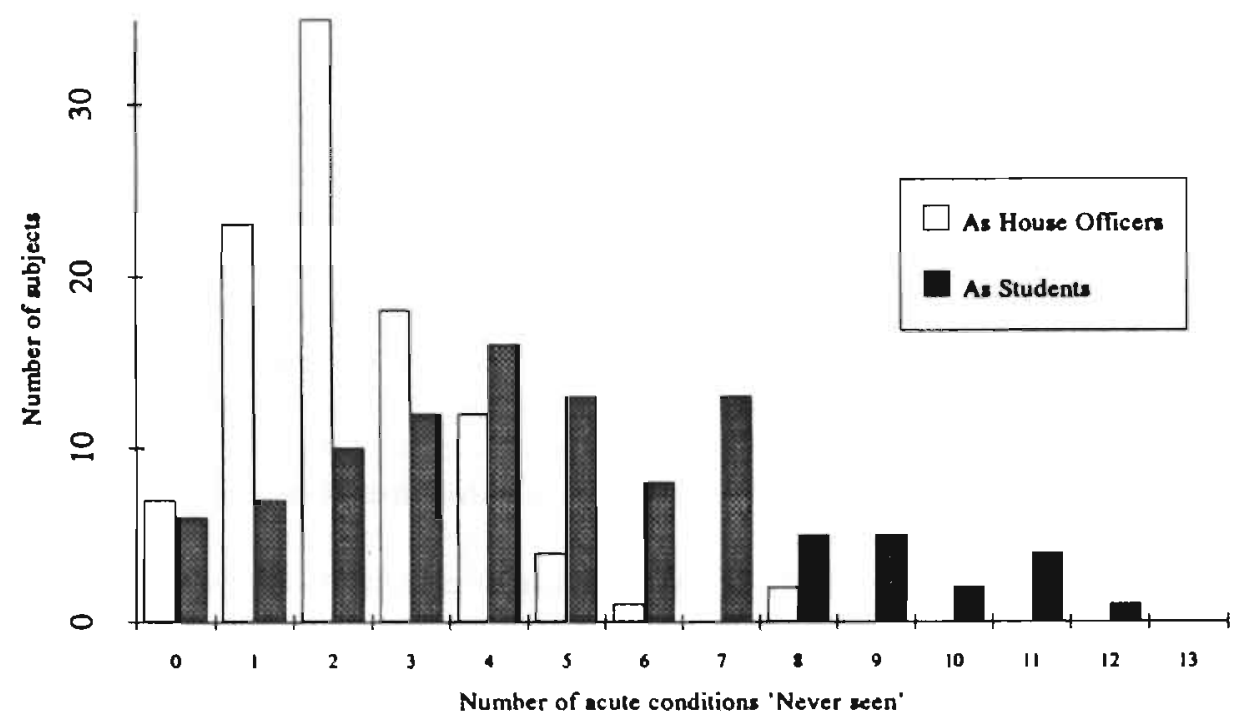

Figure 2. Frequency distribution of number of acute procedures 'never seen' 
or that lack of it caused much time to be wasted. Also, comprehensive experience in them under supervision was seen as having the potential to reduce anxiety and stress, particularly in the first few months in post (I).

Other reasons given (I and Q) for the salience of this type of experience were its role in building confidence in both phases, as a yardstick for self evaluation in the undergraduates phase, to help integrate theoretical knowledge, to reduce the number of "embarrassing" problems passed on to seniors, the need to be proficient in some hospitals where house officers roles encompass more, and its general validity as an early sample of medical life.

\section{Discussion}

Although a reasonable return for a postal study the sample was reduced in School B probably by a delay in mailing which may have meant that some subjects did not receive the questionnaire. However, all post-hoc statistical comparisons made between the sample and the population suggested that the sample was representative. The results from school A closely resembled those from an unpublished pilot study, (which disclosed no significant differences from those data included here) and all data are in line with other recent studies on house officers themselves, (Wakeford and Allery 1986).

Although the study relied largely on self-report data, evidence from interviews, in which remarks could be pursued, corroborated many of the questionnaire statements.

Practical experience is seen by most as an essential prerequisite to the house-job, and as a focus of the educational experience as a whole. There were a number of common procedures at which respondents felt themselves not to be proficient. There were some subjects who as students showed considerable gaps in their practical experience, even for relatively common occurrences.

Although effort has gone into the development of communication skills in both schools there is a need to expand the scope and nature of this training. Currently training is given in interview skills for history taking in several departments including sociology, psychiatry and general practice. However this does not normally include giving bad news or informing of death. Moreover, many consultants maintain that they themselves normally 
carry out such tasks or that it is inappropriate for house-officers to do so alone. Nevertheless, it is plain from our evidence that this burden often falls to underprepared house officerss. This effect is not particular to the two hospitals wherein students qualified, as $50 \%$ of the sample were house officers currently working elsewhere. Although it is difficult to envisage how these complex skills can be tackled at undergraduate level, particularly with reference to protecting the interests of patients, some assistance should be provided, perhaps at the beginning of the 'postgraduate training year'.

Additionally, the attitude that the house-job is where doctors should primarily learn practical skills is questioned by the perspective of graduates who find themselves required to carry out certain procedures or manage some situations alone, often at night. Although it is plain that some issues are adequately dealt with at undergraduate level, the existing confusion must have implications in terms of patient care and working relationships. While the frequency and by implication the range of skills experienced, has been shown naturally to increase, the study demonstrates that there is room for a more structured approach to development of skills in both phases of the clinical course.

One recommendation is that there cannot be too much monitoring of both undergraduates $G$ and house officer phases. Often, for very good reasons such as the fragmentation and curricular problems which can result from both modular courses and increased specialization, schools lack insight into the impact they are having on students, what curricular deficiencies exist and what the "knock-on" effects of these might be. Perhaps the latest General Medical Council guidelines on General Clinical Training, (1987), will have some effect, especially in respect of difficult communication skills. In the meantime both schools are reviewing their curricula in a number of areas. 


\section{References}

Crisp AH. (1985) Initiatives in the pre- registration year (general clinical training) British Medical Journal, 290 , 1764-1765.

Duffy DL, Hammermann D and Cohen, MA. (1980) Communication skills of house officers. Annals Internal Medicine, 93, 354-357.

Elizabeth JE and Hughes S. (1956) An assessment of the pre-registration year experience. British Medical Journal, 293, 1559.

Evans I and Wakeford RE. (1983) House officers' perceptions of their experience and competence. Medical Teacher, 5, 65-69.

General Medical Council. (1987) Draft revised recommendations on general clinical training. London: General Medical Council Education Committee.

Horder J. (1983) An important opportunity: an open letter to the General Medical Council. British Medical Journal, 288, 1507-11.

Hunskaar S and Seim SH. (1983) Assessment of students' experiences in technical procedures in a medical clerkship. Medical Education 17, 300-04.

Hunskaar S and Seim SH. (1984) The effect of a checklist on medical students' exposures to practical skills. Medical Education, 18, 439-442.

Jolly B and Macdonald MM. (1986) Practical experience in the preregistration year in relation to undergraduate preparation. Proceedings of the 25th Annual Conference on Research in Medical Education, New Orleans pp171-176. Washington: Association of American Medical Colleges.

Kilpatrick GS. (1983) Occasional paper, No.2: The pre-registration Year. Dundee: Association for the Study of Medical Education.

Lowenstein SR. (1981) Cardiopulmonary resuscitation by medical and surgical houseofficer Lancet ii, 679-81.

Schatzman L and Strauss A. (1973) Field research strategies for a natural sociology Englewood Cliffs N. J. Prentice Hall.

Siegel S. (1956) Non parametric statistics for the behavioural sciences, New York: McGraw Hill.

Skinner DV, Camm AJ and Miles S. (1985) Cardiopulmonary resuscitation skills of pre registration house officers. British Medical Journal 290 1531-2.

Wakeford RE. (1954) Recent research into the pre registration Year. In: The Pre-registration year. Dundee: Association Association for for the Study of Medical Education.

Wakeford RE and Allery L. (1986) Doctors attitudes medical philosophy and political views, British Medical Journal 292, 1025-27. 


\section{Chapter 3}

More Effective Evaluation of Clinical Teaching \& Learning: The Role of the Clinical Teacher 


\section{MORE EFFECTIVE EVALUATION OF CLINICAL TEACHING \& LEARNING: THE ROLE OF THE CLINICAL TEACHER}

\section{Introduction}

Since the 1960s, theories of educational evaluation have achieved considerable variation and sophistication generating information on issues such as rationales for change; programme effects; accountability; directions for development; feedback on student/teacher performance; client satisfaction and departmental or faculty improvement. In the $1980 \mathrm{~s}$, evaluation instruments have become marketable commodities (e.g. learning environment questionnaires), moreover, evaluation is often the chosen career field for many researchers.

Evaluation methodologies have been influenced by changes evolving within research and, like these, have striven for greater understanding of educational events. Much of this has come about by rejecting some assumptions and by widening the field of inquiry, thus asking more varied questions to illuminate the practices and beliefs of those involved in the educational process, e.g. students, teachers, administrators. Parlett et al. (1969) as ethnological researchers, were instrumental in questioning the previously accepted norms of traditional, quantitative, psychometric approaches concerned with outcomes or results in favour of more emphasis on using techniques such as 'progressive focusing' to investigate the educational process (Parlett \& Hamilton; 1972,1976). They have also highlighted the human social and intellectual 'milieu' of the department as important for our understanding of 'process' and the profound effects the environment has on learning and development. This milieu is a network of

"cultural, social, institutional or psychological variables. These interact in complicated ways to produce a unique pattern of circumstances, pressures, customs, opinions and work styles".

We now seek explanations and explore casual relationships for enlightenment within what is often called 'the illuminative paradigm'. A process approach was also posed by Stenhouse (1975) in reaction to the inadequacies and inappropriateness of behavioral objectives to describe, and subsequently monitor and evaluate, work in the Humanities. 
Although ethnographic approaches have recently been criticised by McIntyre (1983) for their lack of consensus criteria, rules and validity, medical education as part of mainstream education, has been affected by their incorporation into evaluating practices. Benbasset (1986) has set out the merits and demerits of the product/process models of evaluation, claiming that both are necessary for a balanced approach within medical education. Product (outcomes) is usually derived from examination and assessment results. Written information on process evaluation is normally provided by standardised student rating scales, various forms of response sheets, global ratings and questionnaires. Other interpretations and opinions can be drawn from oral debriefings and interviews.

It is within such a context that the work reported in this paper has been carried out. It draws attention to student perceptions of teaching at three different stages of clinical studies, and is also concerned with the implications for teachers in the ways in which they reflect upon their evaluation practices and the efficacy and comprehensiveness of the theories and knowledge which they bring to bear on them. However, it is first necessary to consider the ways in which medical education, particularly in the unique context of the clinical setting, differs frcm higher education in general. These differences may have relevance for the context, process and evaluation methodologies used in medical education. Irby (1978) has said on this subject that:

"The evaluation of teaching effectiveness is complicated by the extensive use of clinical instruction. Standardised classroom rating forms are not applicable to clinical teaching because of the unique aspects of clinical instruction, the use of multiple instructors, and the small number of students involved".

While one might dislike his use of the word 'instructor', bedside teaching and the clinic certainly present problems and are complex, fascinating scenarios for the researcher.

\section{An overview of the clinical context}

The Socratic image of master and pupil is exemplified in medicine by the apprenticeship model in which teaching is carried out by expert demonstration, although regrettably the true dialogue so vital for stimulating learning, is often absent (Atkinson, 1976). Medicine has always recognised the benefits of the small group to convey information and techniques but has ever been mindful of that important third party, the 
patient, in modifying responses and behaviours in the teaching process. The issues of confidentiality, ethical responsibilities, student developmental abilities and sensitivities have marked effects on discussion. Atkinson (1976) and Arluke (1980) found the teacher/pupil interaction in the ward is often noted for its interrogative, closed questioning which limits discussion and is often knowledge based despite ostensibly probing content and technique.

Clinical teaching has its own codes of behaviour and esoteric protocols which can be supportive or otherwise to all participants. The privilege of examining a patient, the need to request permission, make introductions and conduct procedures from the left hand side of the bed, the authority of the teacher, the reactions of the patient and the nature of the presenting illness all affect the learner. In addition, the environment varies from cramped screened cubicles where it is often difficult to see and hear, to spacious more than adequate surroundings. Lowdermilk and Stritter (1984) found that environmental factors such as physical setting, organisational conditions and social climate influence clinical skill profoundly.

Perhaps it is the teacher in authority, unchallenged, in the dominant role conforming to student and patient expectations which epitomises clinical teaching and therefore the 'expert/novice' apprenticeship pattern is perpetuated and sustained. Teaching in medical schools is controlled and monitored by Deans and Committees appointed by universities and colleges. There are no requirements for teaching qualification, accreditation is not an option, and many clinicians teach students while fulfilling their main service requirements to the National Health Service. As such, they fall outside the control of the university. Medical teaching can often display the art and craft of the trade at its brilliant best but falls prey to al the faults shared by teaching and teachers in general.

Finally, assessment in medicine, at least in the UK, is heavily dependent on examination results, particularly MCQs, which are said to cause factual overload, limit learning approaches and stress outcome at the expense of process (Entwistle and Newble, 1986; Bordage, 1987). Criterion referenced assessment has posed problems in the field but is currently being developed, particularly to assess competencies in communication and other skills.(Naerra, 1987) 


\section{Previous research in effective clinical teaching}

A comprehensive critical review of research in this area, of which only key papers are cited here, was carried out by Daggett et al. (1979). Cotsonas and Kaiser(1963) used students' rating scales to identify important components in teacher performance, including technical skills and attitudes towards patients. In a seminal study, Reichsman et al. (1964) found serious deficiencies in ward teaching such as haphazard organisations and mediocre presentation. Interestingly for this paper, the latter study was among the first in medical education to address individual student learning needs, although not in detail. Jacobson (1965) used critical incident techniques to form effective teaching categories in nursing education which included the importance of successful interpersonal relations, skilled teaching methods and evaluation procedures.

Later, Hildebrand et al. (1971) found that ineffective university teachers were described "by a lack of attributes associated with effective teaching rather than by characteristics associated with poor teaching". Successful components of classroom teaching included good organisation and presentation skills; enthusiasm and knowledge base. Irby, (1978) using rating scales, added to these the categories of clinical supervision, clinical competence and the teacher's ability to model professional characteristics, as being important to medical students. Stritter et al. (1975) also using rating scales, determined six dimensions of 'teacher' behaviour: active student participation' preceptor attitude towards teaching; emphasis on problem solving; student centred instructional strategy; humanistic orientation and emphasis on research. Stritter's work was concerned to be more precise in giving teachers' concrete advice since previously identified characteristics were too broad to be of specific individual help. Skeff (1985) using videotape analysis to investigate the process/product model, correlated eight educational criteria such as learning climate, feedback and stimulation of further learning with the out-comes of knowledge, skills and attitudes and found many significant results. Attempting to define and improve the teaching of attending physicians, Mattern, (1983) and Weinholtz et al, (1985) employing ethnographic techniques, pointed to the difficulties inherent in documenting and analysing 'good teaching'. Clinical creditability, attitudes towards patients, initial orientations by physicians, feedback, skilful discussion techniques and visual representations were important to learners. Rosinski and Hill (1986) have addressed the prescient problems of student, as opposed to teacher, perceptions of courses and the excessive attention to effective teacher performance at the expense of illuminating students' activities. 
Table 1. Study 1. 1983 Clinical Review. Frequency of Citations of Firms Rated Most enjoyable' and 'Best Taught' (Number of students rating each, cut off $\mathrm{N}=3$ in at least one column)

\begin{tabular}{lrr}
\hline Firm & Most Enjoyable & Best Taught \\
\hline Surgical Firms & 14 & 18 \\
Firm A & 18 & 8 \\
Firm B & 1 & 11 \\
Firm C & 9 & 6 \\
Firm D & & \\
Medical Firms & 4 & 1 \\
Firm E & 3 & 0 \\
Firm F & 0 & 3 \\
Firm G & 3 & 31 \\
Orthopaedics & 16 & 3 \\
Obstetrics & &
\end{tabular}

\section{Study 1}

A comprehensive questionnaire and interview study was used to review the clinical curriculum in one traditional London medical college in 1983. Rating scales and written and oral responses to open questions were included, but observation was not used. Questions included items on course structure, teaching practical procedures, assessment and facilities. One hundred and six (106 of 137) students returned the questionnaire and, in addition, from an intended random sample of thirty, 13 Male and 13 Female students were interviewed. In the questionnaire, students were asked to cite one 'firm' (student attachment, usually of 8-10 weeks, to a group of hospital doctors) and supply reasons to support their choices, in each of four categories: 'best taught', worst taught', 'most enjoyable', 'least enjoyable'. They were also asked to rate each choice, using a five point Likert-type scale, on up to 24 attributes selected from relevant literature and pilot interviews.

\section{Results}

In Tables 2 and 3 the Likert item responses have been assigned scores of -2 (very low) to +2 (very high) and mean scores and standard deviations are presented. Surgical firms (see Table 1, ranked 1-4 inclusive), clearly 
Table 2. Study 11983 Clinical Review. Characteristics Applied to 'Best' and 'Worst' Taught Firms

A B

Best taught firms

Item

Least well taught firms

Item

M St.d.

1. Level of presentation

2. Number of cancellations

$+1.4 \quad 0.6$

1. Enjoyment

$-1.5 \quad 0.8$

3. Number of absentees

$\begin{array}{ll}-1.4 & 0.7\end{array}$

2. Encouragement in clinical $\quad-1.4 \quad 0.9$

4. Clarity of presentation

$\begin{array}{ll}-1.4 & 0.7\end{array}$

3. Amount of responsibility

$\begin{array}{ll}-1.4 & 0.8\end{array}$

5. Interest of presentation

$+1.3 \quad 0.6$

4. Openness to problems

$\begin{array}{ll}-1.3 & 0.7\end{array}$

6. Enjoyment

$+1.2 \quad 0.7$

5. Scope for interest

$-1.3 \quad 0.9$

7. Coherence in session

$+1.2 \quad 0.7$

$+1.0 \quad 0.7$

6. Emphasis on research

$-1.3 \quad 1.0$

8. Emphasis on research

$-1.0 \quad 0.9$

7. Student workload

$-1.2 \quad 0.9$

Table 3. Characteristics Applied to 'Most' and 'Least' Enjoyable Firms

A

Most enjoyable firm

Item

1. Encouragement in clinical $+1.5 \quad 0.6$

2. Number of cancellations $\quad-1.5 \quad 0.8$

3. Friendly staff

4. Number of absentees

5. Co-operative colleagues

6. Quality of teaching

7. Emphasis on patients

8. Inform staff/student relationship

$+1.3 \quad 0.8$

$+1.2 \quad 0.7$

$+1.10 .8$
B

Least enjoyable firm

Item

M St.d.

1. Amount of responsibility $\quad-1.5 \quad 0.7$

2. Encouragement in clinical $\quad-1.5 \quad 0.8$

3. Openness to problems $\quad-1.4 \quad 0.9$

4. Emphasis on research $\quad-1.4 \quad 0.9$

5. Student workload $\quad-1.3 \quad 0.9$

6. Friendly staff $\quad-1.3 \quad 0.9$

took precedence over medical firms in 'best taught'/most enjoyable' categories. Although good teaching and enjoyment are most often synonymous in firms, it is not always the case and students clearly differentiated between these categories. The main reasons given by students to support 'good' teaching (see Table $4 \mathrm{a}, \mathrm{N}=106$ ) were: structure and good organisation ( $44 \%$ of all respondents); teaching by senior staff (30\%); enthusiastic staff and students $(29 \%)$; practical procedures $(20 \%)$; approachable, friendly staff (15\%). In the ratings scales for 'well taught' firms (see Table $2 \mathrm{a}$ ) respondents highly regarded clear, interesting presentation pitched at the appropriate level of understanding. Enjoyment, coherence 
Table 4. Study 1 1983, Clinical Review. Reasons applied to 'Best' and 'Worst' taught firms

A

Best taught firms

Structure and good organisation

Teaching by Consultants or Sen Reg.

Enthusiastic staff and students

Practical experience and procedures

Approachable friendly staff

Involvement in clinical work

Assessment (regular)

Miscellaneous
B

\% Least well taught firms

Uninterested or disinterested staff

Lack of or poor teaching

Cancellations

33

Lack of structured teaching

Too specialised, advanced or

irrelevant content

Lack of attention to basics

13

Other (miscellaneous)

Table 5. Reasons applied to 'Most' and 'Least' Enjoyable firms

\begin{tabular}{|c|c|c|c|}
\hline \multicolumn{2}{|l|}{ A } & \multicolumn{2}{|l|}{$\mathrm{B}$} \\
\hline Most enjoyable firm & $\%$ & Least enjoyable firm & $\%$ \\
\hline \multirow{8}{*}{$\begin{array}{l}\text { Made to feel welcome by staff } \\
\text { Good teaching } \\
\text { Degree of clinical involvement in } \\
\text { work of firm } \\
\text { Amount of practical experience } \\
\text { gained high } \\
\text { Amount of responsibility given to } \\
\text { students }\end{array}$} & 54 & \multirow{2}{*}{$\begin{array}{l}\text { Unapproachable, unfriendly senior } \\
\text { staff/made to feel unwelcome }\end{array}$} & \\
\hline & 52 & & 37 \\
\hline & & Cancellations of teaching & 35 \\
\hline & 49 & Lack of supervision and teaching by & \\
\hline & & Consultants, Students largely ignored & 23 \\
\hline & 18 & Lack of structure \& curriculum design & 17 \\
\hline & 14 & $\begin{array}{l}\text { Intimidating consultants 'teaching } \\
\text { by humiliation' }\end{array}$ & 12 \\
\hline & & Miscellaneous & 45 \\
\hline
\end{tabular}

between sessions and research emphasis were also appreciated. Cancellations and absenteeism were important issues for this group. It may be the case that the momentum and stimulation which can arise in a small group is highly regarded by students and that the flow in patient care and learning is interrupted by absentees. On the whole, medical students show tolerance towards tutor lateness and some cancellations, recognising that emergencies take precedence.

'Least well taught' firms (see Table 2b) were rated low in enjoyment and were associated with little encouragement in clinical work, little responsibility given to students and the lack of 'openness' in staff. They also contained few opportunities for research and scope for individual inter- 
ests. Similar issues were identified as being characteristic of "least enjoyable' firms with minor variations in rankings (see Tables $2 b, 3 b$ ). Questionnaire (free response) reasons relating to 'least well taught' firms (see Table $4 \mathrm{~b}, \mathrm{~N}=106$ ) were concerned with low staff interest $(42 \%$ ); poor teaching (35\%); cancellations (33\%); lack of structure $(30 \%)$ and too specialised or irrelevant content (18\%). 'Most enjoyable' (Table 5a) firms were reported by students as welcoming, encouraging clinical work, responsibility and practical experience. Discussion on these issues will be taken with the next study.

\section{Study 2}

Initiated to investigate the undergraduate curricula of the above school and another traditional college in London from the perspectives of graduates one year after qualification, this study was also carried out using a comprehensive questionnaire and depth interviews. A total of 259 questionnaires was sent out and 102 were returned. The random interview sample, balanced for sex and first job (Job - on graduation house officers are required to do 6 months medicine followed by 6 months surgery or vice versa) was 24 ( 23 completed). Since 11 of these interviewees did not return a questionnaire, the final sample was 113 , which although low was representative of male and female populations in each college. As well as data on their undergraduate education, information was obtained on experiences, supervision, career interests and job satisfaction. However, we report here on questionnaire responses which retrospectively identified those two undergraduate general firms which were 'most and least useful' for the pre-registration year and why this was the case. Some important interview issues are also included.

\section{Results}

Once again, surgical firms were cited more often than medical firms in graduate choices (see Table 6). The free response questionnaire reasons supplied to support this position are shown in Table 7. In rank order of percentages derived from citation frequency these reasons are Good tutorial teaching and enthusiastic/welcoming staff, $(\mathrm{N}$ citations $=104$, 24.7\%); High patient turnover, high student/patient ratio and experience in clerking, $(\mathrm{N}=102,24.2 \%)$; Practical procedures and acute conditions and clinical skills ( $\mathrm{N}=54,12.8 \%)$; Involvement and being allowed to take responsibility $(\mathrm{N}=52,12.4 \%)$. 
Table 6. Study 2. 1985 Pre-Registration Study. Frequency of Citations of 'Most Useful' General Firms

\begin{tabular}{|c|c|c|c|c|}
\hline \multirow[b]{2}{*}{ Firm } & \multicolumn{2}{|c|}{ Sex } & \multirow[b]{2}{*}{ Total } & \multirow[b]{2}{*}{$\%(\mathrm{~N}=102)$} \\
\hline & M & $\mathrm{F}$ & & \\
\hline General Surgery & 53 & 40 & 93 & 91.2 \\
\hline General Medicine & 43 & 31 & 74 & 72.5 \\
\hline General Elective & 8 & 4 & 12 & 11.8 \\
\hline
\end{tabular}

Table 7. Frequency of Citations of Reasons for 'Most Useful' General Firms

\begin{tabular}{|c|c|c|c|c|}
\hline \multirow[b]{2}{*}{ Reasons } & \multicolumn{2}{|c|}{ Sex } & \multirow[b]{2}{*}{ Total } & \multirow[b]{2}{*}{$\%$ (All citations) } \\
\hline & M & $\mathrm{F}$ & & \\
\hline Quality in Teaching & & & 104 & 24.7 \\
\hline Good teaching in tutorials & 42 & 27 & 69 & \\
\hline Enthusiastic and welcoming staff & 18 & 9 & 27 & \\
\hline Patient Tumover/Mgt Experience & & & 102 & 24.2 \\
\hline High patient turnover & 22 & 11 & 33 & \\
\hline High student patient ratio & 17 & 12 & 29 & \\
\hline Experience in clerking & 11 & 13 & 24 & \\
\hline Practical experience & & & 54 & 12.8 \\
\hline Practical procedures and acute cons. & 18 & 20 & 38 & \\
\hline Clinical skills & 6 & 4 & 10 & \\
\hline Responsibility/Involvement & & & 52 & 12.4 \\
\hline Ability to get involved & 16 & 10 & 26 & \\
\hline Allowed to take responsibility & 5 & 7 & 12 & \\
\hline \multirow[t]{2}{*}{ Common Conditions } & & & 29 & 6.9 \\
\hline & 18 & 11 & 29 & \\
\hline Miscellaneous & 45 & 35 & 80 & \\
\hline
\end{tabular}

On licensure, the young house officer fulfils a highly complex job comprising a rapid acceleration in responsibilities which include patient admission, care and management, all, of course, under supervision. The administration is considerable and the house officer is also exposed to difficult communication tasks such as dealing with terminal illness and 
bereaved relatives. This study found deficits in preparation and teaching in practical procedures, acute conditions and communications skills, (Jolly and Macdonald, 1986; see Chapter 2).

Whereas questionnaire data might have been subject to bias from a voluntary return, the interview study (for methodology see Schatzman and Strauss 1977) was completed randomly with no refusals. It is from the interview analysis that we begin to approach what it is like to acquire professional attitudes and skills from the perspectives of learners.

The 'daily dilemma of asking, or not asking, for help' (Coles \& Mountford, 1983) affects some house officers more than others. Our interviews confirmed the constant rationalising process, part of the decision making, which is a source of tension for some young doctors. Two contrasting views are quoted.

"When I needed supervision I asked for it. It's a matter of judgement (it's) unrealistic (that) someone should hold your hand... the sign comes from you."

"One was discouraged from ringing... to cope on your own (is) a bit hassling at times... yes, I felt a very high level of anxiety."

Feedback is vital to motivation and performance. Several interviewees noted that they were always blamed when things went wrong but seldom praised or encouraged when work went well. In other words, they received negative reinforcement. This point is illustrated by two quotations, the first refers to undergraduate specialisation, the second to the house year.

"I would have found more feedback useful with respect to what I was doing; there was too much emphasis on instruction with obscure clinical problems which become more easily understood when one is actually managing such patients".

"Negative reinforcement... not supervision... bit cruel... (In the) House officer year, you learn by your mistakes... get shouted at... humiliated into not doing it again. people very rarely sit down and explain what you're expected to do."

While there is an acknowledged need for house officers to work under pressure, it was clear in interviews that the lack of positive feedback and supportive relationships were perceived to be stressful. 


\section{Discussion}

\section{Studies 1 and 2}

Since Study 1 asked students to name a specific "well taught" firm, the results may be personality dependent. Also, in study 2, house officers' views on 'useful firms' for their immediate needs, may be problematic since undergraduate preparation must attempt to cover a wide field of knowledge (e.g. paediatrics do not usually figure in early posts). However, the rating scales' issues and results in these studies are substantially similar to the previous parallel research of Stritter and Irby. Results also echo what might be described as the 'Hildebrand Factor'. Both studies accredit high ratings to surgical firms which we feel is attributable to vocational interests and the availability of practical procedures and hands on' experience.

These studies (largely based on questionnaires) tell us what students appreciate and, like all questionnaire studies, are constrained by the predetermined items or questions selected by evaluators. Notwithstanding the fact that we have reported only a fraction of the data, they are limited in their illumination of the teaching process and they do not enlighten the leaning contexts. An example of this is student absence (see Table 2a, 3a). One might hypothesise that fewer students might mean more attention to those present but we need more information for a deeper understanding of the curriculum in action. The quotations from graduates in Study 2 also illustrate the learners' perceptions of feedback and support in the job and the different developmental teaching/learning contexts. They also point to the need for greater pastoral support from some senior colleagues.

One of the main disadvantages of rating scales, however, is that they are usually teacher oriented. That is they define teaching/learning usually in terms of (precise) teacher behaviour and not in terms of learner perceptions, goals, expectations and fulfilments. Stritter et al. (1975) commenting on the significance of his dimension 'Active student participation', drew attention to this point.

"The student respondents may have been reacting to that particular teaching characteristic in calling attention to their feeling that what the student does may be the most important in his learning in contrast to what the teacher does".

Unfortunately, researchers have tended to overlook this factor. 


\section{Study 3}

This two year project (1984-86), was designed to monitor the introduction of tutorials in Problem Based Learning (PBL) into a traditional curriculum and to test, in the short term, some clains for PBL such as increased motivation and self directed learning (for a fuller account, see Thompson, et al.1987).

Four first year clinical firms in two colleges were observed by two researchers using participant observation in ward teaching, clinics, lectures and tutorial. Three firms acted as 'controls' and one firm contained the innovation. All firms were chosen on the basis of known internal 'good teaching' student evaluations. All staff and students were interviewed at least once each. An action research approach was used during the reflections and observations of the tutor who conducted the experimental tutorials. The research focused on learning activities, the learning experience, the tutor's role and the learning environment. The researchers recorded events, incidents, sequences, flow, interaction, group reactions, questioning and responses as recommended by Miles and Huberman (1984). The data reported here were mainly revealed in interviews. We are not concerned here to analyse differences between innovatory and traditional firms, but to illustrate students' responses to clinical work in general. First we digress to include an important conceptual framework.

This project has been partly enriched by the work in student learning research which, in the last decade, has provided us with new ways of analysing, describing and interpreting the learning process and individual differences. Entwistle and Newble, (1986) reviewing the historical background and research in this field, pointed to two distinct branches. American work is rooted in mainstream cognitive psychology whereas European studies have developed from research into the everyday learning environment to describe the learning experience. The literature has suffered from its apparently shifting and confusing terminology but this has recently found acceptable stability. The key concepts of four researchers are summarised and an apology is made for what might appear as gross simplification.

To Pask (1976) we owe the term 'Learning Styles'. Interested in learning strategies and the way students set about tasks involving the assimilation and classification of information, he determined from card sorting experiments, two distinct categories: 'Holists' (those who adopted a global approach or 'comprehension learning'), and 'Serialists' (those who used step by step methods or 'operation learning'). Each of these styles of learning is 
also associated with a specific learning pathology. Marton (1976) from reading experiments, found that students used 'Deep' or 'Surface' Approaches to interpret the content. Those who used the former approach interacted with the material with the intention to understand it whereas a surface approach encouraged reproducing tendencies and subsequent short term content retention. Perry (1970), found nine stages of student intellectual development which can be reduced to three main phases: 'Dualist', 'Relativist' and 'Commitment' during which students passed from seeing things in black and white terms of right and wrong, to adopting personal interpretations and conclusions from evidence. Entwistle et al. (1979) building on these studies and incorporating Australian and other American work, developed a 'Learning Style Inventory' containing four subscales: 'Meaning', 'Reproducing', 'Achieving' and 'Learning Styles: Each of the first three scales is associated with a specific aspect of Motivation: 'intrinsic', 'extrinsic', and 'achievement' respectively. This inventory has been successfully used to predict performance and to detect individual learning difficulties. The PBL project has been enriched by this conceptual framework, especially in understanding student interview comments and attitudes towards learning experiences.

Teaching activities in PBL have been neglected as a research topic where many assumptions require to be challenged. Example of issues which require to be made explicit are the tutor's facilitating role in conducting sessions which depend on sensitivity in listening and the exchange of control between students and teacher during teaching. Weinholtz, (et al. 1986) in his work on clinical teaching in ward, corridor and hallway locations, has said 'That teaching behaviours perceived as effective in one context or location are not necessarily viewed as effective in other contexts or locations'. However, in his findings, listening was negatively and significantly correlated with effective teaching. ('Listening might be viewed as an abdication of [the attendant physicians'] responsibilities.) In our experience, listening to students wrestle with reasoning and problem solving issues without intervention, is an important tutorial skill involving judgement and selection.

We observed exchange of control for example, as students went to chalkboards and visually developed their own ideas; as inter-student arguments proceeded and as students role played patient simulations. These learning experiences are student centred and to paraphrase Stritter's words - what the teacher appears not to do may be more important in terms of learning outcomes in PBL activities. 
Student perceptions of teaching are also dependent on the 'set' they bring towards them from previous learning. This is especially true as students make the transition from traditional, factually oriented, didacted preclinical teaching to the clinical environment, and also applies to their reactions to innovatory teaching. Typical attitudes and the effects of previous experience are reflected below.

Control firm student:

"On the ward, a lot goes in and goes out. I try hard to commit it to memory. I don't write notes... when I'm writing notes I tend not to take it all in.... " (and reflecting on Pre-Clinical)

"I just learnt parrot fashion... (I'd look) at a certain part of a page... I mapped it out... and learnt it like that... I knew exactly where it was..."

PBL firm inter-student discussion:

A: "He (tutor) doesn't teach us, he just talks to us..."

$B$ : "Is it good?"

A: "He doesn't teach us medical facts."

The last quotation discloses that students are led to expect that teaching is primarily a diet of factual information.

Most student PBL Interview responses to open questions about 'good teaching' were automatically made with reference to clinical practical settings. Some comments have 'Cognitive', 'Clinical' and 'Interpersonal' orientations which often overlap and also reflect different approaches and styles of learning.

'Cognitive comments' tended to come from students who liked 'the full story' in learning clinical details. They preferred a framework which contained an organised presentation, usually built around patient management and prognosis, including investigation details such as X/Ray and laboratory results which was rounded off by a summary. Other students, in response to what they appreciated in a teaching session, alluded to the need for teaching to be pitched at their stage of development as is indicated in the following comments.

A: "Doesn't take it for granted you have understood"

B: "If the teacher can relate to your lack of knowledge.... no humiliation... (being) able to ask questions without being jumped on..." 
Some of the responses were also related to the ways in which these students learned clinical medicine.

\section{For example:}

"Somehow to me... makes things simple... doesn't go into the last detail.... you can get that from books... I'm not going to remember that five minutes later".

Or,

"I like it if they explain the pathology... (he) explains how to think it out... the way he (teacher) has learnt things, in long lists.... absolutely incredible! I can't think like that... Can you tell me the five causes of this... and I get it wrong..."

At the beginning of clinical teaching, many students are clearly impressed by $\mathrm{Dr}$ /patient relationships and their criteria for effective teaching are based on tutors' professional behaviour and inter-personal communication skills. Others respond to good personal relationships between themselves and the tutor. This is highlighted in one student's words:

"His attitude towards me... his enthusiasm... (the way) he or she comes across... has a good rapport basically... and all sorts of personalities can develop this... (his) attitude to patients... he's accepting of having a student"

Students found these tutorials very enjoyable and many said they helped logical thinking. They were highly critical of and often frustrated by lack of tutor feedback, which again emphasises this aspect not only from the student point of view, but in the need for mutual feedback in which there is reciprocity between teacher and student as learners. In our case, these tutorials acted as a vehicle to explore the deeper aspects of the learning process. It is within the responses to questions about the tutorials as part of small group settings, that students were more inclined to talk about their personal learning experiences and study weaknesses. Examples of issues raised were: the effort involved in making contributions to discussions, fear of being wrong, tolerance of uncertainty, shyness or personal knowledge gaps.

\section{Conclusion}

Our evaluations of effective teaching and the learning/teaching process have led us to a greater understanding of the range and complexity of 
issues involved. In particular, it is obvious that although the complexity of clinical teaching makes study and analysis imperative, it is impractical to ask independent evaluators to monitor the whole clinical process. Evaluation and improvement must be based on self evaluation by the clinical teacher. However, to do this without some basic grounding in the educational developments of the last fifteen years would be difficult. Therefore staff development programmes should include, as well as prescriptions for 'teaching improvement', some emphasis on learning styles and approaches, research methodology and educational counselling.

We wish to emphasise some key features which are important for self evaluation and which deserve greater attention in future research on this topic. Initial orientations to learning, whether to courses as a whole or individual teaching sessions, clearly affect student expectations and the ways in which they organise and assimilate their student expectations and the ways in which they organise and assimilate their experiences. According to Rotem and Ewan (1985) teaching has to be 'managed' for the three successful phases of learning, 'activation', 'acquisition', 'incorporation', to take place. Activation enlists the learner's readiness and preparedness to learn and orientation is crucial to this phase.

Evaluations should take more account of the learning context and the environment. This means probing much more deeply into the ways in which individuals perceive their learning experiences at various stages of their development. A knowledge of the conceptual frameworks in student learning should enable teachers to be more student centred and to focus more expertly on individual approaches and differences in learning.

It is also clear at least in the two schools studied, that some of the learning habits and skills acquired in the pre-clinical phase are inappropriate for the kind of inquisitive, critical and observant individual with whom clinicians expect to work. The expectation of many of these students is that the content to be learned needs to be laid bare for easy absorption. Clinical teachers need to be equipped with measures to counter this approach. Whether this extends to the wholesale adoption of problem based methods in pre-clinical courses is a moot point. Nevertheless, it may be useful to make teachers and institutions more accountable for their practices.

Accountability in teaching practices is a relatively new concept which is only now finding its way into medical education parlance. It is certainly desirable but only when accompanied by a structured programme for staff development and appraisal. There is also a need within medical education 
for a policy which rewards success in teaching to place the latter on an equal footing with research. Only in a commitment to this ideal will a clear career and promotion structure emerge for academic clinicians which will raise expectations and standards within the profession. 


\section{References}

Arluke A. (1980) Roundsmanship: Inherent Control on a Medical Teaching Ward. Social Science and Medicine, 14A, 297-302.

Atkinson PA. (1976) The Clinical Experience: An Ethnography of Medical Education. unpublished PhD Thesis (Edinburgh University).

Benbasset J. (1986) Practical Issues in the Evaluation of Medical Education, in Page G (Ed) Essays on Curriculum Development and evaluation in Medicine. Report of the Second Cambridge Conference. Vancouver: University of British Columbia.

Bordage G. (1987) The Curriculum: Overloaded and Too General? Medical Education, $21,183-188$.

Coles C and Mountford B. (1983) Views of the Pre-registration year: A small sciale study of Southampton Graduates in the Wessex Region. Dundee: ASME Report, The Pre-registration Year.

Cotsonas NJ and Kaiser HF. (1963) Student Evaluation of Clinical Teaching. Journal of Medical Education 38, 742-745.

Dagget CJ, Cassie JM and Collins GF. (1979) Research on Clinical Teaching. Review of Educational Research, Vol. 49, No 1, 151-169.

Entwistle NJ, Hanley M and Hounsell DJ. (1979) Identifying Distinctive Approaches to Studying. Higher Education, 8, 365-380.

Entwistle N and Newble D. (1986) Learning Styles and Approaches: Implications for Medical Education. Medical Education 20, 162-175.

Hildebrand M, Wilson RC and Dienst ER. (1971) Evaluating University Teaching. Unpublished monograph, Berkeley Ca: Berkeley Center for Research and Development in Higher Education, University of California.

Irby DM. (1978) Clinical Teacher Effectiveness. Journal of Medical Education, 53, 808-815.

Jacobson MJD. (1965) Effective and Ineffective Behaviour of Teachers of Nursing as Determined by their Students. Unpublished Doctorial Dissertation, George: Peabody College for Teachers.

Jolly BC and Macdonald MM. (1986) Practical Experience in the Pre-Registration Year in Relation to Undergraduate Preparation. Research in Medical Education. Proceedings of the Twenty-Fifth Annual Conference, Washington: Association of American Medical Colleges.

Lowdermilk DL and Stritter FT. (1984) Environmental Factors Influencing Clinical Learning of Residents in an Ambulatory Care Setting. Proceedings of the Twenty-fifth Annual Conference Research in Medical Education, Washington: Association of American Medical Colleges.

Marton F and Saljo R. (1976) On Qualitative Differences in Learning 1 - Outcome and Process. British Journal of Educational Psychology, 46, 4-11.

Mattern WD, Weinholtz D and Friedman CP. (1983) "The Attending Physician as Teacher", New England Journal of Medicine, 308, 1129-1132.

McIntyre D. (1983) Curriculum Evaluation and Action Research. A paper for the St Margaret's Project University of Stirling.

Miles MB and Huberman AM. (1984) Qualitative Data Analysis: A sourcebook of New Methods. Beverly Hills: Sage Publications.

Naeraa N. (1987) On Making Laboratory Report Work More Meaningful Through Criterion-based Evaluation. Medical Education 21, 199-206.

Parlett M, Synder BR and Kahne MJ. (1969) Undergraduate Teaching Observed, Nature 223, 1102-1104. 
Parlett M and Hamilton D. (1972) Evaluation as Illumination: A new approach to the study of innovatory programs. Occasional Paper No 9, Centre for Research in the Educational Sciences. Edinburgh: University of Edinburgh.

Parlett M and Hamilton D. (1976) The Open University Educational Studies: A Second Level Course-Curriculum Design and Development, Units 19, 20 and 21 p.73.

Pask G. (1976) Styles and Strategies of Learning. British Journal of Educational Psychology 46, 128-148.

Perry WG. (1970) Forms of Intellectual and Ethical Development in the College Years: a Scheme. New York: Holt Rinehart and Winston.

Reichsman MD, Browning FE and Hinshaw JR. (1964) Undergraduate Clinical Teaching. Journal of Medical Education 39, 147-163.

Rosinski EF and Hill P McN. (1986) Student Expectations and Personal Perceptions as an Approach to a Course Evaluation, Medical Education, 20, 228-233.

Rotem A and Ewan C. (1985) A Framework for the Analysis of Effective Teaching. School of Medical Education Newsletter, University of NSW, Australia.

Schatzman L and Strauss A. (1977) Field Research: Strategies for a Natural Sociology, Englewood Cliffs, N.J. Prentice Hall.

Skeff KM, Campbell M and Stratos G. (1985) Process and Product in Clinical Teaching: A correlational Study. Proceedings of the Twenty-fourth Annual Conference on Research in Medical Education, Association of American Medical Colleges.

Stenhouse L. (1975) An introduction to Curriculum Research and Development. Heinemann, London.

Stritter FT, Hain JD and Grimes MD. (1975) Clinical Teaching Re-examined. Journal of Medical Education, 50, 876-882.

Thompson DG, Jolly BC, Macdonald MM, Cookson J, Holman J and Keech T. (1987) Students' Approaches and Attitudes to Solving Computer Presented Problems: an Innovation in a Medical Curriculum. Journal of Computer Assisted Learning 3, 240-250.

Weinholtz D, Albanese M, Zeitler R, Everett G and Shymansky J. (1986) Effective Attending Physician Teaching. Proceedings of the Twenty-fifth Annual Conference Research in Medical Education, Washington: Association of American Medical Colleges. 
Chapter 4

More Effective Evaluation of Clinical Teaching and Learning:

Independent Learning - an exploration of Student Grand Rounds 


\section{MORE EFFECTIVE EVALUATION OF CLINICAL TEACHING AND LEARNING: \\ INDEPENDENT LEARNING - AN EXPLORATION OF STUDENT GRAND ROUNDS}

\section{Introduction}

The University of Toronto is a traditional school with a high lecture load, at which curriculum renewal documents had drawn attention to "too much passive learning' and a 'lack of... meaningful clinical exposure'. (University of Toronto), 1982-1986 As a response, in the academic year 87-88, a programme of Grand Rounds (GR's) for students was instituted separately at each of two teaching hospitals (Toronto Western, $\{\mathrm{TWH}\}$; and Toronto General, $\{\mathrm{TGH}\}$ ).

\section{Background}

There are no published studies on GR's for students. As distinct from the 'ward round', (see for example Mattern, et al., 1983; Bennard \& Stritter, 1989) very little research exists on the educational structure and benefits of the hospital Grand Round. At a traditional school, (St Bartholomew's, UK), where student GR's, albeit of a different format, were tried, they fell into disuse after 2 years - student attendance dropped and staff felt the time devoted to GRs was not warranted by the outcome. In these GRs clinicians would often use the time for discussion between themselves, and little attention was paid to student presentation skills. Students in the institution generally adopted a passive attitude to learning (Jolly and Rees, 1983).

Fleming (1986) has shown how students, asked to present cases individually on ward rounds, develop poor educational practices. He ascribed this to the professional demands of the clinical situation, in which both staff and students accept an 'interrogatory' style of teaching as 'the only way to learn' (p11-12).

\section{The Format of Toronto GRs}

GRs involved collaboration between members of a group of six students who, over a 2- 3 week period, researched, discussed, and prepared a presentation of one or more patients' case histories for a 25-40 minute 'Grand Round' delivered to their classmates on one afternoon about every two weeks. The context for the GR varied slightly between the two hospi- 
tals - at TWH there was an existing tutorial system underpinning round preparation, whereas at TGH students were assigned special round mentors or supervisors. At TWH (42 students) two GRs per student group were scheduled but only one per group at TGH (60 students). On average 5-6 staff attended each round: the presenting group's tutor and several colleagues. Coffee and doughnuts were served to all participants.

There was no formal assessment linked to the GRs. Their aims were to:

1) activate student skills in independent literature research and interpretation relevant to the presentation of clinical cases.

2) promote interaction between students and other clinical and laboratory specialists.

\section{Purpose of the Study}

Within a few months of initiation Toronto GR's became informally highly regarded by both staff and students. It was therefore decided to carry out a study:

1) To evaluate the programme in terms of its aims.

2) To isolate important features of GRs which may be useful to other schools wishing to implement similar programmes.

Evidence that the aims had been accomplished could not be gathered merely from observing the presentation of the GRs.

Thus a major focus became the student and staff interaction preceding and following the round. The main research issues were;

1) What are the attitudes of staff and students towards the round?

2) What criteria do staff use to judge the outcomes and are these consistent with aims.

3) Towards what perceived goals was student activity directed?

4) What was the extent of 'independent' student preparation, (how much did staff, especially the tutor and laboratory personnel, contribute to this process?)

\section{Methodology}

A variety of research techniques was employed in the study, carried out using primarily an ethnographic approach. Qualitative methodology was 
used even though the main research questions had been previously defined because of the range and complexity of the situations under study. All data were collected over a 4 month period from January - April 1988.

A questionnaire consisting of 13, 4-point items (Table 2) on round presentation, and 8 free response questions about round attendance or preparation was distributed to the entire class $(\mathrm{N}=102)$ of Year III (first year clinical) students at both hospitals.

In addition the first author observed student preparation sessions for 5 groups, 2 at TGH and 3 at TWH. For 2 of the TWH groups all preparation sessions were observed over a total of $30 \mathrm{hrs}$. In addition 12 round presentations were observed, 3 at TGH and 9 at TWH. The second author was also the primary chairman of the GRs at TWH.

A total of 25 people ( 17 students (15TWH, 2 TGH), 7 staff involved in tutoring groups and one co-ordinator of medical education) were interviewed (by BJ) for between $3 / 4$ and 1.5 hours each about their participation in GRs.

Interviews were open ended for students, usually beginning with the question -'So what did you think of the GR's' or 'Tell me about the GR's'. For staff, questions focused more on workload, amount of academic input, criteria for a 'good' round and perceived personal benefit to themselves and to the students.

Extensive notes were taken during interviews and observations, which were rewritten with additional material recalled from memory between 1 and 2 hours after the event. Following general ethnographic methodology, (Schatzman and Strauss, 1973; McCall 1969) all notes were coded to indicate the main topic or idea expressed and sorted for topics or concepts. A process of cross checking these topics with the main aims of the study resulted in the elucidation of several major issues.

\section{Results}

Response rates for the questionnaires are shown in Table 1. The total sample size for interviews and questionnaires, (not including observation) was 78. Response from TWH, where the main research effort was directed, and where the authors were known to participants, was higher. However, throughout the sample, no subject selected for interview refused, and no 
Table 1. Response rates to Questionnaire and indices of participation in GRs by hospital.

\begin{tabular}{lllll}
\hline & & $\begin{array}{l}\text { TGH } \\
(\mathrm{n}=60)\end{array}$ & $\begin{array}{l}\text { TWH } \\
(\mathrm{n}=42)\end{array}$ & $\begin{array}{l}\text { Both } \\
(\mathrm{n}=102)\end{array}$ \\
\hline 1. & Number returning questionnaire & 25 & 33 & 58 \\
& $(\%)$ & $(42)$ & $(78)$ & $(57)$ \\
2. $\quad$ Mean \% of GRs attended per student & 69 & 73 & 71 \\
& (SD) & $(28.6)$ & $(25.0)$ & $(20.01)$ \\
3. $\quad$ Mean number of GRs presented & 1.0 & 1.5 & 1.24 \\
$4 . \quad$ *Mean time spend on preparation (hours) & 8.0 & 11.6 & 10.1 \\
& (SD) & $(4.2)$ & $(7.8)$ & $(6.7)$ \\
\hline
\end{tabular}

*Self-reported.

request for observation was denied. Below in quotations $\mathrm{T}=$ tutor; $\mathrm{S}=$ student; I=interviewer. Within a quote... represents words omitted within a sentence;... words omitted across two or more sentences and [ ] words included to clarify meanings or protect subjects' anonymity.

\section{Student Attitudes}

Ratings of GRs presentations were very positive (Table 2). Most students rated them audible and legible, and reported that they were frequently able to ask questions. Students found that the presentations were usually pitched at the right level and evidenced considerable amounts of research. The least positive ratings occurred for 1) the usefulness of the subject matter for exams, 2) the appropriateness of clinicians comments and 3) the interest of the presentation.

Self-reported attendance at GRs was about 70\% in both hospitals which was congruent with staff perceptions (Table 2). Mean preparation time for each round was $10 \mathrm{hrs}$. Students at TWH were more likely to report that they could 'see and hear everything presented', more likely to infer that the 'presenters had done considerable amounts of research'(Table 2) and reported spending about $50 \%$ more time on round preparation (Table 1) than those at TGH. This was unrelated to the fact that TWH and TGH differed in the average number of GRs each group was required to present (Table 1). There were no differences on any questionnaire items between students who had presented 1 or 2 GRs.

The main perceived purposes of GRs were:

1) Learning and presenting in detail a well researched clinical content area 
Table 2. Ratings of grand round presentations. ( $n=58$ ) (Figures are percentages) (*indicates significant difference between hospitals (Kendall Tau)).

\begin{tabular}{|c|c|c|c|c|}
\hline Item & $\begin{array}{l}\text { Very } \\
\text { Often }\end{array}$ & $\begin{array}{l}\text { Quite } \\
\text { Often }\end{array}$ & $\begin{array}{l}\text { Some- } \\
\text { times }\end{array}$ & Never \\
\hline $\begin{array}{l}\text { The subject matter of rounds was interesting } \\
\text { The subject matter of rounds was clinically }\end{array}$ & 31 & 55 & 14 & 0 \\
\hline useful & 22 & 52 & 26 & 0 \\
\hline The presentation of the rounds was interesting & 17 & 62 & 21 & 0 \\
\hline The presentation was pitched at the right level & 41 & 48 & 11 & 0 \\
\hline $\begin{array}{l}\text { The subject matter of rounds was useful for } \\
\text { examinations }\end{array}$ & 3 & 36 & 59 & 2 \\
\hline $\begin{array}{l}\text { Clincians' comments during rounds were } \\
\text { appropriate }\end{array}$ & 18 & 48 & 34 & 0 \\
\hline $\begin{array}{l}\text { Aspects of the case in which I was interested } \\
\text { were discussed }\end{array}$ & 16 & 67 & 17 & 0 \\
\hline $\begin{array}{l}\text { Information presented was related sufficiently } \\
\text { to the clinical/cases. }\end{array}$ & 26 & 64 & 10 & 0 \\
\hline I could hear and see everything presented* & 57 & 29 & 14 & 0 \\
\hline I was able to ask questions when I wanted to & 50 & 38 & 10 & 2 \\
\hline I was able to ask questions at an appropriate level & 27 & 55 & 18 & 0 \\
\hline $\begin{array}{l}\text { The presenters had done considerable amounts } \\
\text { of research* }\end{array}$ & 44 & 49 & 7 & 0 \\
\hline
\end{tabular}

2) To experience preparing a round in terms of literature search, distillation and compilation.

3) Learning how to present the round.

4) Working with colleagues on these activities.

Two typical responses were:

'Being organised, learning what is important to present and what isn't, public speaking opportunity, interaction with clinician, understanding the topic presented' TGH.

'....you became a mini-expert in the area.... the idea of working together as a group.'TWH.

Although 26 (45\% of questionnaires) reported no drawbacks to the process of doing GRs, perceived difficulties were; lack of time, interference with exams, the organisational difficulties of marshalling seven busy people to meet for preparation and the division of labour towards presentations. 


\section{Staff Attitudes}

Most staff found participation in the programme rewarding. They regarded the students as developing rapidly during these activities in terms of confidence, presentation skill, knowledge acquisition, and organisational ability.

Staff members had different views about the purpose and role of GRs. One tutor described GRs as:

'a forum for some independent learning... [aimed at] enhancing student skills in presenting to their peers and to staff'

Others saw GRs as an important intellectual and academic challenge, or as a means of increased interaction with other clinicians. Another view was that they provided a formalised socialisation vehicle for acceptance into the hospital milieu -the learning activities involved (reading journals, discussion) had high fidelity to those required in career development.

One staff member perceived the academic benefit to be outweighed by the effort expended on GRs.

Staff regarded GRs as taking a considerable investment of their time which, in two cases, led to withdrawal from the programme. In at least two (of 17 groups) there were group-dynamic problems perceived by staff as moderately detrimental to outcome.

The tutor who remained unconvinced of the 'cost benefit' of GRs also experienced problems with motivation in the group which, she said, consequently had to be more closely structured, subduing initiative.

There was some general disappointment, in contrast to one innovative round at TWH (see p. 85), that students tended to present GRs in a traditional and academic fashion. Staff also voiced disappointment about the tendency on occasion of a few staff members to monopolise discussion, to reiterate their favourite academic or clinical hobby horse', or to become too 'confrontational'. This was also mentioned by 4 students, who would have preferred staff to 'take more risks' outside their own academic areas when suggesting topics for GRs.

Most staff were satisfied with the role played by GR's in the hospital academic life. One summarised the criteria of success as: 
' The students all took part as presenters... the content was well researched, up-to-date and useful... their presenting skills were good... they used slides or whatever media was (sic) available... and there was an adequate amount of audience participation and discussion.' TWH

\section{Student Preparation}

A typical use of the $10 \mathrm{hrs}$ or so of time spent on preparation was about 1 hour talking to others (orientation), 5-6hrs in the library (individual and group work), $2 \mathrm{hrs}$ of organisation and slide preparation, and then 2 -4hrs rehearsal, either alone or with the group. However, variability existed in perceived goals of the GRs, how these were tackled by various groups and, between the two hospitals, in the extent of collaboration on preparation and presentation.

The presentation itself always appropriated some importance as it became an operational index of the group's activity, but differences in emphasis were discernible which depended on the perceived purpose of GRs. For example, in groups which valued erudite research (TGH) the rehearsalphase discussion and negotiation was subdued compared to those where the presentation was viewed as of paramount importance (TWH).

\section{The Purpose of Rounds.}

GRs were designed as a means of discussing clinical cases and their ramifications. However the students felt themselves professionally inadequate to conduct these discussions fully. Therefore the GR presentation often became the focus of their efforts. One group, for example, took this to the point of constructing (impressively) a clinical scenario with which the audience had to interact - a sort of medical soap opera with interposed questions. Others saw the round as a precursor of their future activities as house officers on ward rounds, or as an opportunity to mimic what senior clinicians do at their 'Grand Round'. Each approach conditioned preparation and presentation in a different way. For example the 'erudite research' approach led on several occasions to vast amounts of technical clinical data being presented on crowded OHP's (e.g. 147 words in 18 mostly unreadable lines). In two groups, students presented obviously under-rehearsed and under-discussed duplicate information, often unable to adjust their talk as this became apparent.

Initial Preparation: Orientation.

Students preferred to chose or negotiate cases rather than have them imposed by tutors/supervisors. This was so even for the initial GRs when, in order to get things running, staff had often preselected a case. In one 
group, collective ownership of the presentation, an important feature, was effectively delayed by the imposition of a case by the tutor and a student who had seen the patient.

Students preferred to have tutors who acted as a sounding board for ideas and assisted in or catalysed subsequent follow-up.

'Without the tutor medical students tend to be all chiefs and no indians, they have difficulty in getting organised... each person is a good organiser in their own right - they like to be Number One 'TWH

Library work almost always followed the selection of a case, with some prior group definition of task for each student. Several students said that library research was often confusing, especially when;

'trying to understand and synthesise information from various and sometimes conflicting medical papers' TWH

There was little evidence of this confusion being tackled in the group sessions, which were more likely to be deployed on organisational and presentational issues and on rehearsals.

\section{The Role of the Tutor}

At TGH there was no existing tutoring system when GR's were started, nor was one foreseen. Conversely at TWH a tutor system was instituted at the same time as GR's, although some students' round tutors were different from their personal clinical supervisors. For TWH students therefore, GRs provided additional interaction (up to $4-5 \mathrm{hrs}$ per week), as both clinical and rounds' tutors often attended round presentations. GRs also provided a focus for those tutors unsure about their function, while for those with a well developed map of their 'duties' it merely provided an added stimulus.

Two comments relating to tutoring and independence occurred repeatedly. First, students saw tutors' disagreements at round presentations over clinical or ethical matters as both stimulating and essential, often legitimising their own concerns.

Asked about this one student replied:

$S:$ 'It's excellent!'

I: 'Why?'

S: 'It has to do with black and white and grey. In basic sciences everything is black and white... because [students] don't understand anything yet. 
In GR's you learn that they are all grey areas. Medical students don't tend to get taught that way....Getting into the GR, nothing is right or wrong just different opinions. It actually matures students too...'

\section{I: 'Why 'matures'?'}

$S:$ 'Students become a little bit more reserved about saying things. They don't get angry when a clinician contradicts something they've read.' TWH

Second, students preferred to have more leeway to 'screw up', for example in terms of the analysis and presentation of information.

'The first time we did it everything wanted to be perfect. He [tutor] looked at everybody's slides... and wanted things memorised. It was very rigid and for this sort of programme rigidity is not a very useful characteristic to learn. They should listen to your ideas... let you think it through and act as a sounding board... They [tutors] can suggest, discuss and set up meetings, but as long as the purpose is to facilitate then if we're going to screw up then let us screw up - parodying [them] is not instructional.'TWH

Tutors needed the resilience to allow students to make their own mistakes and sometimes to insist that work was done, for example when students complained that there was not enough time to do everything or when, in a rehearsal, a tutor warned a student of possible questions, but refused to accept responsibility for giving the answers at the Round.

However, in general, most students reported, and observation confirmed, that after presentation tutors were often too ready to field questions addressed to students. Sometimes this was due to the student's insecurity with the subject matter. At a rehearsal a student who regarded herself as inadequately prepared for a discussion of sideroblastic anaemia and with little time to improve, mentioned this. The tutor replied:

T: 'That's life - you're going to get this 1000 times; you're going to be asked to present the next day and not know anything about the case and have to go home and read up.'

S: I'm going to say what I know about sideroblastic anaemia. The part that makes me nervous is when I get questioned about it.'

$T$ : 'I will field all the questions'

$S:$ 'as long as I don't have to get up there and say things...'

T: 'I will field everything for you' 
Although this effectively restricted the student's task for her, it also limited the group's potential for obtaining feedback on the content of their presentation.

\section{Rehearsal}

Rehearsal formed a major part of preparation, especially (e.g. at TWH) where presentation was highly regarded. Most of this was used profitably in actual rehearsal of discourse and in the correction of two common flaws in presentation - the mismatch of speech and visual aids and the presentation of too much detail. In turn this led to highly professional presentations. When lack of rehearsal time prevented viewing students' slides or overheads this resulted in poor co-ordination and presentation and to factual overcrowding. It also reduced the chance that students would be forewarned about possible questions and how they might be answered, and led to the type of avoidance mentioned above where the tutor deflected questions.

One of the most noticeable features of rehearsals was the opportunity they gave students to express disagreement with the tutor. This most often took the form of controversy over the interpretation of clinical information or a diagnostic image (photograph/radiograph) etc. The expression of dissent was dependent upon a supportive group, a friendly and tolerant atmosphere and a student sufficiently confident to express an opinion.

\section{Individual and Group work}

\section{Networking}

One of the GRs' aims was to get students to interact with hospital specialists (e.g. pathologists), as clinicians might do when incorporating such expertise in a round. Only exceptionally did this take place. Evidence suggested this happened usually under three conditions.

1) where students where determined enough to track down the appropriate person. This was rare ( 2 cases), but the students involved benefitted greatly by an increased awareness of the accessibility of the expertise and a realisation that perseverance paid off.

2 ) where the person sought was associated with the admission of the patient, or their treatment.

3) where the meeting was set up by the tutor.

Although the value of the resource person was recognised this in itself did not mean that contact was inevitable: 
'the only people I attempted to get in touch with-unsuccessfully-were a Neurosurgeon and an Ophthalmologist;... but I never actually got to speak to them. Its hard to find them - its easier if its your clinician.... But Id never met [name].... and she didn't know me... and I didn't have a clue about how you make an appointment with a resident, - so its not something I would spend a lot of time doing. But you can get information [this way] faster, even faster than the journals... its not even in the textbooks.' TWH

\section{Independent Learning}

Several interviewees, in particular two mature students, mentioned the apparent difference between the educational philosophy of the GR's and that of the rest of the medical school. Most students, especially the three mature students interviewed, relished the freedom and creativity that the rounds offered them, within a circumscribed task - the fairly fixed parameters of the rounds required information to be marshalled and presented in well defined ways.

During round preparation it became obvious that some students were operating at a more independent or self sufficient level. For example when reviewing data on the use of Prednisone in the treatment of autoimmune disorders one student said to the tutor;

'I'll try to enumerate the clinically relevant points; I'll get you [the tutor] to take a look at that and see if there's anything you think should be added...'TWH

Other students needed more prompting, but were still rewarded for venturing into unknown territory. One student had been reluctantly manoeuvred into reviewing the role of the mental status exam (MSE) which seemed to him to bear little relation to the condition under review.

'I'm not about to show that the mental status exam will give rise to a definitive diagnosis, but to show that its probably a little more useful than we often give it credit for. 'TWH (Round Prep)

That the student had changed his view about the usefulness of the MSE exam (revealed in interview) was due to contact (networking) with a specialist;

'They were showing me how much information they could glean from a simple mental status exam - that we've all learnt on introductory clinical 
methods -if I'd have been aware of that previously...' / The student went on to relate how he would have recognised the relevance of the MSE earlier. [Interview].

\section{Motivation and The Learning Process}

The motivation for investing a considerable amount of time in 'rounds' varied between students. Sometimes it was a desire to understand a topic which had previously appeared opaque or to become expert in one particular area. Almost all students were motivated by the group activity. In all questionnaires, observations and interviews, only three students $(\mathrm{N}=78)$ evidenced, or were reported (e.g. by tutors) as, lacking motivation. One of these clearly had extensive personality problems.

Practice in the skills of presenting was clearly important for most interviewees, eg:

'The more you do it the more comfortable you will be as a resident... I know in clerkship you do presentations every two weeks, also in residen$c y$, when you answer the questions you have to know everything, including the dates and titles of articles.... I feel that if you present you are a semi-authority on it-you have a pride in knowing what you're presenting' $T G H$

Motivation was generally not fear of failure or of being ridiculed:

S: 'Well talking to peers there's not a lot of pressure, external or internal. Grand rounds... aren't part of our official evaluation, I don't want to look foolish, but for me I want to do it well-its less of a fear about doing poorly.'TWH

The role of the tutor was also important for fostering this view:

'Dr [name] was excellent. That's another reason why I was personally more motivated. She was willing to teach and walk through the reasoning behind treatment... and give guidance, push you to find out for yourself. And give backup, she doesn't just throw you to the lions' TWH

In summary reasons frequently given for the energising effect of GRs were: the cohesion of the group; individual pride; the lack of summative assessment; guidance rather than intervention on the part of the tutor; the supportive atmosphere of GRs meetings (including refreshments); the consistent attendance of staff and the excellence of many of the presentations. 


\section{Feedback}

About a third of students would have liked more feedback especially after delivery of their presentation.

'People say it was good or it went really well, but there's no individual feedback, nothing constructive.... These skills we've acquired are well worth working on and feedback is a way of knowing that, but the clinicians are too worried about hurting our feelings -but they could tell us more, as long as they say it nicely-we need to know the things we can work on and follow up on.' TWH

The post-round discussion at TGH was often less wide ranging and less interactive within the audience than that at TWH. The likely reasons were that presentations at TGH were often longer (by about 10 minutes), more detail was presented (see above), questions of clarification were more numerous, and the staff played a slightly larger part in answering questions.

\section{Discussion}

The attitudes of both staff and students to GR's are clearly favourable. They are seen by both groups as, on the whole, stimulating, relevant, worthwhile, time consuming and achieving their aims.

The criteria used to judge rounds are two dimensional. On the one hand there are clearly rewards for depth of understanding or research. On the other, presentation, irrespective of whether this was buttressed by deep or merely adequate knowledge, needed to be competent, centred on basics, and relevant. The first of these views tended to predominate at TGH and the second at TWH.

The lack of formal assessment was useful in allowing an independent learning and presentation format. But students needed more freedom to make mistakes, with appropriate feedback. e.g. through the tutorial review system.

As far as the aim of allowing independent learning was concerned, GR's were overwhelmingly successful. However, the goal of providing more meaningful clinical contact, either with clinicians or with individual patients was not readily achieved. Only rarely did all students in a group 
see and examine the patient, and in some presentations the research done on a topic was presented without reference to the actual case under discussion.

There was a tension between the need for a tutor to see the group succeeding and the amount of leeway he or she allowed in 'independence'. Some tutors may need help in standing back.

Student preparation was extensive. Sometimes this was too dependent on slide preparation at the expense of other more producible media (eg OHP). However, resulting presentations were generally of an excellent standard which increased attendance at Rounds.

The range of activities undertaken by students was appropriately broad for an independent learning programme, including personal study in the library, clinical examination, planning a talk, requesting slides or making them using an 'Apple Mac' computer.

Students were much more interested in presenting rounds than in being a member of the audience. Occasionally students found ways of stimulating or intellectually rewarding the audience, e.g. the soap opera. Keeping topics to common or life threatening diseases is another way of achieving this, as was the provision of refreshments, which allowed time for informal interaction and increased the perceived status of rounds. Topical issues in the hospitals or for the local ethnic populations; aids, drug abuse, tuberculosis, sickle cell disease etc could also be used.

Fleming, (1986) discussed students' strategies for case presentations on ward rounds in a UK medical school.

'Students' major preoccupation in preparation is to ensure they have identified all the important facts and can offer an explanation for them, rather than devising a teaching strategy which will help their colleagues learn about a particular disease... They have 'good' strategic reasons for adopting poor teacher preparation tactics, (which)...are 'you must really know your stuff to avoid being picked to pieces'. p9.

'... staff and students... take for granted this interrogatory style of teaching as 'the only way you are going to learn'... this form of teaching constitutes the core of medical socialisation.... What students learn is what is reportable and how to report it... Case presentations do not have 
the characteristics an educationist might associate with good teaching, i.e. feedback, summaries, conclusions, advance organisers, a systematic progression of ideas' p11-12.

Fleming was observing small-group (6 students) case discussion in the first clinical year. His contention was that the educational setting is so affected by 'professional socialisation' that research must take account of the professional practice to which the education leads. The students in Toronto, while possessing their UK colleagues' nervousness about presenting seemed much more educationally aware, and co-operative than those reported on in Fleming's study. Yet the underlying clinical practice should be the same-medicine is practised similarly throughout the western world.

The key differences probably lie in the amount of educational freedom. The Toronto tutors tolerated a large measure of autonomy in preparation and rehearsal. Although more research is needed, this finding may well be grounded in the observation that staff in Toronto, who had no special training for their roles, generally accorded students a higher status than they possess in the UK system and provided them with an appropriate context, (see Boud, 1988; p38) for their GR presentations. 


\section{References}

Bennard BC and Stritter FT. (1989) Teaching Medical Students in Ambulatory Clinics: Prescribed vs actual practice. Proceedings, Research in Medical Education, pp 141-146. Washington: Association of American Medical Colleges.

Boud D. (1988) Moving Towards Autonomy. in Boud D. (Ed.) Developing Student Autonomy in Learning. Sydney: Kogan Page.

Fleming W. (1986) 'Good' professional reasons for 'poor' educational practice: the interaction of medical and educational work in presenting cases during junior clerkship. Paper presented to Society for Research in Higher Education, Imperial College. Birmingham: (mimeo) Educational Services Unit, Birmingham Medical School.

Jolly BC and Rees L. (1983) Report on The Clinical Curriculum. London: mimeo, St Bartholomew's Hospital Medical College.

Mattern WD, Weinholtz D and Friedman C. (1983) The attending physician as teacher. New England Journal of Medicine, 308, 1129-1132.

McCall G. (1969) Data quality control in participant observation. in McCall G and Simmons JL. Issues in Participant Observation. Reading Mass.: Addison-Wesley.

Schatzman L and Strauss A. (1973) Field Research: Strategies for a Natural Sociology. NJ: Prentice-Hall.

University of Toronto, 1982-1986. Curriculum Renewal Documents -(mimeo) Faculty of Medicine, Associate Deans Office. 
88 


\section{Chapter 5}

How to Get Students to Focus on Clinical Skills:

The Learning Effect of Re-using Stations in an Objective Structured Clinical Examination 


\section{HOW TO GET STUDENTS TO FOCUS ON CLINICAL SKILLS: \\ THE LEARNING EFFECT OF RE-USING STATIONS IN AN OBJECTIVE STRUCTURED CLINICAL EXAMINATION}

\section{Introduction}

The importance of examinations in directing student learning is well known (Newble \& Entwistle, 1986; Fredrickson, 1984; Miller \& Parlett, 1974). In fact, any test will influence students' behaviour if its format and content are known in advance. This influence may be evident in a variety of ways. It may be a general one affecting the overall approach to studying, (Newble \& Entwistle, 1986). It may also produce strategic attempts to identify questions or to apportion effort relating to the components which comprise an examination, (Miller \& Parlett, 1974; Newble \& Jaeger, 1983).

For example one study showed how apparently reasonable changes in the final year assessment procedures, linked to a medical curriculum review, led to student behaviour which was the antithesis of that intended, (Newble \& Jaeger, 1983). Subsequent modifications of the assessment system restored the balance, showing how careful management of the format and content of an examination can produce desirable effects on student behaviour and promote a higher level of competence, (Newble et al., 1978).

Such findings raise the possibility of using examinations in a more precise way to direct student learning. For example, certain components of professional competence might be given a higher priority and this could be conveyed to students by giving them more weight or by testing these components more frequently. These intentions are best made explicit, but if not they will be gleaned by students usually through the informal network which exists between them and those in previous years (Miller \& Parlett, 1974); an example of what has been termed the "hidden curriculum" (Snyder, 1971). An alternative is through collated knowledge, either formal or informal, of test papers from previous years. Either way, in most academic institutions it is usually assumed that students attempt to increase their marks by using whatever partial knowledge they have of the items. 
This paper reports an attempt to detect the learning effects of administering identical clinical stations to two or more classes over a 12 year period within an objective structured clinical examination (OSCE).

\section{Methods}

The data are generated from the OSCE component of a comprehensive examination of clinical competence administered to final year medical students at the University of Adelaide. The format and psychometric characteristics have been described in detail elsewhere, (Newble, 1988; Newble \& Swanson, 1988).

Each year, for logistic reasons, the class was split into two halves and two separate, but equivalent, examinations each containing 15 stations were used. This format has remained essentially unchanged over a 12 year period. During this time no significant alterations have been made to the structure of the final year curriculum nor to the information provided to students about the examination. This information consists of written details of the final year objectives on which the examination is based, and briefings on the test procedures.

A survey was conducted of all stations in the OSCE component at which students were observed performing a clinical (patient-based) task. In the first 6 years there were three of these per examination, but this was subsequently increased to five. In any one year, therefore, there was a total of 6 or 10 'clinical' stations in the two halves of the examination. Over the twelve year period, 59 different clinical stations were used. Of these, sixteen were reused. Ten were administered twice, five were used three times, and one was administered to 5 classes in all, (See Table 1). In this last instance only, Cardio-pulmonary resuscitation [CPR], was a station deliberately re-used to direct student learning, but students were not told this nor were they informed when the station was to be included. The reason for all other reuse was simply the practical one of the effort required each year to develop enough new clinical stations. However, reused stations were usually selected by staff because of their relevance and perceived importance.

Approach to Analysis

The main purpose of this study was to investigate the effect of administering the same station to different classes over time. 
One problem is that there are several factors other than reuse which might also lead to changes in performance. In this study we do not claim to have a totally robust design for addressing this problem: a watertight design and analysis in a real educational setting would be very difficult to achieve. However the lack of design precision can be offset by the reality and representativeness of the situations we are studying (Snow, 1974). Moreover, we have taken advantage of the long period over which data were collected and the large number of stations used to help in making some assumptions.

1) If each station individually was first used or reused more or less randomly in different years, differences between the same group of stations at different points of use (first, second etc) should be small, and not statistically significant, unless affected by a systematic factor like reuse or gradual improvement in students' ability over time.

2) In the absence of any other effect, differences in class means of any one OSCE station due to year by year fluctuations in cohorts' ability levels should cancel out over time, if sampled often enough. That is, although statistically significant year to year differences might be expected from random operation of factors like class ability, etc., no particular trend should be discernible. If the same trend were discernible in a number of individual stations, reused in different years after different time lapses, it would be very suggestive of an effect due to some persistent chronological variation. A practical example (null hypothesis) would be that in a group of stations administered twice, given the random operation of all other factors, half the stations mean scores would be expected to increase on the second use and half to decrease. Furthermore, the average difference in scores between first and second administration, over all stations would be expected to be very small.

These inferences depend on the assumption that other factors like cohort ability, curricular fluctuations, etc. operate more or less randomly. They also depend on the reasonable assumption, over the 12 year period, that the reuse of particular stations is also essentially random. (In fact this assumption can be borne out by inspection of Table 1)

3) There is also the problem of the meaning of the station scores from year to year. This problem has been addressed by concentrating the analysis only on the OSCE's clinical (patient-based) stations which have precise, essentially criterion referenced, items. This increases the chances that the meaning of the test score across years is more or less equivalent. Although instruction may differ in effectiveness from year to year, most 
such clinical tasks are well defined in the clinical curriculum and usually chosen because of their perennial relevance. Hence the variability of scores is probably more due to differences in individual student preparation than to vagaries of the curriculum.

The main analysis, which springs directly from assumption 2 , uses a series of one-way analyses of variance (ANOVA), using reuse as the factor, on individual student's station scores. If the majority of stations were to show an increase in scores over time, subsequent one way analyses on trends within individual stations would be justified. Under our assumptions an underlying trend is more likely to be discernible on very frequently used stations. This is due to the cancelling out of other random factors over a long period of time, acting together with an increasing recognition, on the part of the students, that the station(s) is important.

\section{Analyses of Variance}

First it was necessary to compare stations administered to only one class with the first administration of those given to two or more classes to show that reused stations are not inherently less difficult than stations used once. The means of all stations $(n=43)$ that had not been reused were compared as a group to the initial use of those stations $(n=16)$ which were subsequently reused, using one-way analysis of variance (ANOVA, see Winer, 1971). (For this analysis the means had to be used because the raw data for some of the non-reused stations in some years was not available, only the mean, N's and standard deviations).

This analysis was followed by comparisons of means for the first and second usage of each of the sixteen stations used twice, (the 10 stations used only twice and the first two uses of the others) and for the main effects and trends over all administrations of the six stations used three or more times. The analysis on CPR scores over its 5 administrations included trends up to the cubic polynomial.

\section{Results}

Table 1. provides information on the nature of the reused stations, the grand mean of each reused station and of all other stations over all years, and the number and year of the reusage.

In any one year the number of clinical stations reused from previous years varied from 0 (in 1982 and 1988) to 7 (out of 10) in 1986. 
Table 1. Mean station score over all administrations and all students and sd's, number of administrations per station, years when used and total $\mathrm{N}$ per station.

\begin{tabular}{|c|c|c|c|c|c|}
\hline Station & $\begin{array}{l}\text { Overall } \\
\text { Mean }\end{array}$ & SD & $\begin{array}{l}\text { Times } \\
\text { Used }\end{array}$ & $\begin{array}{l}\text { When } \\
\text { Used } \\
\text { (Years) } \\
\begin{array}{lllll}1 & 2 & & & \\
1 & 4 & 5\end{array}\end{array}$ & $\begin{array}{l}\text { N } \\
\text { Per } \\
\text { Grou }\end{array}$ \\
\hline Arterial Blood Gases & 74.37 & 11.98 & 3 & 858790 & 137 \\
\hline Asthma Inhaler & 78.00 & 13.64 & 2 & 8789 & 90 \\
\hline Breast Examination & 75.71 & 13.21 & 2 & 8486 & 109 \\
\hline Cardio-Pulmonary Resus.(CPR) & 62.55 & 23.32 & 5 & 7980858689 & 474 \\
\hline Cranial Nerves & 76.45 & 13.19 & 3 & 798187 & 154 \\
\hline Cardiovascular system & 69.78 & 13.07 & 2 & 7983 & 114 \\
\hline Epilepsy & 52.47 & 11.39 & 2 & 8386 & 101 \\
\hline Knee Examination & 66.52 & 14.81 & 3 & 798490 & 162 \\
\hline Breast Lump & 64.09 & 11.29 & 2 & 8586 & 102 \\
\hline Multiple Sclerosis & 66.25 & 11.65 & 2 & 8486 & 108 \\
\hline Peripheral Vascular Disease & 64.49 & 12.94 & 3 & 798386 & 158 \\
\hline Peripheral Vascular System & 73.18 & 10.94 & 2 & 8789 & 90 \\
\hline Respiratory System & 79.87 & 10.93 & 3 & 838790 & 142 \\
\hline Shoulder Dislocation & 66.66 & 16.88 & 2 & 8486 & 110 \\
\hline Valve Murmurs & 67.61 & 12.71 & 2 & 8690 & 88 \\
\hline Wrist Examination & 72.68 & $20.37 *$ & 2 & 8490 & 103 \\
\hline NON-REUSED Stations ( $n=43$ ) & 62.70 & $11.03^{*}$ & 1 & ALL YEARS & 1935 \\
\hline TOTAL & 67.79 & 17.32 & & - & 2551 \\
\hline
\end{tabular}

This sd is for 43 station means not for the total number of subjects. All other sd's are based on the appropriate total Ns.

Analysis of Variance: Comparison between stations

There was no significant difference between the non-reused stations and the initial administration of the reused stations. (Non-reused mean $=62.7$, Reused mean $=63.86$ ). The means of all reused stations over their respective administrations, $p$ values for main effect and linear trend, and the slope are shown in Table 2 . In the case of the stations used only twice, the $p$ values for main effect and linear trend are identical, and the slope is merely the difference between first and second administration of the station.

Table 2 shows 12 of the 16 overall trends to be statistically significant. Of these, 10 were positive, showing a significant increase with reuse (mean increase per use $=9.4$ ) and 2 showed a decrease in scores with reuse (mean decrease per use $=5.2$ ). The mean slope over all 12 significant results 
Table 2. Means, Main Effects due to Reuse and Linear Trend Components of all 16 Reused Stations and the Grand mean of all the non-reused stations. (Standard deviations have been omitted for clarity. Slope for the first six stations is weighted).

\begin{tabular}{|c|c|c|c|c|c|c|c|c|}
\hline Station & lst & 2nd & 3rd & 4 th & 5 th & $\begin{array}{l}\text { Main } \\
\text { Effect } \\
p=\end{array}$ & $\begin{array}{l}\text { Linear } \\
\text { Trend } \\
\text { p }=\end{array}$ & $\begin{array}{l}\text { Slope } \\
\text { of linear } \\
\text { trend }\end{array}$ \\
\hline \multicolumn{9}{|l|}{ Cardiopulmonary } \\
\hline Resuscitation & 47.0 & 52.7 & 65.7 & 80.2 & 82.8 & .000 & .000 & +8.1 \\
\hline Arterial Blood Gases & 78.2 & 73.7 & 70.4 & & & .007 & .002 & -3.6 \\
\hline Cranial Nerves & 68.2 & 84.6 & 77.6 & & & .000 & .000 & +5.6 \\
\hline Knee Examination & 64.7 & 58.4 & 81.1 & & & .000 & .000 & +9.2 \\
\hline \multicolumn{9}{|l|}{ Peripheral Vascular } \\
\hline Disease & 66.9 & 60.4 & 66.5 & & & .010 & $.85 \mathrm{~ns}$ & -0.2 \\
\hline Respiratory System & 74.8 & 79.9 & 86.3 & & & .000 & .000 & +5.8 \\
\hline Asthma Inhaler & 75.4 & 80.7 & & & & .048 & .048 & +5.3 \\
\hline Breast Examination & 76.7 & 74.5 & & & & .390 & $.39 \mathrm{~ns}$ & -2.2 \\
\hline Cardiovascular System & 61.6 & 79.2 & & & & .000 & .00 & +17.6 \\
\hline Epilepsy & 49.8 & 55.5 & & & & .010 & .01 & +5.7 \\
\hline Breast Lump & 46.9 & 63.0 & & & & .000 & .00 & +15.1 \\
\hline Multiple Sclerosis & 65.5 & 67.2 & & & & .431 & $.431 \mathrm{~ns}$ & +1.7 \\
\hline \multicolumn{9}{|l|}{ Peripheral Vascular } \\
\hline Disease & 66.9 & 60.1 & & & & .010 & .010 & -6.8 \\
\hline Shoulder Dislocation & 64.8 & 69.1 & & & & .029 & .029 & +4.3 \\
\hline Valve Murmurs & 66.1 & 69.4 & & & & .061 & $.061 \mathrm{~ns}$ & +3.3 \\
\hline Wrist Examination & 65.7 & 82.5 & & & & .000 & .000 & +16.8 \\
\hline All Other Cases & 62.7 & & & & & & & \\
\hline
\end{tabular}

(positive or negative) was +6.9 , indicating an average increase in performance on these stations of 6.9 points per reuse. The mean slope over all stations was +5.4 points.

Further investigation of Table 2 revealed that the average increase of class mean scores between first and second administrations only of reused stations was about $6 \%$. Twelve stations increased and four decreased in mean score from first to second usage. Comparisons for these pairs of station scores showed 10 of the increases, and two of the decreases to be statistically significant. A Wilcoxon signed rank test (one tailed) on the likelihood of such a pattern of differences occurring by chance alone in 16 pairs was statistically significant $(p=.011)$.

The ANOVA on the individual raw scores of the six stations used at least three times showed a similar pattern of results. Although the average increase in scores from first use to second was small for these six stations, the increase from second to third use was quite large and statistically 
significant (Mean increase 7.7\%) Care must be taken in interpreting these trends because size of the change is not uniform over all six stations. The trend analyses on individual stations showed that 4 of the six were consistent with positive linear trends from 1st to 3rd use, and one (Arterial Blood Gases) was consistent with a negative trend. However, in post hoc analysis, when all consecutive pairs of means were compared for these six stations, the only significant decrease in pairs of means was between administrations 2 and 3 of Cranial Nerves, and even here the data were consistent with a positive linear trend overall.

It is possible that the improvements in score on reused stations might have been an expression of a decrease in difficulty level of the examination over time, an improvement in 'test-wiseness' of the students or an actual increase in the students' competence. However an analysis of variance, with trend analyses, of all station scores (for this analysis all available raw scores were used) over the whole twelve years of the study showed no monotonic trend in an upwards or downwards direction. In fact from 1981 to 1987 the overall performance was essentially flat. The partition of variance into trends showed components at cubic or higher levels to explain the highest proportion $(66 \%)$ of the between year variance. Notably, the year in which the overall performance on stations was lowest, 1988, contained no reused stations. Taken together this suggests that the overall difficulty level of the examination may have fluctuated from year to year but did not become easier.

\section{Analysis of Variance: Trends within a Frequently Reused Station} Line 1 of Table 2 shows the class mean performances on the most frequently used station - cardio-pulmonary resuscitation. This was initially a difficult station with a class mean score of only $47 \%$. A steady improvement was noted subsequently reaching a ceiling of about $80 \%$ at the fourth administration. The one way ANOVA on CPR over 5 administrations showed significant differences $(F=64.15$; df 4,$468 ; \mathrm{p}<.01)$. A trend analysis showed that a linear trend explained by far the most variance $59 \%(\mathrm{~F}=235.9$; df 1,$3 ; \mathrm{P}<.01$ ). Post hoc comparisons (Newman-Keuls Range Test) showed significant differences between three groups of means; administrations 1 and 2 together, versus administration 3 versus administrations 4 and 5 together. 


\section{Discussion}

The results suggest that using a station in an OSCE generally leads to an improvement in the performance of subsequent cohorts of students on the same station. With only 4 exceptions, reused stations showed an increase in scores of between $5 \%$ and $18 \%$ from one administration to the next. The average increase in score was about $5-7 \%$ per repeat. Only two stations had reuses that showed statistically significant decreases in score.

Furthermore it is interesting to note that the largest increases in station scores usually took place on the third usage. This may be due to the fact that students cannot 'flag' a station as being particularly important until it has occurred twice. Although students were presumably aware, from 1980 onwards when CPR was first reused, that such reuse could occur.

There are other possible explanations for the data. A gradually increasing standard of intake of students might have had a similar effect on scores, but we have no reason to believe there was a general incline in ability amongst entrants coinciding with the period of the study. Some stations could have been so difficult to start with that improvement was almost inevitable. However only 3 of the 16 reused stations had class means which were below $60 \%$ on the first administration, and although these showed increases in scores when reused, some of the largest increases were on stations with initially high scores. For example, cranial nerve examination and examination of the cardiovascular system improved mean scores from $68 \%$ and $61 \%$, to $84 \%$ and $79 \%$ respectively from first to second administration. Although the cranial nerve station score dropped back on its third use to $77 \%$, this was still significantly $(\mathrm{p}<.01)$ well above its initial mean.

Another factor which may have contributed is violation of test security, which conceivably could have affected quite markedly any scores in a test in which such a violation occurred. However, lack of security in a particular year would presumably affect all stations not just the reused ones. Over 12 years the effect of lack of security on the difference between single and reused stations would be negligible. However, knowledge of individual stations could have contributed to the within station trend analyses producing artifacts. Nevertheless, to the authors' knowledge no such violations occurred during the period of the study.

We did not have the opportunity of establishing whether the students in this study were actively 'spotting' OSCE stations. However as teachers we are impressed with the impact that new stations have on student be- 
haviour. In a recent example, the introduction of a station on collecting specimens for microbiological examination produced demands, not previously evident, from the following year's students for practical demonstrations and tutorials from the Department of Infectious Diseases. With one exception, CPR, the reuse of stations in this study was not deliberate. If it had been, and this intention was communicated to the students, the effect might well be greater - the hidden curriculum would be taken out of the closet.

The effect of reusing a station more than once seemed to provide an ongoing stimulus to the students as further increases in performance were engendered. Presumably, this is because such reuse provides further evidence of the priority given by the Faculty to the topic. The effect seems quite long lasting as there is no evidence that the distance between administrations is a major factor. This effect should also be stronger with stations in which the initial performance is low. However only one such station really fulfils this criterion - CPR, and this was indeed the station in which the most dramatic improvement was seen, but it was also the most frequently reused.

The study also highlights the inadvisability of comparing institutions purely on examination results, which is a common practice in at least UK medical schools. For example, in 1991, an examination year not included in the present study, the CPR mean score was $85 \%$. If such comparisons were made in 1991, students at Adelaide would probably be seen favourably compared to those in other institutions. However their impressive results would partly be due to the 'targeting' effect of CPR being reused so frequently in the OSCE.

This study, and other recent experiences, confirm the profound effects that assessments have on student behaviour and performance. All too often these influences are detrimental, (Fredrickson, 1984; Miller \& Parlett, 1974, Newble \& Clarke, 1986) Occasionally, mainly when assessments are formative and developed in a supportive environment, they can stimulate autonomous learning., (Jolly \& Ho-Ping Kong, 1991, see Chapter 4). Nevertheless these effects are complex and affect students in different ways, and some students more than others. A failure to recognize this, and to act appropriately, can lead to problems for students that may not be appreciated by them or their teachers. On the other hand, a knowledge of how assessments affect students could be used constructively to provide direction and feedback in a way that may be more efficient and effective 
than any other means. To be successful this requires a careful match of the breadth and depth of the content and of the format of the assessment to the aims and objectives of the curriculum. 


\section{References}

Fredrickson N. (1984) The real test bias. American Psychologist, 39, 911-918.

Jolly BC and Ho-Ping-Kong H. (1991) Independent Learning: an exploration of student grand rounds at the University of Toronto. Medical Education, 24, 334-342.

Miller CM and Parlett M. (1974) Up to the mark: a study of the examination game. Guildford: Society for Research in Higher Education.

Newble DI and Entwistle N. (1986) Learning styles and approaches: implications for medical education. Medical Education, 20, 162-175.

Newble DI, Elmslie RG and Baxter A. (1978) A problem-based criterion referenced examination of clinical competence. Journal of Medical Education, 53, 720-724.

Newble DI and Jaeger K. (1983) The effect of assessment and examinations on the learning of medical students. Medical Education, 17, 165-171.

Newble DI and Clarke, R. (1986) The approaches to learning of students in a traditional and in an innovative problem based medical school. Medical Education, 20, 267-273.

Newble DI and Swanson D. (1988) Psychometric characteristics of the objective structured clinical examination. Medical Education, 22, 325-334.

Newble DI. (1988) Eight years experience with a structured clinical examination. Medical Education, 22, 200-204.

Snow RE. (1974) Representative and Quasi-representative Designs for Research on Teaching. Review of Educational Research, 44, 265-291.

Snyder BR. (1971) The Hidden Curriculum. New York: Knopf.

Winer BJ. (1971) Statistical Principles in Experimental Design (2nd Ed). New York: Mcgraw-Hill. 
Chapter 6

Training vs Experience in the Acquisition of Bedside Manners 


\section{Training vs Experience in the Acquisition of Bedside Manners}

Picking up a practice on one's own has the advantage of freedom freedom to experiment without the constraints of received views. But it also has the disadvantage of requiring each student to reinvent the wheel, gaining little or nothing from the accumulated experience of others. Apprenticeship offers direct exposure to real conditions of practice and patterns of work. But most offices, factories, firms, clinics are not set up for the demanding tasks of initiation and education. Pressures for performance tend to be high; time, at a premium; and mistakes, costly. Senior professionals have learned, in addition, to expect apprentices to come equipped with rudimentary practice skills. Nevertheless, many novices still learn through apprenticeship, and many senior practitioners and critics of professional education still see it as the method of choice. (Schön, 1987, p37).

\section{Introduction}

The chapters of this book have addressed several issues concerning the development of clinical expertise. In particular they have illuminated some of the characteristics and products of learning in the hospital setting. In the opening chapter questions about why clinical education is important and where it came from were addressed. The historical distinction between academic and hospital/patient based medicine was highlighted. Following that, other chapters confronted what learning clinical medicine involves in a number of different settings. Research has been presented and discussion undertaken on learning technical skills, the location of teaching (the ward round and the 'Grand Round'), and the effects of assessment alone on learning clinical skills.

The reasoning behind this approach has been the need to find a general strategy to enhance the delivery of clinical education. This has been done by looking both at what educational theory says and what participants think is good practice. Much of the work described has focused on using descriptive or correlational techniques to characterise 'good' clinical teaching. The definition of quality has usually come from the consumers, from clinicians or from observers using an educational framework. A number of factors have been proposed as important including, for example, feedback and the amount of clinical work experienced by the learner (see Chapters 1-3) as well as the contribution of students themselves (Chapter 4). 
However one important relationship has so far been ignored. An essential question in such a thesis should be;

What is the connection between the measurable outcomes of clinical education and its content or process?

This issue is the focus of the two studies in this chapter. Since one of the easiest areas to investigate is the development of basic clinical skills and techniques, the research concentrates on the relationship, over a period of three years in a traditional hospital setting, between outcomes on an OSCE type examination and structured or unstructured clinical experience.

Since 1990 St Bartholomew's Hospital Medical College has used an OSCE at the end of the first year of clinical training. Its role is to provide a hurdle-type examination to require students to demonstrate accomplishment in basic clinical skills - patient examination, history taking, venepuncture, catheterisation and so on. The OSCE is taken in April or May of the first clinical year. The preparation for this OSCE, the first clinical course, starts in the previous October with a four-week introductory course, followed by attachments for 8 weeks each to medical and surgical teams in groups of 3-10 students, depending on the number of staff available. Students are attached first to one of 10-12 medical 'firms' (a group of 2-3 senior doctors, 'consultants', with a team of junior staff, who constitute an independent clinical group responsible for their own patients in the hospital), then to one of 11-13 surgical firms. Half the students do medical firms first and half surgical firms. Some of these firms are in the hospital attached to the medical school, but a growing number of firms from district general or other urban teaching hospitals outside major cities are used to take students for their introductory courses. A course in clinical pathology of 4 weeks is also taken during the period JanuaryFebruary.

In order to relate experience to outcome some appropriate criterion measure is required. First it was necessary to establish that the OSCE was an appropriate and sensitive indicator of changes in educational strategy within the curriculum. This was done in the first study desribed below using the 1991 OSCE. A sub-group of the year's students were trained, or had naturally occurring experience, in a specific marker skill (ophthalmoscopy) to ascertain whether the effects could be traced in the OSCE 2 months later. Based on the finding that the OSCE was indeed responsive 
to such changes, the purpose of the second study was to investigate the relationship between the clinical experience of the students in the 'firm' attachments and their performance on this clinical examination.

In the second study the educational experiences available to students in each of the firms in 1992-3 were monitored and quantified, and regression analyses undertaken of the effect of the variation in these experiences on the subsequent OSCE scores to identify those specific, 'naturally' occurring, educational experiences correlated with high OSCE scores.

\section{Study 1: The Effect of Formal Instruction in Ophthalmoscopy on Medical Student Performance in an OSCE Station. ${ }^{1}$}

\section{Introduction}

Practical experience and the development of clinical skills should be an important part of medical curricula (GMC, 1980). In practice very little formal instruction is provided in teaching hospitals in the UK and in the USA, usually due to the constraints of time, workload, and availability of patients (Thatcher, 1991; van Selm, 1985; Nelson \& Traub, 1993). The experience of individual students is dependent on a variety of factors as described in Chapters 2-4, and on their own endeavours. Although OSCEs have been used for the assessment of skills (Harden \& Gleeson, 1985), prior to using an OSCE as an index of achievement in a specific situation, its potential to demonstrate the effects of differences in experience should be established.

In order to do this for the OSCE used at St Bartholomew's Hospital Medical College, a specific marker skill was chosen; fundoscopy. The performance of a selected sub-group of first year clinical students in 1991 in fundoscopy was monitored, before and after specific formal training and again 2 months later in the end of year OSCE.

\section{Methods}

An ophthalmoscopy checklist with objective structured-type questions (Harden \& Gleeson, 1985) was devised to provide a means of assessment.

1 This study uses the data and a large part of the discussion from a published study, (Cordeiro, Jolly and Dacre 1993) designed originally to show the effects of instruction. However it is used here to demonstrate the efficacy of the OSCE to be senstive to instructional activities. 
To validate the checklist 2 independent observers used it to rate 29 (of 109 in the year) volunteer untrained medical students who performed ophthalmoscopy, on a mannequin, to the best of their current ability, under examination conditions. Agreements were good on all 8 checklist items with Kappa (Cohen, 1960) $\geq 0.79$. Following this initial assessment, each of the 29 medical students was formally instructed on ophthalmoscopy using one of their peers in the group as patients. Each student was trained in one session, by the same instructor in groups of 4-5, over a period of a few weeks to a criterion of $90 \%$ on the checklist. The 29 volunteers were assessed before and after ophthalmoscopic instruction using the same scale as was used in the OSCE. The remaining 80 students - the control group- were not assessed at this time. Their experience in ophthalmoscopy was attained as part of the normal clinical examination skills taught variably during their 2 firm attachments.

Subsequently, approximately 2 months later, all 109 students took an OSCE containing 185 - minute stations, of which 12 stations were directed at aspects of clinical skill, (e.g. a nursing station involving lifting a patient, interpreting an ECG, etc). One station assessed fundoscopy.

\section{Results}

Using a Student's paired t-test, Table 1 shows the comparison between the experimental group's performance before training and after 2 months in the OSCE. This group significantly differed in its performance by about $40 \%,(t=5.73 ; \mathrm{df}=28 ; \mathrm{p}<0.001)$.

Figure 1 shows the results of the experimental and control groups in all OSCE stations. In comparison with the remainder of the year, the 29 students trained in ophthalmoscopy scored on average $20 \%$ more at fundoscopy in the OSCE station $(t=3.34 ; \mathrm{df}=107 ; \mathrm{p}<0.01)$. Performance on fundoscopy for this group was also the highest, in percentage terms, of any of their skills (see Fig 1). The scores of this volunteer group on all but two OSCE stations was also higher than the control group. However no comparison was significant for any individual station other than fundoscopy although a sign test on the direction of the differences across all stations $(9+v e ; 2$ no difference) is significant $(p<.01)$. The performance, after their experience on clinical attachments, of the control group on ophthalmoscopy was significantly better than the pre-test performance of the volunteer group (Means 6.4 and 5.3 respectively; unpaired $t$-test $t=2.18 p<$ 0.05 ). 
Table 1. Comparison of scores of 29 volunteers before and after training in Ophthalmoscopy.

\begin{tabular}{lll}
\hline & Mean & S.D. \\
\hline Pre-instruction & 5.34 & 2.25 \\
Post-instruction (at OSCE) & 7.71 & 1.74 \\
Mean Difference & 2.37 & 2.23 \\
\hline
\end{tabular}

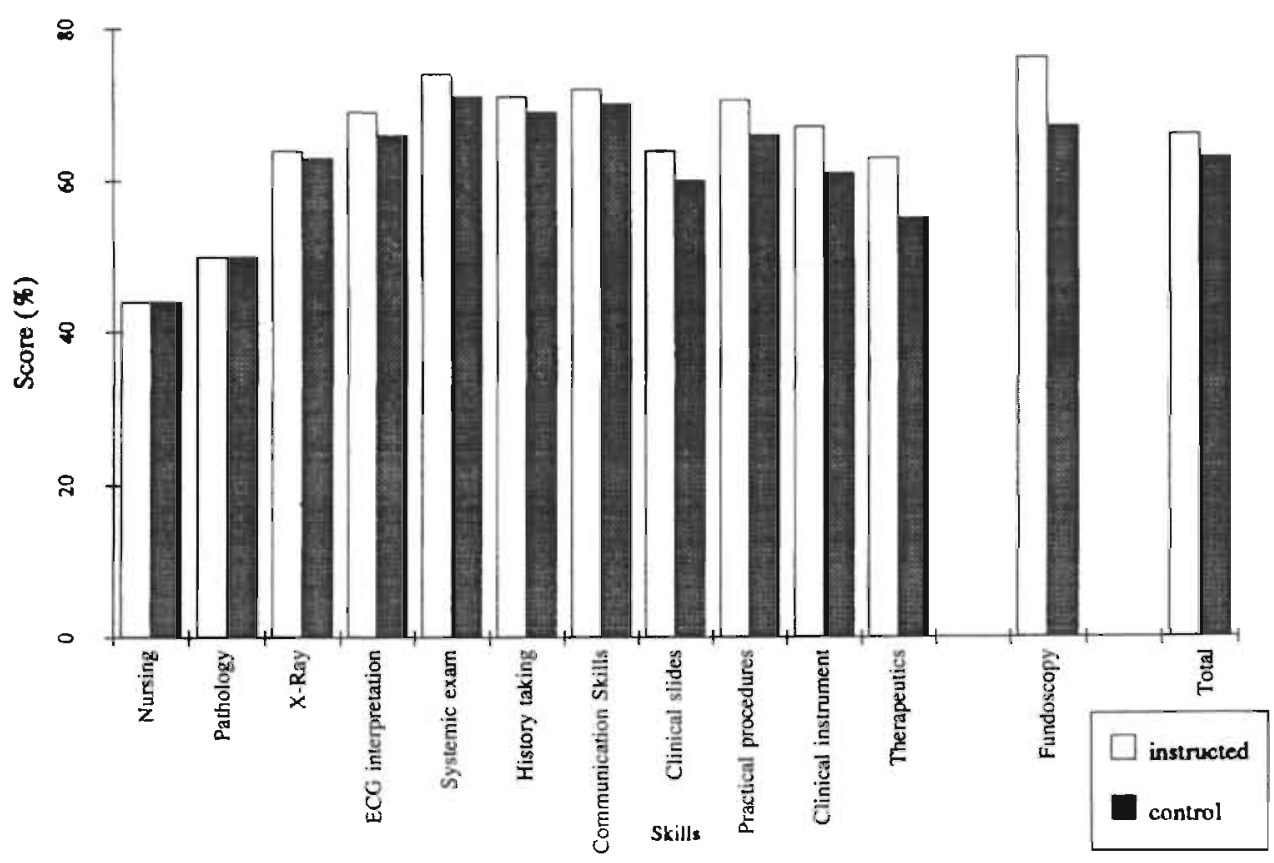

Figure 1. Scores of group instructed opthalmoscopy $(n=29)$ and control group $(n=80)$ in all clinical skills

A comparison of total OSCE scores, excluding the ophthalmoscopy station, between the two groups was significant at the $\mathrm{P}<.05$ level. A comparison between the two groups scores on a 50 item MCQ, administered adjacently to the OSCE, showed no differences between the mean scores (volunteer group $=28.73$; remainder $=29.58$ ).

\section{Discussion}

The study showed that differences in training could be detected up to 2 months later on one station within an OSCE. Clinical experience, as well 
as specific training, benefitted students. The study also suggested that the volunteer group were more interested or motivated towards clinical skills, since their performance was consistently higher across all skills, but not on an adjacent MCQ test.

The inference that the OSCE is capable of detecting differences in training is limited by the fact that only one skill was chosen as a marker. However this was all that was practicable in the 1991 teaching year given staff commitments and availability of volunteer students. Nevertheless the fact that the differences between the volunteer group and the others were consistent is also strong evidence that the OSCE is capable of detecting differences in group experiences.

An alternative explanation of the results is that they were caused by the increased motivation of the experimental group. Although this group also performed better on skills across the board (Figure 1) only the ophthalmoscopy station was significant. The pattern of performance, with ophthalmoscopy being the best score for the experimental group and the largest difference between the groups, also suggests that the OSCE is reflecting more than a motivational difference between the two groups.

Some investigators have recently used OSCE stations to establish correlations with or detect inadequacies in training programmes, (Anderson et al, 1991; Higgin and sym, 1992) and this research looks promising. In the former study the authors showed that sites rated poor for neurology teaching produced students with poor scores on the neurology components of a 20 station OSCE. However the measures of training programmes used were couched only in characteristics of teachers or in the self-ratings of students about how much they thought their skills had improved. Hence they ignored environmental and experiential factors. Nevertheless they did exclude the possibility that differences in performance by students at different sites was related to the fact that better students attended at those sites.

The study by Higgin and sym found that a hospital with a low staff-student ratio in gynaecology and fewer faculty-directed clinical experiences resulted in poorer performance on an obstetric/gynaecology targeted OSCE, but did not attempt to control for the possibility that better or more clinically oriented students attended at different sites. The only control undertaken was to show that students' MCQ scores across sites were similar, but the study also demonstrated the lack of correlation between MCQ and clinical scores. 
It was decided to attempt a study to investigate the relationship between clinical experience and OSCE performance avoiding some of the deficiencies of earlier studies. The next part of this thesis reports an attempt to investigate what reported aspects of training, if any, correlate with success on a comprehensive 25 station OSCE measuring attainment of basic, general clinical skills over the years 1992-1993.

\section{Study 2: The Correlation of Student Feedback about their Junior Clinical Attachments (Firms) with their Performance.}

\section{Introduction}

As stated in Chapter 1, worldwide, clinical teaching has been largely by haphazard experience. Although many clinical teachers would disagree with this, arguing that they attempt to provide a structured clinical exposure, data collected from students would suggest otherwise. In most studies of clinical education large differences between attachments are found, and clinicians consistently differ from students in their estimates of how much structured teaching takes place, (see Chapter 1, Chapter 3, Mattern et al 1983 as examples). Locally, from 1988, curriculum monitoring has shown that major differences exist in the amount of educational experience available in different attachments. For example, unpublished data from the Chesser and Brett study (1989) showed that on 32 different introductory firms at the London Hospital Medical School, the number of hours of bedside teaching available per week ranged from 0 (zero) to 22 . Moreover there were consistent differences in experience reported by male and female students on two of these firms.

Since 1990 the monitoring of students' clinical attachments at Barts has been expanded, for reasons outlined in Chapters 1, 3 and 4. Chesser and Brett (1989), clearly demonstrated the importance of six factors; amount of clinical activity, workload, staff-student relationships, organisation of teaching feedback to students and type of clinical activity in conceptualising the clinical environment. Their analysis went beyond the simple scrutiny of teaching activities. This is important if only because students experience a number of different teachers and teaching styles in any one attachment, but workload and patient throughput are geared to organisational and patient needs outside the control of teachers (see Chapter 3). Hence a large number of questions about what the students did on a day to day basis while on the firms, as well as perceptions of students as to how useful the attachments had been, were introduced into the monitoring process. 
In 1992 and 1993 the OSCE referred to in Study 1, an examination integrated for medicine and surgery, was expanded to 25 stations. This was done for two reasons. First, reproducibility analyses had shown that the 18 station OSCE was insufficiently reliable to measure clinical performance across disciplines; Cronbach's alpha for 1990 and 1991 were 0.54 and 0.58 respectively. Second, changes to the curriculum made the OSCE a required 'hurdle' type examination, albeit of basic clinical skills, that students had to pass before entering for clinical final examinations two years later. A broader, more reliable examination, including many more stations was thought more appropriate for this type of usage.

Because Study 1 confirmed that some differences between students and between training programmes could be detected by an OSCE at least 2 months later, it was decided to investigate the relationship between the clinical experience available within different firms at St Bartholomew's Hospital Medical College, and performance on the end of year OSCE examination. We confidently expected to show that some structural aspects of the curriculum, for example the extensive experience and involvement offered by some firms, resulted in improved performance of students in those attachments. There would be general trends overriding personal serendipitous experience. In this way a more rational approach to curriculum planning or choice of attachments for clinical skills could be undertaken.

\section{Method}

\section{Course Structure}

In 1992 and 1993 students were attached to one medical and one surgical firm for a period of 10 weeks on each. Half the students took medicine first and half surgery. The course structure is shown in Figure 1. The total number of firms involved was 27 over the two years, approximately 10-11 surgical firms and 12-13 medical firms in each year. Eighteen of these firms took students in both years. Students are allotted to both firms randomly, in groups of between 3 and 10 depending on staff numbers and availability. Hence the number of firm combinations (first firm plus second firm) is great even though there are only about 12 firms in each specialty. The number of firms used by the College had been reduced from previous years so as to attempt to acquire more central control and to regulate the amount of teaching available. Almost all the firms were led by, or included, staff who were generally regarded as good teachers and many had won teaching awards, voted for by the students, in previous years. The attach- 
Figure 1: Diagram of the course structure and OSCE examination. (January - May)

\begin{tabular}{lllll}
\hline $\begin{array}{l}\text { Student } \\
\text { Group }\end{array}$ & $\begin{array}{l}\text { Pathology } \\
\text { (approx 4 } \\
\text { weeks) }\end{array}$ & $\begin{array}{l}\text { First Attachment } \\
\text { (10 weeks) } \\
\text { (Firm 1) }\end{array}$ & $\begin{array}{l}\text { Second Attachment } \\
\text { (10 weeks) } \\
\text { (Firm 2) }\end{array}$ & $\begin{array}{l}\text { OSCE } \\
\text { (2 hours) }\end{array}$ \\
\hline $\begin{array}{l}\text { Half Year } \\
\text { Group (A) }\end{array}$ & $\begin{array}{l}\text { 4-week } \\
\text { pathology } \\
\text { course }\end{array}$ & $\begin{array}{l}\text { Medicine (one of } \\
12 \text { medical firms) }\end{array}$ & $\begin{array}{l}\text { Surgery (one of 10- } \\
11 \text { surgical firms) }\end{array}$ & $\begin{array}{l}\text { 25 Station } \\
\text { OSCE (of which } \\
\text { 24 stations } \\
\text { contribute to } \\
\text { data in this } \\
\text { chapter) }\end{array}$
\end{tabular}

Half Year

Group (B)
Surgery (one of 10-

11 surgical firms)
Medicine (one of 12

medical firms) *

* Clinical experience data collected here

ments ran from mid January to May in each year; a period giving rise to much acute medicine, and regarded, with the exception of autumnal influenza epidemics, as the busiest time of year.

\section{Questionnaire}

Students undertaking their second period of attachment, whether medicine or surgery, in $1992(\mathrm{~N}=133)$ and $1993(\mathrm{~N}=117)$ were asked to fill in an anonymous questionnaire (see Appendix 1) summarising their experiences on their second attachment only. Most of the items in the questionnaire had been identified by previous studies (see Chapters 2 and 3 ), by the literature and by a factor analysis of data from another London medical school, (Chesser \& Brett, 1989), to be representative of what staff and students felt was important in monitoring clinical attachments. The questionnaire concentrated on clinical and environmental issues as well as staff characteristics. The attachment acting as the focus of the questionnaire, the second of two undertaken by each student, took place in the 10 weeks immediately preceding the students' first year OSCE. The questionnaires were slightly different depending upon whether they addressed a surgical or medical firm, but the vast majority of items were common (see Appendix 1). Items included 'factual' data such as who taught them, how many hours of bedside, classroom and other teaching they had, how many patients there were available to clerk each week, how many patient encounters they had, how many of these were reviewed by staff, and whether firms had arrangements for in-course assessment. There were also items about how the students felt about the activities of the firm, such 
as how useful was being on-call, and so on. These items gave rise to a total of 34 indices of firm activity, covering the 6 main factors, discussed on $p 7$, and in Chapter 1, that were used in subsequent analyses.

The questionnaires were returned anonymously because that was the traditional way of collecting data in the College on clinical firms. Students receive a grade at the end of their attachments and were (and still are) hesitant to be critical of attachments unless protected by anonymity. However this introduced some problems into the method of analysis (see below).

Second attachments were chosen for monitoring because of their proximity to the examination. It was thought that this was the period when students would be preparing maximally for the examination and using their experiences productively. It would have been preferable to monitor both attachments for all students but experience in a previous year had shown that having to fill out two lengthy questionnaires inhibited the response rate from students. (In 1991 only 15\% of all questionnaires had been returned). However the group of firms providing teaching in the first attachment is identical to that available in the second.

\section{OSCE}

In May of each year students took a 25 station OSCE. OSCE reliabilities were .78 and .80 in 1992 and 1993 respectively. The OSCEs in both years were identical with the exception of one station, which was eliminated for the purposes of this study - hence the OSCE scores reported below are based on 24 common stations. Stations included male catheterisation (on a dummy), focused history taking, (e.g. for alcohol abuse), joint examination, abdominal examination, cardiovascular system examination, and so on. Test security was high. Students were not informed that the examination would be the same as the previous year, and on previous occasions (1990-1992), changes had been made each year. Although feedback had been given to previous years' students this did not entail written checklists or detailed descriptions of scoring schedules.

\section{Analyses}

The data on the firms from the individual anonymous questionnaires were averaged for each firm for each year. Hence the data for each firm were derived from between 3 and 10 students individual responses (see results for an explanation of how dichotomous data were treated). In addition 
further indices were included, like the number of students on each firm, and a dichotomous coding for year (1992 vs 1993), because year might conceivably have affected the pattern and quality of experience were used.

The data summarising experience on the firms were used in two ways. First, the mean indices for each firm were used as independent variable correlates of individual students' total score performance on the OSCE. Since the data on firms were collected anonymously, it was the group average for the firm that was used in these correlations. Students on the same firm thus had different OSCE scores (as individuals) but the same values (as a group) for the independent variables expressing characteristics of firms. (Any correlations found will therefore be conservative estimates since individual variations in experience within the firm contributing to OSCE variance are ignored.) Hence, at best, the resulting coefficients summarise the amount of variance attributable to firms in the OSCE score compared to that attributable to students. Analyses were performed for both years together and separately. All correlates with a value greater than 0.15 were selected for entry into a multiple backwards stepwise regression analysis in which firm characteristics were used as predictors of OSCE scores across both years.

In the second analysis, those indices contributing to the factors identified by Chesser and Brett (1989) were combined and the resulting six factors correlated with OSCE scores across both years.

\section{Results}

\section{OSCE}

The distribution characteristics for the OSCE for the 1992 and 1993 cohorts of students are given in Table 2. No significant difference overall was observed, apart from a tendency for the 1993 test to produce a lower standard deviation. This suggests test security was at least adequate. It

Table 2. Distribution characteristics (Means, sd's etc) of 1992 and 1993 cohorts on 24 station OSCE.

\begin{tabular}{llllllll}
\hline Year & Mean & SD & SE & Skew & Kurtosis & Min & Max \\
\hline $1992(\mathrm{~N}=136)$ & 69.61 & 7.68 & 0.65 & -.27 & -.27 & 48 & 85 \\
$1993(\mathrm{~N}=120)$ & 69.28 & 5.56 & 0.51 & -.31 & -.28 & 54 & 82 \\
Difference & 00.33 & & & & & & \\
\hline
\end{tabular}


was therefore reasonable to combine the two years for the purposes of the regression analysis as long as a year coding variable was included in the regression analysis.

\section{Questionnaires}

Ninety three (70\%) and 86 (73\%) students returned questionnaires in 1992 and 1993 respectively. There were large differences in reported clinical experience between individual firms in both years. Some firms had much higher average workloads and student activity levels than others. As an example only, and to save space in reporting largely negative findings (see below) the mean indices on 6 characteristics (out of 34 measured) for different firms in 1992 and 1993 are given in Table 3. In particular, examples show the different data types collected. For the data in column 2 students were asked to give definitive answers; the indices vary according to how many students on the firm experienced the introductory talk. In column 4 students were asked to give actual numbers of patients available; the index represents the mean value for the firm. In column 6 students were asked to rate their experience on a 1-5 scale; the index represents a mean value on a 5 point scale.

Reading down the table the reader can draw an impression of the extent of differences between attachments - the six items chosen are typical of the 34 indices. There are moderate to large differences between firms on some items. There were also moderate differences between recorded experience of students within firms on some indices (not shown in Table). For example in 1992 Firm 11, a moderately 'busy' firm, had a mean index of 15 patients per week available. The within-firm standard deviation for this value was 12.2 from 4 students giving individual returns of $5,5,20$ and 30 patients. On the other hand, Firm 12 in 1992 had 6.5 patients per week with a standard deviation of 4.6 from 2 students returning values of 3 and 10 patients. Although the sd's are high, there is an order of magnitude difference between firm 11 and 12 in the availability of patients.

There were also moderate to high positive correlations of mean indices of firms' activity between 1992 and 1993. Out of 34 correlations, 25 were positive (from 0.13 to 0.84 ) and 9 negative (from -0.06 to -0.43 ). The most stable across the two years were those relating to teaching input and workload, such as number of hours of bedside or classroom teaching available and patient availability. The least stable were those relating to student input and those characteristics determined centrally by the medical College, such as the amount of input on firms made by students 
Table 3: Examples of characteristics of firms as rated by students in 1992-3 after their second attachment. See Appendix 1 for complete questionnaires. (6 only of 34 possiblecharacteristics are included in this table). Medical firms are marked with an asterisk, the remainder were surgical.

\begin{tabular}{|c|c|c|c|c|c|c|c|c|c|c|c|c|}
\hline \multirow[t]{2}{*}{$\begin{array}{l}1 . \\
\text { Firm } \\
\text { Number } \\
*= \\
\text { Medical }\end{array}$} & \multicolumn{2}{|c|}{$\begin{array}{l}2 . \\
\text { Introductory } \\
\text { Talk Given? } \\
\Upsilon_{(1=y e s,} \\
0=\text { No; } \\
\text { Indexes less } \\
\text { than } 1 \\
\text { indicate not } \\
\text { all students } \\
\text { received } \\
\text { introduction) }\end{array}$} & \multicolumn{2}{|c|}{$\begin{array}{l}3 . \\
\text { Did Students } \\
\text { have a written } \\
\text { timetable } \\
\text { (see I) } \\
\end{array}$} & \multicolumn{2}{|c|}{$\begin{array}{l}4 . \\
\text { Number of } \\
\text { PatientsAvail- } \\
\text { able to Clerk } \\
\text { each week } \\
\text { \&(Students } \\
\text { asked to give } \\
\text { the actual } \\
\text { number) }\end{array}$} & \multicolumn{2}{|c|}{$\begin{array}{l}5 . \\
\text { Number of } \\
\text { Patients } \\
\text { clerked } \\
\text { fully per } \\
\text { week } \\
\left(\text { see }^{\S} \text { ) }\right.\end{array}$} & \multicolumn{2}{|c|}{$\begin{array}{l}6 . \\
\text { How useful } \\
\text { for your } \\
\text { learning did } \\
\text { you find } \\
\text { being 'on take' } \\
\text { (Students } \\
\text { asked to rate } \\
\text { on 1-5 scale) }\end{array}$} & \multicolumn{2}{|c|}{$\begin{array}{l}7 . \\
\text { Was there } \\
\text { an adequate } \\
\text { range of } \\
\text { patients for } \\
\text { you to see? } \\
\text { (see I) }\end{array}$} \\
\hline & 1992 & 1993 & 1992 & 1993 & 1992 & 1993 & 1992 & 1993 & 1992 & 1993 & 1992 & 1993 \\
\hline $1^{*}$ & 0.00 & 1.00 & 1.00 & 1.00 & 4.50 & 8.25 & 1.75 & 1.5 & 3.50 & 3.75 & 0.50 & 0.75 \\
\hline $2^{*}$ & 1.00 & 1.00 & 0.50 & 1.00 & 25.00 & 14.00 & 4.00 & 3.6 & 3.50 & 3.00 & 1.00 & 0.20 \\
\hline $3^{*}$ & 1.00 & 1.00 & 1.00 & 1.00 & 2.40 & 3.67 & 1.60 & 3.00 & 4.00 & 4.00 & 0.80 & 1.00 \\
\hline $4^{*}$ & 1.00 & 0.50 & 1.00 & 1.00 & 3.00 & 8.00 & 3.00 & 2.50 & 4.00 & 3.75 & 0.00 & 0.50 \\
\hline $5^{*}$ & 0.67 & - & 0.67 & - & 1.00 & - & 4.50 & - & 3.67 & - & 0.00 & - \\
\hline 6 & 1.00 & 0.80 & 1.00 & 1.00 & 4.14 & 10.40 & 1.43 & 3.60 & 3.57 & 3.00 & 0.29 & 0.80 \\
\hline 7 & 0.67 & - & 1.00 & - & 6.33 & - & 0.50 & - & 2.1 & - & 0.17 & - \\
\hline 8 & 0.22 & 0.43 & 0.30 & 1.00 & 4.80 & 2.00 & 4.20 & 2.67 & 3.4 & 2.57 & 0.50 & 0.29 \\
\hline $11^{*}$ & 1.00 & 0.67 & 1.00 & 1.00 & 15.00 & 9.00 & 7.40 & 2.00 & 3.60 & 3.67 & 1.00 & 1.00 \\
\hline $12^{*}$ & 0.33 & 一 & 1.00 & - & 6.50 & 一 & 6.00 & - & 3.67 & - & 0.33 & - \\
\hline $13^{*}$ & 0.80 & 0.33 & 1.00 & 1.00 & 12.60 & 26.7 & 4.40 & 16.67 & 4.20 & 4.67 & 0.80 & 1.00 \\
\hline $14^{*}$ & 1.00 & 1.00 & 1.00 & 1.00 & 21.00 & 30.00 & 4.00 & 16.00 & 4.50 & 4.00 & 1.00 & 0.75 \\
\hline 15 & 0.50 & 1.00 & 1.00 & 1.00 & 2.75 & 10.5 & 1.50 & 6.50 & 3.25 & 4.75 & 0.00 & 0.50 \\
\hline 16 & . & 1.00 & & 1.00 & & 1.00 & 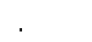 & 1.00 & & 2.50 & & 0.00 \\
\hline 17 & 0.00 & 0.00 & 1.00 & 0.60 & 11.50 & 13.20 & 2.25 & 2.40 & 4.50 & 2.80 & 1.00 & 1.00 \\
\hline 19 & 0.00 & 0.00 & 1.00 & 1.00 & 6.00 & 10.00 & 2.00 & 2.00 & 4.00 & 3.00 & 1.00 & 1.00 \\
\hline 20 & 1.00 & 1.00 & 0.00 & 0.20 & 20.00 & 13.75 & 4.00 & 1.60 & 3.00 & 4.20 & 1.00 & 1.00 \\
\hline 22 & 1.00 & 0.67 & 1.00 & 1.00 & 37.50 & 30.00 & 4.50 & 12.67 & 3.50 & 4.67 & 1.00 & 1.00 \\
\hline $24^{*}$ & 1.00 & 1.00 & 1.00 & 1.00 & 4.00 & 5.40 & 3.33 & 3.00 & 4.00 & 4.40 & 0.67 & 0.60 \\
\hline $25^{*}$ & 0.67 & 1.00 & 1.00 & 1.00 & 5.00 & 5.25 & 3.33 & 2.67 & 3.50 & 4.25 & 1.00 & 0.75 \\
\hline 26 & 1.00 & 0.83 & 1.00 & 0.83 & 2.00 & 3.83 & 2.00 & 2.5 & 5.00 & 3.20 & 0.00 & 0.17 \\
\hline 27 & 1.00 & 1.00 & 0.20 & 0.40 & 9.17 & 19.00 & 2.11 & 2.40 & 3.80 & 5.00 & 1.00 & 1.00 \\
\hline 28 & 一 & 1.00 & - & 1.00 & - & 7.00 & - & 5.67 & - & 3.33 & - & 1.00 \\
\hline $29^{*}$ & 一 & 1.00 & - & 1.00 & - & 7.25 & - & 5.00 & - & 4.25 & - & 1.00 \\
\hline
\end{tabular}

themselves and the occurrence of firm-based assessments respectively. This suggests that while there was some variation from year to year, firm characteristics were moderately constant. 
Correlations of Indices (Firm characteristics) with OSCE Scores and Regression Analyses.

Correlations were performed initially between the data from second attachments and OSCE scores, for both years combined. In general, correlations between indices of firm activity and OSCE scores were low. Most were non-significant and many were numerically close to zero.

It may be argued that the OSCE results may not only depend upon the second period of attachment, but rather be influenced by both attachments. Since no direct measurement of first attachment characteristics were available and in the search for more positive findings the data on firms collected during the second period of attachment were used as indices of the activity levels of the first attachment (leading to a different configuration of the raw data for correlation) and these values correlated with the OSCE scores again. In this analysis it is thus assumed that the attributes of firms noted by students during their second attachment were similar to those that would have existed for their fellow students on the same firms 10 weeks before. This assumption might be reasonable because individual firm clinical activities are arranged and timetabled by the hospital and the staff for a whole year (or longer) and are usually invariant over a 20 week period. This analysis was thought plausible because activity on first attachments would be similar but different students would be attached to them. This might reveal primacy effects - the activity of students' first firm might contribute more to the development of skill than that on their second. The assumption that these values can be substituted is also tested by comparing the same firm from 1992 to 1993 (see p 79). Such correlations between the values of firm characteristics from 1992 to 1993 were shown to be high and positive. This suggests that substituting the second-period values for the first-period attachments is both feasible and valid since many indices gathered a year apart have high positive correlations. Nevertheless this method of sampling does not totally rule out the possibility that the second group of students on a firm may have had a somewhat different experience to the first group.

However these correlations were also low. The only variables with correlations $\geq 0.10$ for either first or second period of attachment are shown in Table 4. All other correlations were less than 0.10 .

In an effort to investigate the data further, indices were calculated for each specific combination of firms (first and second) based on averaging estimates for both firms derived from the data collected in the second firm. 
Table 4. Variables showing most, degree of correlation with Total OSCE Score

\begin{tabular}{|c|c|c|}
\hline Variable & First Firm & Second Firm \\
\hline Was there an introductory talk & 0.12 & 0.02 \\
\hline Was there a written timetable & -0.11 & -0.05 \\
\hline $\begin{array}{l}\text { Number of special investigations } \\
\text { on patients attended by students. }\end{array}$ & 0.15 & 0.02 \\
\hline Presence of tormal test of skill on firm & 0.02 & 0.13 \\
\hline Presence of formal test of knowledge on firm & 0.05 & $\left({ }^{*} \mathrm{p}<.01\right)$ \\
\hline Presence of other tests on firm & -.08 & 0.16 \\
\hline $\begin{array}{l}\text { Proportion of students feeling they achieved } \\
\text { progress on the firm }\end{array}$ & -.06 & 0.14 \\
\hline $\begin{array}{l}\text { Number of students on the firm } \\
\text { (actual number for each firm, first or second) }\end{array}$ & 0.08 & 0.13 \\
\hline
\end{tabular}

This yielded much more variability in the data on firms. These values represented estimates of groups of students passing through the same combinations of firms; there were 28 such combinations. These values were also correlated with OSCE scores. Hence an estimate of the total activity over both firms for all 34 indices was obtained. These correlations did not improve on those reported in Table 4.

Variables representing the factors identified by Chesser and Brett (1989) were constructed by adding the various indices for the items loading on those factors. Correlations were again no better than those for the individual indices. Separate analyses for both factor scores and individual indices were performed for 1992 and 1993 separately. Although correlations with individual indices became larger and more positive for 1993, the opposite occurred for 1992. This was taken to be indicative of the problem with using data in a single year, and not controlled in previous studies, that firms with high activity indices who also happen to have able students assigned to them will give rise to spurious correlations. The reason for combining the data from both years in the present study was precisely to minimise this effect.

Backwards stepwise regression analyses were performed for those variables listed in Table 4 and for factor scores. However the maximum proportion of variance explained by any combination of indices or factors for either year was $23 \%$. These data are not, therefore, reported. The activity index variables were investigated for deviant distributions and unusual properties. Although some, calculated from originally 
dichotomous data, such as columns 1,2 and 6 in Table 3 , were clearly non-normal, and others had been derived from students reporting different degrees of experience within the same firm, most approximated normal distributions.

However in 1993 another test - a workbook assignment (see Cushing et al 1992, Jolly et al, 1994) that students had to comprehensively examine, take a history from and describe the psycho-social context of a ward-based patient - was available for use as a covariate to control ability level. This assignment correlated 0.28 with OSCE score ( $8 \%$ variance). Therefore a forwards stepwise regression was carried out using the workbook score as first entry, and using all other available variables as potential entries into the equation. This yielded a solution that included only 2 further variables: the usefulness of being 'on take' contributed a further $9 \%$ variance, and whether students had a test of knowledge on their attachment, which contributed another $5 \%$. The amount of unique variance attributable to the workbook assignment after regression increased from $8 \%$ to $9 \%$.

\section{Discussion}

There are two main constraints on the interpretation of the data; the insufficiency of the measurement and the possibility that students can overcome numerous obstacles to or difficulties in learning whatever the environment.

There are three main problems with the data. First, the accuracy (reliability) of the indices for each firm varies in the data, due to the fact that two firms (in 1993 only) had only 3, while others had from 6-10 students attached. The return rate for the questionnaires (approx. 72\%) means that indices were calculated on the basis of data from 2 students only from one of the firms (in 1993). Wolfhagen, (1993) has suggested that about 10 students are required to give accurate estimates of the quality of clinical attachments ( 138 ), where the measurements are treated as random factors (Cronbach et al, 1972). However, the data reported here represent estimates from $70 \%$ of the students on attachments which occurred only twice per year, and, for the estimates of the second attachment only, almost all the data available were collected. This estimate could be viewed therefore as a fixed factor, but this might limit the generalisability of these findings. 
Second, students not returning a questionnaire may have had vastly different experiences from those who did, but there is no way of knowing. Comparison of the non-response group to see if their OSCE scores are representative of the whole year is not possible because all questionnaires were returned anonymously.

Third, the questionnaire is biased towards workload and teacher activity. It does not reflect as many indices of student activity as are contained, for example, in the studies by Wolfhagen, (1993). However the primary purpose of the questionnaire was to monitor activities on firms that could be changed or avoided, like low patient loads and lack of bedside teaching and to give feedback to staff.

Even so, given the level of measurement possible, some differences were shown between firms, and in study 1 , the OSCE was shown to be sensitive to relatively minor curricular differences at a group level.

Hence the remaining issue is the extent to which students might have devised strategies to overcome inadequate firm-based experiences. Despite the inability to track individual student experience, there were, nevertheless, large differences between firms on many of the indices measured, and although there were variations between individual students' experiences within firms, students were often reporting experience of the same order within such a firm. For example in Table 3, students on average reported 25 and 14 patients per week available for clerking on Firm 2 in 1992 and 1993 respectively, but the corresponding values for Firm 24 were only 4 and 5.4 . Such differences might suggest that, if the case for more and better clinical exposure is in any way cogent, stronger relationships should be found between such indices and OSCE scores. This was not the case. Students within any firm or combination of firms performed highly variably on the end of year OSCE. Even if it were possible in the current study to measure individual students' experience more precisely, it is difficult to envisage the correlations increasing by much. Variation between firms is, on the whole quite large, (e.g. see Table 3 ), and that within firms quite moderate by comparison. Essentially the data suggest that the overriding determinants of an individual student's OSCE score are factors idiosyncratic to the student and unrelated to those features of firms measured in the current study. The fact that data for individual students' experiential histories were not available in a form that would enable direct correlation with their examination results may mask the fact that students employ highly variable ways of learning within 'good' or 'bad' environments. 
This view is supported by a recent study by Harrell et al (1993). They collected data on a total of 5,940 encounters between patients and a cohort of 60 third year (first clinical year) medical students. Students recorded, for each encounter, a log of activities in 15 different areas. They also recorded their confidence in dealing with the patient's problem. The activity indices were regressed onto the confidence data. Only three significant factors were found. The degree of responsibility assumed by the student for the patients management explained $40 \%$ of the variance in confidence scores, and prior exposure to the problem and completion of laboratory studies on the problem contributed $8 \%$ and $6 \%$ respectively. However, the authors were dealing with student perceptions only not with performance criteria.

The results of the current studies are frankly disappointing. Certainly they point to the need of monitoring individual student activity much more closely. Only then will progress towards the discovery of key activities be possible. However they also suggest that commonly held ideas about the strength of the relationship between clinical experience and learning may be challenged. There must be a missing link between the delivery of clinical education and the development of clinical skill that is not dependent merely on the quantity and quality of the clinical experience itself. Throughout the book data suggest that this link is determined by characteristics linked more to the individual student's learning history, or by the assessment systems, and are not simple functions of clinical activity. These factors may also not be recognised by students. Most of the work on student evaluation of clinical teaching has been done in order to monitor 'the curriculum'. Students in our and other institutions are adamant that they cannot learn without certain conditions in place. These conditions are exactly those examined here and in other studies. The fact that we cannot show strong correlations between activities designed to encourage certain types of behaviour and those behaviours should be of concern to all, because it challenges the essence of clinical education and its structure.

The possibility that students employ compensation startegies to overcome deficiencies in experience or teaching should be the focus of more rigorous study. 


\section{References}

Anderson DC, Harris IB, Allen S, et al. (1991) Comparing students' feedback about clinical instruction with their performances. Academic Medicine, 66, 29-34.

Chesser A and Brett M. (1989) Clinical Teaching in Context: A factor analysis of student ratings. Research in Medical Education. Proc. 28th Annual Conference, 49-54. Washington: AAMC.

Cohen JA. (1960) Coefficient of agreement of scales. Educational and Psychological Measurement, 20, 37-46.

Cordeiro FM, Jolly BC and Dacre JE. (1993) The effect of formal instruction in ophthalmoscopy on medical student performance. Medical Teacher, 15, 321-25.

Cronbach LJ, Gleser GC, Nanda H and Rajaratnam N. (1972) The dependability of behavioural measurements: theory of generalisability for scores and profiles. New York: Wiley, 1972.

Cushing A, Jolly BC, Bowden A and Dacre J. (1992) The assessment of communication skills in OSCEs. in Hart I, Harden, RMcG and Mullholland H. (Eds) Approaches to the Assessment of Clinical Competence. Proceedings of 5 th Ottawa Conference on Medical Education, Dundee, 1991.

General Medical Council. (1980) Recommendations on basic medical education. London: GMC Education Committee, 1980.

Harden, R McG and Gleeson F. (1979) Assessment of clinical competence using an objective structured clinical examination (OSCE). Medical Education, 13, 41-51.

Harrell PL, Kearl GW, Reed EL, Grigsby DG and Caudill TS (1993) Medical students confidence and the characteristics of their clinical experiences in a primary care clerkship. Academic Medicine, 68, 577-9.

Higgin JR and Harasym PH. (1992) Using the OSCE to identify strengths and weaknesses in learning at three teaching hospitals. in Hart I, Harden, RMcG and Mullholland H. (Eds)Approaches to the Assessment of Clinical Competence. Proceedings of 5th Ottawa Conferenceon Medical Education, Dundee, 1991.

Jolly BC, Cushing A, Dacre J, et al. (1994) The validity and reliability of a workbook-based assessment of clinical and communication skills. Paper to be presented at the 6th Ottawa Conference on Medical Education, Toronto, June 1994.

Mattern WD, Weinholtz D and Friedman C. (1983) The attending physician as teacher. New England Journal of Medicine, 308, 1129-1132.

Nelson MS and Traub S. (1993) Clinical skills training of US medical students. Academic Medicine, 68, 926-8.

Schön DA. (1987) Educating the reflective practitioner. San Francisco: Jossey Bass.

Thatcher PG. (1991) Undergraduate medical education, British Medical Journal, 302, p306.

van Selm J. (1985) The undergraduate student and the study of ophthalmology, South African Medical Journal, 68, 206-8.

Wolfhagen I. (1993) Kwaliteit van klinisch onderwijs (Quality of Clinical Education). Maastricht: University of Limburg. 
Chapter 7

Discussion and Conclusions 


\section{DISCUSSION AND CONCLUSIONS}

\section{Introduction}

In the preceding chapters several major themes have emerged. In Chapter 1 , the role of clinical education was placed in a historical perspective, demonstrating that the equilibrium between clinical work and theoretical study was affected by a number of factors, frequently including the power, influence and interests of the local scientific or hospital-based community. In addition it was shown, and reinforced in subsequent chapters, that common tacit assumptions about the role and operation of clinical teaching, are often in error. For example, clinicians differ on what they see as the purpose and the essence of clinical work and teaching, and students' experience is equally variable, with piecemeal exposure to topics and patients dependent both on hospital location and individual clinical unit the "minestrone model". Moreover, the image of students' clinical work propagated by physicians, as being directly analogous to problem-basedlearning was also challenged, largely by research in medical sociology. Thus, the main thrust of research on clinical teaching was misguided; it focused, until recently, too often on the activities of the clinical teacher and not enough on the context, or on what happened to or was provided by the student.

In Chapters 2 to 6 different research studies have endeavoured to concentrate on some of these missing features, initially through the perceptions of staff and students and then through attempts to link the experiences of students to their performance on assessment tasks. However Chapter 6 showed that it is difficult to demonstrate direct relationships between clinical experience and outcome.

Here a distillation of the results, synthesising them with previous research, will be undertaken so as to provide guidelines for course planners and clinical teachers, and some indications for future research. This will be done under two headings:

What makes a good clinical education?

What is the relationship beturen clinical education and outcome?

Within these topics the roles of teachers, institutions and students in clinical education in the hospital setting will be described in terms of their contributions to the definition of the curriculum, educational processes and assessment strategies. It is tempting to add a fourth - the role of 
patients. But, as yet, the increasing priority given to the rights and preferences of patients has not yet endowed them with sufficient power over curricular issues, although their use as a group is increasing in assessments. Their involvement will be dealt with under that of the institution.

\section{What Makes a Good Clinical Education?}

\section{The Definition of the Curriculum}

The hospital-based curriculum remains poorly defined. In particular the demarkation and trade-off between learning and working is unclear. In Chapter 2 it was evident that a large number of acute conditions and practical procedures were not addressed in the undergraduate curriculum, although the skills associated with them were expected to be in place soon after. Many of these, e.g. respiratory arrest, ischaemic limb, lumbar punctures, chest drains, are probably confronted only in the hospital setting. Thus considerable effort is needed to map out the boundaries between and the requirements of the undergraduate and house-year phases of training. In particular, the expectations of staff for both students' learning and working in the hospital setting need much clearer definition and, above all, consensus. This consensus should cut across the margins of individual clinical units.

The need for curriculum definition will become even more important as teaching moves out of the hospital ward environment into community activity. Institutional goals and appropriate means to deliver them will be necessary features shared between medical schools, hospitals and general practices. This means, in effect, dividing and assigning responsibility for certain characteristics of professional development to each sector, and not allowing a laissez-faire. Such an attitude has been the main factor in the haphazard attainment of clinical skill seen in these and other studies. In future hospitals should concentrate on those features of clinical education that they are likely to be best at; the abilities related to acute medicine, technical skill, surgical procedures and academic and research development. ${ }^{1}$ Whatever ensues, the 'minestrone' model of clinical education should not be allowed to proliferate. There needs to be rational and

1 There is currently no rationale for this division. An early assessment of the prospective strengths and weaknesses of hospital versus other learning environments should be undertaken for this purpose. 
negotiated control of medical curricula based on a consensus model. Whether this should be seen as 'core vs options' or as merely a unifying process remains an open question.

For example, the contrast between the inefficiency of the minestrone model, and the potential of more structured approaches has been illustrated in this thesis. In chapter $2,38 \%$ of undergraduate respondents had failed to see greater than one third of the acute conditions listed in the questionnaire. This 'hole' in students' experience is increasing in size (McManus et al 1992), especially in medical schools in large cities. It is also known that difficulty with basic technical skills is a significant source of stress in house-officers (Calman and Donaldson, 1991). In contrast, in chapter 6 it was shown that students trained specifically in ophthalmoscopy outperformed those acquiring the skills vicariously on the wards. This suggests that it might be much more efficient to train students intensively, to performance criteria, in all aspects of clinical examination and patient investigation, thus freeing up subsequent time for academic and patient-management-based pursuits. At the same time many infrequently seen procedures and conditions are amenable to simulation. Hence much more effort needs to go into the establishment of patient- and mannequin-based simulation banks. Each medical school/hospital should have a skills laboratory, and clinical skills should be part of the curriculum definition. Students thus trained would be much more confident about approaching and examining patients, would find abnormalities sooner and allow clinical staff to concentrate on aspects of medicine of more interest to them. Although the characteristics of such training programmes need further research, one at least, should be that clinical units should take responsibility for ensuring that students leave their charge with a specified standard of performance in clinical skills.

In addition, students can and should assist in the process of clinical curriculum definition. Part of this important task, given the diversity of experience, is in curriculum monitoring (Chin, Cohen and Jolly, 1988) and in relation to quality assurance (HEFCE, 1993). Students' and graduates views on the content, structure and deficiencies in clinical education should be used formally in quality assurance procedures in medical schools. ( see above and Chapters, 2 \& 3). This notion is often criticised by teachers on the grounds that courses should not be structured on the basis of students' 'happiness' ratings. But in Chapter 3 it was shown that both undergraduate and post-graduate learners were able to distinguish between the enjoyability of courses and their usefulness or teaching quality. 
These emerging initiatives, such as quality assurance and quality assessment, (HEFCE, 1993) need to be generalised to clinical ssettings. A series of criteria could be devised that monitor and promote the delivery of quality in the clinical situation in teaching hospitals, communities and general practices alike (Wolfhagen, 1993).

\section{Educational Processes}

Very little is currently known about the best way to learn clinical skills and procedures, although some guidelines are available, (ATLS, 1993). The research in Chapter 2 was directed more towards initiating skillsbased training than defining its shape. Research in such issues is vital. The important immediate questions are:

1) What are the best ways of, and right times for, teaching skills?

2) Is there an order of learning skills which maximises learning efficiency?

3) What benefits to both patient and student are there of early skill acquisition? Such a study should be easy to accomplish in parallel track or skills-lab based curricula.

4) What is the minimum throughput of patients on which a skill is carried out to maintain quality of performance? The answer to such a question would enable practitioners to seek opportunities for practice, or refrain from practising when in skill deficit.

5) How quickly do skills decline?

Research on these topics is essential if progress towards a rational pedagogy for clinical expertise is to develop.

Another aspect of sound approaches to clinical teaching is the educational expertise of the clinical educator. Chapter 3 demonstrated that, although teachers have to teach relatively independently, they should be given the means to improve their teaching and to take more account of students' ways of learning. This will entail curriculum evaluation. However, using Chapter 4 as an example of such evaluation, in the long term it would be impractical to externally evaluate courses in such depth and breadth. Hence effort should be directed towards self- evaluation by clinical teachers. They need the educational skills to do this, but they also need to be able to analyze the context and environment in which learning takes place - to adopt the skills of the educational researcher (Stenhouse, 1975). This requires a working framework rewarding not only teaching per-se, but also the improvement of teaching, whether by self-, student- or peer evaluation. Such a context also requires considerable development on educational issues for all hospital staff who teach. Independent learning, 
as shown by Chapter 4, is difficult in a traditional institution - it needs support, guidance and flexibility. In particular, the use of constructive positive feedback ('saying it nicely'; $p$ 58) is an attribute that all clinicians must acquire in an environment which purports to encourage active independent learning.

Chapters 3, and 4 and the work of Fleming (1986) cited there, showed the dominant role of the clinical teacher in students' perceptions of what is important in clinical education. Teachers will need help and encouragement to wean students off dependency. Vos (1985) has shown quite clearly, that in most conventional curricula there is a curvilinear relationship between the amount of instructional (teacher initiated) time and the ratio of self- to instructional- time. This shows that high student self-study time is less likely in institutions with 6 or more contact hours per week. Further work in pre-clinical medicine (Gijselaers \& Schmidt, 1992), shows that although medical students' hours per week are much higher, those with more than 10 hours of contact time are unlikely to be spending significant time in independent study. The message is simple - cut down contact hours. However this work has not been generalised in clinical settings and further investigation is required.

Earlier research, outlined in chapter 1, has shown that educational clinical activity is often perceived differently by clinicians and students. In particular research on, as well as evaluation of, clinical teaching has concentrated on situations where the clinical teacher is dominant. Weinholtz et al (1986), in their study of effective teaching behaviours, demonstrated a negative correlation between teacher listening activity and ratings of effective teaching - the 'listening' physician was a poorer teacher! However in Chapters 3 and 4 programmes giving more responsibility to students were studied. In Chapter 3 students found it difficult to take control of a learning situation in which the teacher refused to participate as a repository of knowledge. In Chapter 4 , one of the teachers was clearly uncomfortable in allowing control to move from her to the students. There is undoubtedly a discontinuity between 'problem-based' contexts and those in 'traditional' clinical encounters in what should be seen as normative or desirable teacher behaviours. In the authentic problem-based clinical scenario, control must be passed to the student, as it is in other forms of PBL. This endeavour will entail further staff development, and probably more detailed and efficient student preparation, as well as attention to practical and ethical issues. 
The previous chapter showed that students differ in the experience they glean from the same attachments. Guidelines need to be drawn up for clinical activities. For example, teaching ward-rounds or outpatients should primarily be aimed at visiting the bedside (cf Mattern et al, 1983), observing students in interaction and problem solving activities (cf Bennard \& Stritter, 1989), giving constructive feedback to students, (Chapters $3 \& 4$,) and so-on. Perhaps clinicians as well as students would prefer guidance, both on how to structure teaching and on what to include. At the same time it is essential to monitor, during clinical attachments, what students are actually doing - the fact that some students can see twice as many patients on a firm as their colleagues should be a cause for concern. The difference between what is assumed to take place during education in hospitals and what actually happens is vast. Ward rounds, case conferences, clinical procedures, investigations and inter-professional activity are all available, but somehow (Chapters $2,3,4$ ) escape the involvement of all but the most industrious of students. Frameworks need to be developed to encourage students to develop clinical acumen. Such activities should enable maximal use to be made of increasingly limited ward-based activity. This may entail, apart from skills centres (see p 125), special rounds or outpatients, even student-run clinics, where students are given increased responsibility, with appropriate supervision, for patient investigation and management.

Chapter 3 highlighted the expectations of students, coming from a traditional pre-clinical environment, as being forceful in governing the mobilisation of their learning skills in the clinical phase. This was initially towards passivity and 'parrot fashion' learning. The influence of incoming students' characteristics on the educational process is described in most texts on curriculum design (Newble \& Cannon, 1991). However problembased schools seem more intent on detailed selection procedures designed to match students to courses. (Powis et al, 1988). In comparison many hospital-based traditional schools, in which students must (see Chapter 4) be active learners in the clinical phase to extract any benefit from the curriculum, seem prepared to allow both selection and pre-clinical courses to operate fairly independently from their main curriculum effort. In order for such anomalies to be eradicated a coherent policy on teaching, learning and assessment in the medical school needs to be developed and applied from admission to post-registration. This may mean further definition of the attributes expected of a clinically based learner, or closer entwinement of hospital-, basic-science- and community- based segments of the course. 
The structure of an institution would arguably have an important relationship to the type of curriculum delivered and the way that students are educated, although the studies reported here were unable to show precise links between clinical activity and outcome. However there is markedly little research on the relationship between institutional factors, (size, organisation, role) and clinical education. Study of parallel track curricula might enable development in this area (Tosteson, 1990), but reviews of active versus passive curricula (Schmidt, Dauphinee \& Patel, 1987; Block, Styles \& Moore 1990) have not really addressed institutional issues. Most UK schools are now divided into (up to) 40 departments each wishing to deliver its own portion of curriculum, usually in a hospital setting. The recent merging of institutions has led to rationalisation and multi-site working, even at the tertiary level. Hence the appropriate shape of organisations designed to foster and maintain direct involvement of students in patients' (ongoing, non-hospitalised) problems is not clear, but perhaps the medical school of the future will look more like New Mexico or Ismalia (Cairo), than Johns Hopkins or Cambridge.

In addition to better definition of curriculum responsibilties between postgraduate and undergraduate training, closer links need to be developed across educational processes. The notions of internes or famuli, depicted in Chapter 1, could perhaps be revived and used in clinical training much more effectively. Although increasing students' responsibility for their own learning is common in problem-based schools, especially in the basic-science components, it is not particularly encouraged in the clinical components of curricula in traditional schools, although much lip-service is paid to the issue. In an improved environment students would be made more accountable for certain activities bearing on clinical management. For example, students might be responsible for taking all incoming patients' histories prior to discussion with house officers and senior staff, or for monitoring fluid balance, nutritional status, and other dynamic conditions having academic as well as clinical pay-off. Rather than academic grand-rounds, perhaps students should be encouraged to run shadow ward rounds of their own. Staff could then attend to validate how well the students do in relation to their seniors' endeavours - possibly a much more useful approach to simulation of clinical activity. At the same time supervision of trainees is crucial, (p 30) to the development of skills and the confidence to use them.

Also institutions will need to mobilise patient support and interest to a greater degree than hitherto. If adequate teaching and assessment is to be undertaken against the background of a shrinking patient population, 
hospitals will need to develop simulated patient groups, patient support groups and patients in partnership with health initiatives, to assist with these tasks. Patients may eventually need paying for their services. This, in turn, will open up curricula more directly to local health care needs, and may generate pressures of its own.

\section{What is the relationship between clinical education and outcome?}

Chapter 5, especially in comparison with Chapter 6, demonstrated the effectiveness of assessment as a driving force in curricula. This has been confirmed also at the postgraduate level, (Wakeford, et al, 1992). On the other hand, in Chapter 4, the absence of summative assessment was seen as a positive advantage to learning by both staff and students. However in that study, summative assessment had been replaced, in most groups, by a highly energising formative assessment process. Students and staff exchanged comments about the shape and structure of their forthcoming presentations in a collegiate enterprise. The rules of this assessment system were almost totally covert; the main aim being to do a good presentation in an engaging and seemingly authoritative fashion. Such differences introduce interesting issues about the role and controlling influence of assessment in student- centred vs traditional clinical environments. The importance of assessment is that it confronts the student with an expectation about what is considered 'good' performance.

However a number of questions are apposite. If a formal assessment system had been in place in Toronto would the student-teacher exchange have been as lively? Why did the rounds work as an educational exercise and develop such a strong formative assessment component? There seem to be several contributing factors. Although not proven in Chapter 4, the group size of 40 for the rounds in one hospital (TWH) seemed preferable to 60 in the other. The smaller group seemed to activate cohesion and friendly rivalry between subgroups. Several students highlighted the fact that there was no 'fear of failure'. There was also constant feedback, of a supportive nature. And there was considerable leeway in the degree of independence given. This was coupled with discipline from the teachers, not in how the task was completed, but in exhortations to complete the task in difficult or challenging circumstances.

Clinical and technical skills, as well as patient examination and academic prowess should form part of the assessment programme mounted by any 
institution or national certifying body. The relationship between assessment and capacity or willingness to learn is becoming clearer. What is important for the institution, is to rationalise the assessment system so that it reflects appropriate goals and objectives of clinical education rather than the wishes of discipline-based groups. The lack of lucidity about the goals of clinical education may be one reason why, in Chapter 6, a clear relationship between the activities of students and their resulting capacities could not be demonstrated.

The failure of the analyses in Chapter 6 to demonstrate secure linkages between educational activities and outcomes may also lend weight to the notion, introduced by medical sociologists, that undergraduate clinical training is more of a socialisation process than an educational one, (Becker, 1961, Atkinson, 1977, 1981). If so, this highlights the importance of establishing good role models in clinical medicine, and of monitoring students attitudes during this important phase of development. This may have spin-off into the selection and training of clinical teachers. It also suggests that the purposes of clinical education may need broader as well as more precise definition.

Tools for developing valid and reliable assessments of clinical skills, although far from perfect, are now becoming much more sophisticated, (Newble, Jolly \& Wakeford, 1994). It is essential to generate criterion-referenced assessments and to monitor outcome on a cohort by cohort basis, so that inadequacies in skills can be detected and rectified. Technology is now becoming available to make such measures easier. Previously, for example, itemising OSCE scores would have been laborious and tedious for large cohorts. New optical scoring systems for clinical task proforma now make it very easy to track cohort deficiencies to individual items of procedure, such as the disposal of needles or the lack of courtesy to patients.

The data in Chapter 6 have shown that the variability in students' endeavour generally outweighs that of the institution to provide meaningful experiences. Students appear to benefit in equal measure from vastly different amounts of clinical exposure, while others gain differently from the same experience.

The main weakness of that study was in not being able to undertake analyses at the level of the individual student. The single most problematic barrier to the development of a sensible approach to teaching clinical skills is this difficulty, demonstrated in Chapters 5 and 6, of connecting clinical (educational) experience, in a variety of forms, to 
performance or competence. Although demanding, some success has been achieved in general higher education (Entwistle, 1992), through taxonomies of educational activity. For example learners have been shown to vary considerably in their approaches to the process of learning. The terms deep, surface, serialist, wholist, to name but a few, have been applied to different types of these approaches. The approaches have also been shown to be as dependent on curriculum issues as on the characteristics of the learners. Hence high workload, excessive course material, a lack of choice, poor support, and examinations which reward memorisation and regurgitation, have been suggested as causative factors in 'surface' processing of information (Gibbs, 1992). However the attributes of the deep- as opposed to surface-learner in the clinical setting, have not been studied in detail. For example one of the problems with inferences in Chapter 5, about the origin of higher scores for repeated stations in OSCEs, was that no measure was undertaken of how students prepared for the examination. Van der Vleuten et al, (1989) have highlighted undesirable behaviours on the part of students engaged in examination preparation. More research is needed on the effect that OSCEs have on student study; their time allocation, location of study, restriction of effort to certain skills, amount of practice and so on. Nor has clinical experience been tracked sufficiently at the individual student level to enable linkage to performance on assessments and in practice. This means not only monitoring more closely student activity on clinical attachments, but also studying the way that students attempt to store and use their clinical experience for their work and in preparation for their assessments. It also suggests that students should be provided with the means to benefit from the exposure they do receive by giving adequate feedback, facilitating reflection and encouraging students to seek out clinical opportunities for themselves. This responsibility should be shared between teaching and learning activities and the assessment system as well as the students themselves. 


\section{References}

Atkinson PA. (1981) The clinical experience: the construction and reconstruction of medical reality. Westmead: Gower.

Atkinson PA. (1977) The reproduction of medical knowledge, in Dingwall R, Heath C, Reid M and Stacey M. (Eds) Health care and health care knowledge. London: Croom Helm.

ATLS. (1993) Advance Trauma Life Support: Instructors Manual. Chicago: American College of Surgeons.

Becker HS, Geer B, Hughes EC and Strauss AL. (1961). Boys in White: student culture in medical school. Chicago: University of Chicago Press, 1961.

Bennard BC and Stritter FT. (1989) Teaching Medical Students in Ambulatory Clinics: Prescribed vs actual practice. Proceedings, Research in Medical Education, 1989, 141-146. Washington: Association of American Medical Colleges.

Block SD, Style CB and Moore GT. (1990) Can we teach humanism? A randomised controlled trial evaluating the acquisition of humanistic knowledge, attitudes and skills in the New pathway at Harvard Medical School. Boston: Mimeo Harvard Medical School.

Calman KC and Donaldson M. (1991) The pre-registration house officer year: a critical incident study. Medical Education, 25, 51-9.

Chin V, Jolly BC and Cohen A. (1988) Use of a Database for Curriculum Monitoring - a Clinical application. Paper presented to the Conference on the Application of Computers to Medical Education. University of Toronto, Canada, April 1988.

Entwistle N. (1992) The impact of teaching on learning outcomes in higher education. Sheffield: CVCP Universities' Staff Development Unit.

Fleming W. (1986) Good professional reasons for poor educational practice: the interaction of medical and educational work in presenting cases during junior clinical clerkship. Paper presented to Society for Research in Higher Education, Imperial College London. Proceedings SRHE, Guildford: SRHE Publications.

Gibbs G. Improving the quality of student learning. Bristol: Technical and Education Services.

Gijselaers WH and Schmidt HG. (1993) Investeren in instructietijd: spaarzaamheid loont de moeite. Onderzoek van Onderwijs, 4, 57-60.

HEFCE. (1993) Guidelines on Quality Assurance: notes for higher education institutions. London: Higher Education Funding Council for England.

MacManus IC, Sproston KA, Winder BC and Richards P. (1992) The experience of medical education: changing perceptions of final year students. Paper presented at Fifth Ottawa International Conference on Assessment of Clinical Competence, Dundee, September, 1992.

Mattern WD, Weinholtz D and Friedman C. (1983) The attending physician as teacher. New England Journal of Medicine, 308, 1129-1132.

Newble DI, Jolly BC and Wakeford RE. (Eds) (1994) The certification and recertification of doctors: issues in the assessment of clinical competence. Cambridge: Cambridge University Press.

Newble DI and Cannon R. (1991) A Handbook for Clinical Teachers. (2nd Ed) London: MTP Press (1991).

Powis DA, Neame RLB, Bristow T and Murphy LB. (1988) The objective structured interview of medical student selection. British Medical Journal, 296, 765-8.

Schmidt HG, Dauphinee WD and Patel VL. (1987) Comparing the effects of problem-based and conventional curricula in an international sample. Journal of Medical Education, 62, 305-15. 
Schön DA. (1987) Educating the reflective practitioner. San Francisco: Jossey Bass.

Stenhouse L. (1975) An introduction to curriculum research and development. London: Heinmann.

Thatcher PG. (1991) Undergraduate medical education, British Medical Journal, 302, p306.

Tosteson DC. (1990) New pathways in general medical education. New England Journal of Medicine, 322, 234-8.

Van der Vleuten C, van Luijk $S$ and Beckers H. (1989). A written test as an alternative to performance testing. Medical Education, 23, 97-107.

Vos P. (1985) Zelfstudie als functie van onderwijsdeelname: hypothesetoetsing. Tijdschrift voor Onderwijsresearch, 10, 228-38.

Wakeford RE and Southgate L. (1992) Postgraduate medical education: modifying trainees study approaches by changing the examination. Teaching \& Learning in Medicine, 4, 210-13.

Weinholtz D et al. (1986) Effective attending physician teaching. Research in Medical Education. Proc. 24th Annual Conference, Association of American Medical Colleges, 151-156.

Wolfhagen I. (1993) Kwaliteit van klinisch onderwijs (Quality of Clinical Education). Maastricht: University of Limburg. 


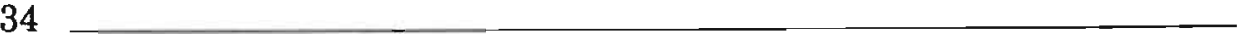




\section{Samenvatting}

Klinische praktijkervaringen vormen een belangrijk onderdeel van de medische opleiding. Deze ervaring wordt opgedaan in verschillende leersituaties, zoals co-assistentschappen, onderwijs aan het bed of in de polikliniek, vaardigheidstraining en wetenschappelijk werk in een klinische context. In vergelijking tot de bestaanshistorie van de geneeskunde heeft het praktisch medisch onderwijs zich pas recent ontwikkeld. De doelstellingen van onderwijs aan het bed waren zelden expliciet en de onderwijsaanpak is meer gegroeid uit historische gewoonten dan uit rationele overwegingen. Het doel van dit boek is de sterke en zwakke punten van het praktisch medisch onderwijs in het ziekenhuis in perspectief te zetten.

Tussen de dertiende en de zeventiende eeuw bestond de opleiding tot arts vrijwel uitsluitend uit theoretische vorming. De opkomst van het empirisme in Europa bracht hierin verandering. De behoefte om theoretische opvattingen te verifiëren in de praktijk leidde tot het ontstaan van de klinische praktijk en het klinisch onderwijs. Er heeft altijd een spanning bestaan tussen de hoeveelheid praktische en theoretische training die noodzakelijk werd geacht in de opleiding tot arts. Deze spanning werd vaak niet expliciet onderkend en heeft ertoe geleid, dat er geen geleidelijke ontwikkeling van een theoretische basis voor klinisch onderwijs heeft plaatsgevonden. De gebruikte onderwijsmodellen hebben zich tussen de extremen van uitsluitend theorie, dan wel uitsluitend praktijk bewogen en zijn zelden gebaseerd op onderwijskundige uitgangspunten.

Het klinisch onderwijs van vandaag is een mengeling van twee modellen, die zich in de Europese geschiedenis ontwikkeld hebben: het leermeestergezel model (apprenticeship) en het universitaire model, zoals dat ontstond in Edinburg, Londen, Wenen en Padua. Kenmerken van het eerste model zijn de een-op-een leersituatie onder strikte supervisie met grote aandacht voor de praktijk van de gezondheidszorg. Het tweede model wordt gekenmerkt door perioden van theoretische studie, colleges en patiëntendemonstraties voor grote groepen studenten.

In de huidige studie geneeskunde wordt praktisch medisch onderwijs vrijwel overal voorafgegaan door een uitgebreid curriculum waarin de 
basisvakken centraal staan. Deze trend heeft zich rond de eeuwwisseling in de Verenigde Staten ontwikkeld naar aanleiding van het rapport van Abraham Flexner, gebaseerd op diens ervaringen met het Duitse medische onderwijs.

Deze ontwikkelingen, en de enorme toename van wetenschappelijke kennis, hebben helaas geleid tot een aantal tekortkomingen in het onderwijsproces, die pas nu onderkend worden: een grote scheiding tussen basisvakken en klinische vakken, een verbrokkelde praktijkervaring in deelspecialismen en een weinig generalistische docentenrol. Ook veroorzaakte het een verwarring ten aanzien van het onderscheid tussen doelen, middelen en resultaten van klinisch onderwijs. De discussie hierover wordt verder gecompliceerd door de noodzaak om afgestudeerden voor te bereiden op het veeleisende "internship", een periode die ingesteld is met een onderwijsdoel, maar feitelijk veelal een zelfstandige gezondheidszorgtaak blijkt in te houden. De schaarse literatuur en onderzoeksgegevens over klinisch onderwijs ondersteunen de gedachte, dat de ingrediënten van het onderwijsdieet moeilijk vast te stellen zijn en leiden tot de conclusie, dat het hier gaat om een minestrone model voor de ontwikkeling van medisch onderwijs. Meer recente onderzoeksgegevens, waaronder deze dissertatie bevestigen dit. De klinische ervaring van studenten blijkt divers, ongereguleerd, opportunistisch, afhankelijk van de docent en van sterk wisselende kwaliteit.

Deze dissertatie poogt een antwoord te formuleren op de vraag: waaruit bestaat goed klinisch onderwijs en wat is de relatie tussen de onderwijservaringen en studieresultaten?

Als startpunt voor het onderzoek werd nagegaan hoe pas afgestudeerden hun voorafgaand klinisch onderwijs beoordelen tegen de achtergrond van de taken, die zij in hun functie als intern moeten vervullen. Vervolgens is onderzocht welke aspecten studenten in hun laatste jaar en afgestudeerden belangrijk vinden in klinisch onderwijs. Ook is nagegaan in hoeverre een sterkere betrokkenheid van studenten effect heeft. Tenslotte is onderzocht welke effecten het gebruik van evaluatie-instrumenten heeft op het leren van klinische vaardigheden en welke relatie er bestaat tussen onderwijservaringen en resultaten op vaardigheidstoetsen.

In hoofdstuk twee worden de resultaten gepresenteerd van een onderzoek met behulp van vragenlijsten en interviews naar de opvattingen van pas afgestudeerden over het klinisch onderwijs in relatie tot hun huidige functie. De gegevens van 113 house-officers, afkomstig van twee Londense medische faculteiten wijzen op een globale tevredenheid over het genoten 
onderwijs. Praktische ervaringen worden door de meeste respondenten als essentieel aangemerkt voor het vervullen van de huidige functie. $\mathrm{Zij}$ constateren echter ook duidelijke tekortkomingen door gebrek aan ervaring met sommige ziektebeelden en medische handelingen, en tekortkomingen in communicatievaardigheden. Afgestudeerden geven aan meer ervaring gewenst te hebben als student in resuscitatie, lumbaal puncties, intubaties en in de behandeling van ketosis, astma aanvallen, infarcten en benauwdheid. Het onderzoek wijst uit dat er mogelijkheden zijn voor de ontwikkeling van klinische vaardigheden in een gestructureerde vorm tijdens co-assistentschappen. Verder wijst het onderzoek uit, dat er behoefte is aan een betere afstemming tussen het klinisch onderwijs enerzijds en de doelstellingen en de eisen van het internship anderzijds.

In hoofdstuk drie worden de data van de bovenvermelde studie en uit twee andere studies gebruikt om sommige belangrijke, controleerbare karakteristieken van de klinische leeromgeving te identificeren. De nadruk ligt op de invloed die de docent kan uitoefenen versus de ongecontroleerde activiteiten in de klinische werkomgeving. Uit de literatuur blijkt, dat zowel de docent als de omstandigheden het leren in een klinische omgeving beïnvloeden. Studenten blijken in staat om een duidelijk onderscheid te maken tussen de aantrekkelijkheid van een leerervaring en de kwaliteit ervan. "Goed" onderwijs wordt gekarakteriseerd door heldere presentaties met een interessante inhoud, interesse voor de student en lage afwezigheid van staf en studenten bij activiteiten. "Slecht" onderwijs werd gekarakteriseerd door weinig verantwoordelijkheid geven aan de student, weinig kans bieden om praktische handelingen door studenten te laten doen, gebrek aan sfeer en een gebrek aan openheid om problemen van studenten te bespreken. Ook het specialisme van de stage-afdeling, interne geneeskunde of chirurgie, is van invloed op het kwaliteitsoordeel van studenten. Afgestudeerden meten het nut van het klinisch onderwijs vooral af aan de doceerkwaliteiten van de docenten en de hoeveelheid praktisch werk, dat men mocht doen. De belangrijkste voorwaarde voor het leren in een klinische cmgeving wordt echter supervisie en feedback geacht.

De laatste studie beschrijft de problemen, die studenten ondervinden bij de start van hun klinisch onderwijs. Deze worden veroorzaakt door het gegeven, dat leren in een praktijksituatie een andere leerbenadering veronderstelt, dan in het voorafgaande onderwijs het geval is.

De rol van de student in de ziekenhuisomgeving staat centraal in hoofdstuk vier. Grand Rounds (GRs) zijn een gebruikelijke vorm van onderwijs in ziekenhuizen, waarbij een of twee patiënten met interessante of moeilijke problematiek uitvoerig besproken worden door een multi-disciplinair 
forum. GR's speciaal gericht op studenten werd in 1987 ingevoerd in twee ziekenhuizen, die geassocieerd zijn met de University of Toronto. Met behulp van vragenlijsten, interviews en observaties werd deze vorm van onderwijs geëvalueerd. Uit het onderzoek, waarbij 78 docenten en studenten betrokken waren, bleek dat het doel van de GRs, het bevorderen van studie op eigen initiatief, bereikt werd, maar dat de interactie tussen studenten en de aanwezige staf gedurende de bijeenkomsten minder was dan bedoeld. Studenten besteedden ongeveer 10 uur aan voorbereidende studie-activiteit. Hun presentaties waren kwalitatief goed en werden op een stimulerende wijze begeleid door docenten. Deze resultaten wijken af van ervaringen gerapporteerd in een studie in Engeland. Hierbij bleken studenten weinig gestimuleerd te worden door hun docenten. Een en ander wijst op het belang van een goede leeromgeving voor zelfstandig leren.

Hoofdstuk vijf rapporteert over een onderzoek naar de effecten van het gebruik van evaluatie-instrumenten op bepaalde aspecten van medische competentie. Het onderzoek toont de effecten van het herhaald gebruik van een onderdeel van een objectief gestructureerd klinisch examen (OSCE) over een periode van twaalf jaar bij verschillende groepen medische studenten in hun laatste studiejaar. De studie werd uitgevoerd aan de University of Adelaide. Uit de variantie-analyse op de resultaten van 16 toetsonderdelen die tweemaal werden gebruikt, en 6 onderdelen die vaker werden gebruikt, blijkt dat er een significante verbetering van 5-7\% op het toetsresultaat per herhaalde afname wordt geboekt. In tien jaar tijd verbeterde het toetsresultaat op een onderdeel, dat vijfmaal werd gebruikt van $45 \%$ tot $80 \%$. Hiermee wordt het effect, dat evaluatie op het leergedrag van studenten kan hebben duidelijk gedemonstreerd. Effecten kunnen zowel positief als negatief zijn, afhankelijk van de situatie en de student. Kennis over de wijze waarop evaluatie het gedrag van studenten stuurt kan op constructieve wijze gebruikt worden om efficiënt en effectief richting te geven aan het leren. Daarvoor is een nauwkeurige afstemming nodig tussen doelen en middelen in het onderwijsprogramma en in het examenprogramma.

De voorafgaande hoofdstukken tonen, dat studenten en pas afgestudeerden een duidelijk beeld hebben van de eisen die aan goed klinisch onderwijs gesteld kunnen worden. Bovendien blijkt evaluatie een duidelijk effect op de kwaliteit en kwantiteit van het leren te kunnen hebben. De precieze relatie tussen leerervaringen en leerresultaten is echter nauwelijks onderzocht: wat zijn de meest voedzame bestanddelen in de minestrone van het klinisch onderwijs? Hoofdstuk zes bevat twee studies waarin deze relatie wordt onderzocht. Het onderzoek handelt over de relatie 
tussen de aard van de klinische leerervaringen en de resultaten op OSCE vaardigheidstoetsen. Het onderzoek werd gedurende drie jaar uitgevoerd in een traditioneel academisch ziekenhuis. Om de relatie tussen ervaring en leerresultaten te kunnen leggen dient men te beschikken over een deugdelijk criterium. Daarom werd nagegaan of een OSCE een bruikbare en gevoelige indicator is om veranderingen in het onderwijs te meten. In 1991 ontving een deel van een jaargroep studenten een speciale training in een klinische vaardigheid (oogspiegelen). $\mathrm{Na}$ twee maanden werden duidelijke verschillen in resultaten vastgesteld in het vaardigheidsniveau van getrainde en niet-getrainde studenten tijdens een OSCE voor oogspiegelen, maar niet voor andere vaardigheden. Het blijkt derhalve mogelijk om verschillen in leerervaring met een OSCE vast te stellen. Op basis van dit resultaat werd de relatie onderzocht tussen de karakteristieken van de leerervaringen van studenten tijdens hun co-assistentschappen en hun resultaten tijdens een OSCE. De onderwijservaringen van studenten op hun verschillende stageplaatsen werden door middel van vragenlijsten geïnventariseerd. Aangezien studenten anoniem deze vragenlijst invulden, kunnen de resultaten op het niveau van een stageplaats nagegaan worden. Door middel van regressie-analyse werd gepoogd de relatie te specificeren tussen bepaalde aspecten van de leeromgeving en de leerresultaten. Hoewel er grote verschillen tussen stageplaatsen werden gevonden, werd er geen relatie vastgesteld tussen dergelijke verschillen en de uiteindelijke leerresultaten. De beperkingen van de gekozen onderzoeksmethode zijn hiervoor deels verantwoordelijk. Maar ook dan blijft de conclusie gerechtvaardigd, dat er kennelijk weinig correlatie bestaat tussen bepaalde onderwijsactiviteiten en de uiteindelijke resultaten daarvan. Daarmee wordt de essentie van klinisch onderwijs en haar structuur bedreigd.

Hoofdstuk zeven plaatst de belangrijkste resultaten van dit onderzoek in perspectief. De belangrijkste elementen van goed klinisch onderwijs worden besproken en er wordt gepleit voor een duidelijker definitie van doelen en middelen. Structuur lijkt een belangrijk kenmerk van goed klinisch onderwijs te zijn, met name bij het aanleren van klinische vaardigheden blijkt een gestructureerde aanpak goed te werken.

Het verschil tussen wat er verondersteld wordt plaats te vinden gedurende stages in ziekenhuizen en wat er feitelijk plaats vindt is groot. Visites, patiëntenbesprekingen, onderzoek en behandeling van patiënten, interprofessionele activiteiten zijn in de leeromgeving aanwezig, maar slechts een beperkt deel van de studenten weet er goed gebruik van te maken. Er zou meer aandacht besteed dienen te worden aan de ontwikkeling van benaderingen om studenten beter gebruik te leren maken van de klinische 
leeromgeving. Daarnaast dient meer aandacht te worden geschonken aan wat er op de stageplaats gebeurt door middel van regelmatige evaluaties. Een aantal organisatorische maatregelen om de kwaliteit van klinisch onderwijs te verbeteren worden besproken. 
Appendix 
St Bartholomew's Hospital Medical College CLINICAL FIRMS QUESTIONNAIRE MEDICINE 
This questionnaire has been designed to reflect the features of firms which have been shown to be educationally important in a series of studies in the UK and USA.

It is important that you complete it accurately and honestly. All information collected will remain confidential, and seen by the firm chiefs only at the end of the data collection period, probably on a yearly basis.

The data will be used to improve teaching programmes and to monitor the general standard of teaching in the Medical College. If you have any problems with filling in the questionnaire you can contact Professor John Wass (8346), or Mr Brian Jolly (06 6077) for clarification.

Thank you for your cooperation.

\section{How to Fill It In}

Please fill in all dates as numerals eg 1st Jan 1991 as 010191.

Write answers legibly.

Where there are boxes please write the answers clearly in the box. Where alternatives are provided please ring the appropriate one for you. In the question on procedures please tick the appropriate box.

Example:

Do you like Mars Bars? Yes/No

How many Mars Bars have you had today?

How do you rate Mars Bars in general?

$\begin{array}{ccccc}\text { Poor } & \text { Average } & & \text { Very Good } \\ 1 & 2 & 3 & 4 & 5\end{array}$

Return to Brian Jolly, Senior Lecturer in Medical Education, Robin Brook Centre St Bartholomew's Hospital, West Smithfield EC1A 7BE. 


\section{MEDICAL FIRM QUESTIONNAIRE}

Consultant

Dates on Firm : Start Day..... Mo..... Yr...... Finish Day...... Mo...... Yr......

Consultant

Consultant

\section{At the Start}

la Was there an introductory talk?

lb Were you given a written timetable?

lc Was the atmosphere friendly and welcoming?

Id Were the objectives made clear?

\section{Work Load}

2 Approximately how many inpatients were there available to clerk each week?

3 How many of these did you clerk fully?

4 How many of these were reviewed by a member of staff

5 How many times on the whole firm did you present a case?

6 On how many days did you spend at least 8 hrs on take?

7 On how many nights did you spend at least 8 hrs on take?

Take: days

Take: nights

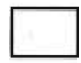

8 From the point of view of your learning, how useful was take?

Useless

1
Learnt

Something

2
3

4
Very

Useful

5

9 How general /specialised was the work of the firm?

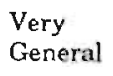

1

Mixed

Very

Specialised

5

10a Was there an adequate range of patients for you to see?

Yes/No

10b Did you attend any special investigations on your patients

Yes/No

I0c How many?

$10 \mathrm{~d}$ Was this valuable

Yes/No 
St Bartholomew's Medical College

CLINICAL FIRMS QUESTIONNAIRE

MEDICINE

\section{Teaching}

11 Estimate the number of hours per week you had formal teaching

$$
\begin{aligned}
& \text { a At the bedside } \\
& \text { b In the classroom } \\
& \text { c Other................. }
\end{aligned}
$$

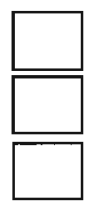

12 Approximately how much, (in \%) of scheduled teaching was cancelled?

13 Was the teaching pitched at the right level of knowledge and understanding for you?

$$
\text { Never }
$$

1
Sometimes

2
3
Very Often

4

14 Rate the approximate contribution of the firm members to teaching in terms of amount of contact time with you, also making allowance for any student led seminars etc.. Please measure this in \% terms.
a) Consultant
b) S. Registrar
c) J. Registrar
d) $\mathrm{SHO}$
e) $\mathrm{JHO}$
f) Students
g) Others (eg).

\section{Total}

15 How many ward rounds did you attend per week?

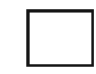

16 Please rate how useful you found ward rounds led by:-
a) Consultant
b) S. Registrar
c) J. Registrar
d) $\mathrm{SHO}$
e) $\mathrm{JHO}$

Did not attend any
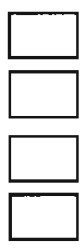

useless

1

2

learnt
something

very

5

1

2

3

4

5

1

3

4

5

1

2

4

5

1

2

4

5 
St Bartholomew's Medical College

CLINICAL FIRMS QUESTIONNAIRE

MEDICINE

17 How much of the time was there nothing for you to do, ie no new patients, and no teaching scheduled, no firm business to do?

$\begin{array}{ccccc}\text { Most } & & \text { About 50\% } & & \begin{array}{c}\text { Hardly } \\ \text { Ever }\end{array} \\ 1 & 2 & 3 & 4 & 5\end{array}$

18 Were firm members open and receptive to students ${ }^{\circ}$ ideas and problems?

Hardly ever

1
Sometimes

3
Very Oten

4
5

19 Apart from official holiday, approximately how many whole days did you miss while on the firm? (please be honest this information is completely confidential).

\section{Procedures}

20 Did you see or perform any of the following procedures?

Tick if seen

a) Phlebotomy

Tick if performed

b) Catheterisation

c) Pleural tap

d) Peritoneal tap

e) Blood cultures

f) Insertion of chest drain
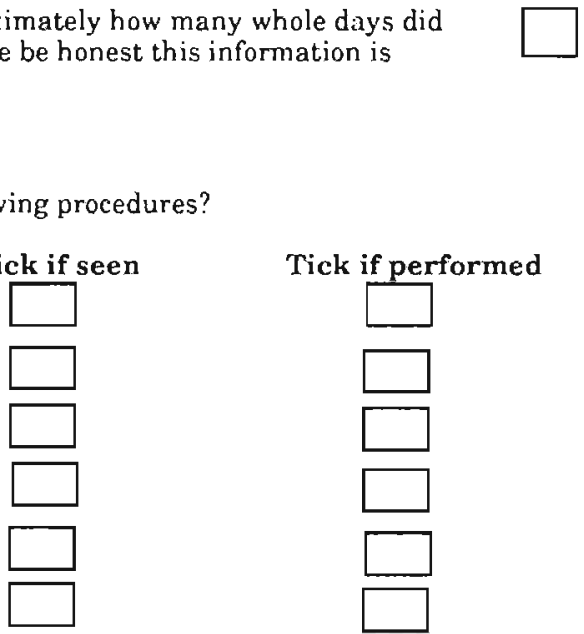

\section{Assessment}

21 How much assessment, both formal and informal, were you getting during this firm on your knowledge and performance?

Very Little

1

$$
\begin{gathered}
\text { Enough to be } \\
\text { Useful }
\end{gathered}
$$

2
3

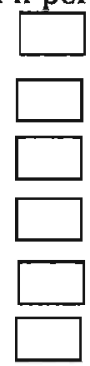

Hardly 
23 Was there a meeting with staff at any time during the firm at which?
a) Your grades were discussed
Yes/No
b) You were given constructive personal feed back
c) You could give feedback to the doctors
Yes/No
Yes/No

24Do you feel you achieved progress in your performance on this firm?

Yes/No

\section{Comments}

Thank you for your help

with this evaluation

(c) Joint Academic Unit of Medical and Dental Education 
St Bartholomew's Hospital Medical College CLINICAL FIRMS QUESTIONNAIRE SURGERY 


\section{SURGICAL FIRM QUESTIONNATRE}

Consultant 1 .

Dates on Firm : Start Day..... Mo..... Yr......

Consultant 2

Finish Day..... Mo...... Yr.....

Consultant 3

\section{At the Start}

la Was there an introductory talk?

YES/NO

lb Were you given a written timetable?

YES/NO

1c Was the atmosphere friendly and welcoming?

YES/NO

1d Were the objectives made clear?

YES/NO

\section{Work Load}

2 Approximately how many inpatients were there available to clerk each week?

3 How many of these did you clerk fully?

4 How many of these were reviewed by a member of staff

5 How many times on the whole firm did you present a case?

6 On how many days did you spend at least 8 hrs on take?

7 On how many nights did you spend at least 8 hrs on take?

Take: day

Take: nights
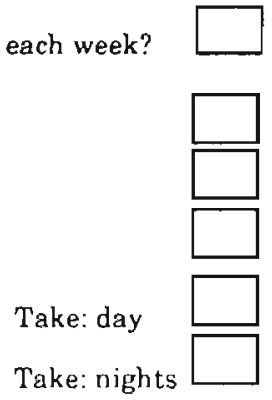

8a Was there an adequate range of patients for you to see?

YES/NO

$8 \mathrm{~b}$ Did you attend any special investigations on your patients

YES/NO

$8 \mathrm{c} \quad$ How many?

8d Was this valuable

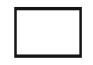

YES/NO

9 From the point of view of your learning, how useful was take?

$\begin{array}{llll}\text { Useless } & & \begin{array}{l}\text { Learnt } \\ \text { Something }\end{array} & \text { Very } \\ \text { Useful }\end{array}$

10 How general/specialised was the work of the firm?

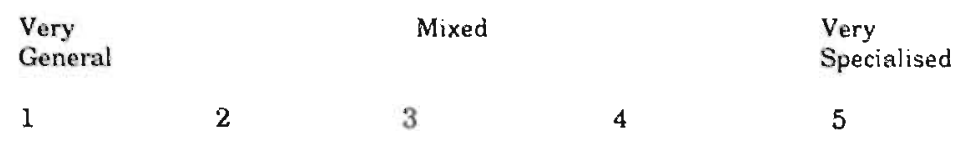


St Bartholomew's Hospital Medical College

CLINICAL FIRMS QUESTIONNAIRE

SURGERY

11a Did you attend any surgical procedures on your patients?

YES/NO

11b How many times?

11c Did you find this valuable?

YES/NO

YES/NO

12a Did you assist at operation?

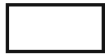

12b How many times?

12c Did you find assisting valuable?

YES/NO

13a Did you perform or see any of the following: (please tick the appropriate box)
Procedure
a Phlebotomy
b Catheterisation
c Pleural Tap
d Peritoneal Tap
e Blood Cultures
f Insertion of Chest
Drain

$13 b$

Operations
a Hernia Repair
b Varicose vein
c Appendicectomy
d Cholesystectomy
e Bowel Resection
f Mastectomy
g Amputation
h Vascular Bypass
i Thyroidectomy
j Gastric/Duodenal Surgery
k Laparotomy for trauma
I Perianal surgery

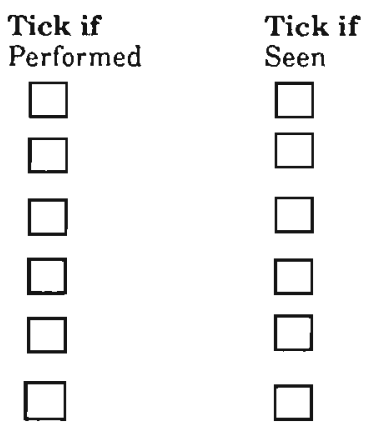

Tick if

Tick if

Assisted

Seen 
St Bartholomew's Hospital Medical College

CLINICAL FIRMS QUESTIONNAIRE

SURGERY

\section{Teaching}

14 Estimate the number of hours per week you had formal teaching
a At the bedside
b In the classroom
c Other (specify

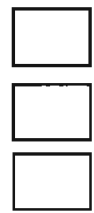

15 Approximately how much, (in \%) of scheduled teaching was cancelled?

16 Was the teaching pitched at the right level of knowledge and understanding for you?

$$
\text { Never }
$$

1
Sometimes

3
Very Often

4
5

17 Rate the approximate contribution of the firm members to teaching in terms of amount of contact time with you also making allowance for any student led seminars etc.. Measure this in \% terms adding to 100 .
a) Consultant
b) S. Registrar
c) J. Registrar
d) $\mathrm{SHO}$
e) $\mathrm{JHO}$
f) Students
g) Others (eg)

\section{Total}

18 How many ward rounds did you attend per week?

19 Please rate how useful you found ward rounds led by:-
a) Consultant
b) S. Registrar
c) J. Registrar
d) $\mathrm{SHO}$
e) $\mathrm{JHO}$

Did not attend any
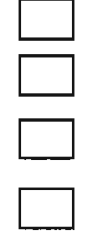

useless

\section{1}

1

1

1

1

\section{learnt something}

very useful

5

5

5

5

5 
20 How much of the time was there nothing for you to do, ie no new patients, and no teaching scheduled, no firm business to do?

\begin{tabular}{|c|c|c|c|c|}
\hline Most & & & & $\begin{array}{l}\text { Hardly } \\
\text { Ever }\end{array}$ \\
\hline 1 & 2 & 3 & 4 & 5 \\
\hline
\end{tabular}

21 Were firm members open and receptive to students' ideas and problems?

\begin{tabular}{lllll} 
Hardly ever & \multicolumn{3}{c}{ Sometimes } & Very Often \\
1 & 2 & 3 & 4 & 5
\end{tabular}

22 Apart from official holiday, approximately how many whole days did you miss while on the firm? (please be honest this information is completely confidential).

\section{Assessment}

23 How much assessment, both formal and informal, were you getting during this firm on your knowledge and performance?

$\begin{array}{ll}\text { Very Little } & \begin{array}{l}\text { Enough to be } \\ \text { Useful }\end{array}\end{array}$
1
2
3
4
5

24 Was there a formal assessment at the end of the firm to test
a) Clinical Skill
b) Knowledge
c) Other

25 Was there a meeting with staff at any time during the firm at which?
a) Your grades were discussed
b) You were given constructive personal feed- back
YES/NO
c) You could give feedback to the doctors

\section{COMMENTS}




\section{Bedside Manners}

teaching and learning in the hospital serting

Clinical exposure is a vital part of medical raining. However, its role in the education of physicians has been relatively recent and many countries still provide lirtle or no such background for their students. Moreover very little research has been done on the process and ourcome of clinical learning. especially in the hospital setting.

This book describes a series of studies on the manner in which medical students learn clinical medicine. In particular, it maces the development of those practical and academic skills which are thought to be essential in the development of the junior doctor. It also artempts to describe what fearures of the clinical environment produce success on assessments of clinical comperence.

\section{Brian C Jolly}

